\title{
Diagnostics at the point-of-care in general practice
}

\author{
Citation for published version (APA):
}

Schols, A. M. R. (2018). Diagnostics at the point-of-care in general practice: acute cardiopulmonary symptoms. [Doctoral Thesis, Maastricht University]. Maastricht University. https://doi.org/10.26481/dis.20181017as

Document status and date:

Published: 01/01/2018

DOI:

10.26481/dis.20181017as

Document Version:

Publisher's PDF, also known as Version of record

\section{Please check the document version of this publication:}

- A submitted manuscript is the version of the article upon submission and before peer-review. There can be important differences between the submitted version and the official published version of record.

People interested in the research are advised to contact the author for the final version of the publication, or visit the DOI to the publisher's website.

- The final author version and the galley proof are versions of the publication after peer review.

- The final published version features the final layout of the paper including the volume, issue and page numbers.

Link to publication

\footnotetext{
General rights rights.

- You may freely distribute the URL identifying the publication in the public portal. please follow below link for the End User Agreement:

www.umlib.nl/taverne-license

Take down policy

If you believe that this document breaches copyright please contact us at:

repository@maastrichtuniversity.nl

providing details and we will investigate your claim.
}

Copyright and moral rights for the publications made accessible in the public portal are retained by the authors and/or other copyright owners and it is a condition of accessing publications that users recognise and abide by the legal requirements associated with these

- Users may download and print one copy of any publication from the public portal for the purpose of private study or research.

- You may not further distribute the material or use it for any profit-making activity or commercial gain

If the publication is distributed under the terms of Article $25 \mathrm{fa}$ of the Dutch Copyright Act, indicated by the "Taverne" license above, 
Diagnostics at the point-of-care in general practice acute cardiopulmonary symptoms 
The research presented in this dissertation was conducted at the Care and Public Health Research Institute (CAPHRI), Department of Family Medicine, Maastricht University. CAPHRI participates in the Netherlands School of Public Health and Care Research (CaRe), acknowledged by the Royal Dutch Academy of Science (KNAW).

The research presented in this dissertation was supported by a grant of the Netherlands Organisation for Health Research and Development (ZonMW, grant number 91614078).

All rights are reserved. No part of this book may be reproduced or transmitted in any form or by any means, without the written permission from the author or, where appropriate, the publisher of the article.

Copyright (c) Angel M.R. Schols, Maastricht 2018

Cover design: Bonné+Jan

Layout: Angel Schols

Printed by: $\quad$ Gildeprint - Enschede

ISBN: 978-94-9301-462-6 


\title{
Diagnostics at the point-of-care in general practice
}

\author{
acute cardiopulmonary symptoms
}

\author{
PROEFSCHRIFT \\ Ter verkrijging van de graad van doctor aan de Universiteit Maastricht, \\ op gezag van de Rector Magnificus, Prof. dr. Rianne M. Letschert, \\ volgens het besluit van het College van Decanen, \\ in het openbaar te verdedigen, \\ op woensdag 17 oktober 2018 om 14.00 uur \\ door
}

Angel Maria Ronnie Schols 


\section{Promotores}

Prof. dr. J.W.L. Cals

Prof. dr. G.J. Dinant

\section{Beoordelingscommissie}

Prof. dr. O. Bekers (voorzitter)

Prof. dr. P.M.M. Bossuyt (Universiteit van Amsterdam)

Dr. A. van den Bruel (Katholieke Universiteit Leuven)

Prof. dr. A.W.J. van 't Hof

Prof. dr. J.A. Knottnerus 
Contents 


\section{CONTENTS}

Chapter 1 General introduction

Chapter 2 Access to diagnostic tests during GP out-of-hours care:

A cross-sectional study of all GP out-of-hours services in the Netherlands

European Journal of General Practice 2016;22:176-181

Nederlands Tijdschrift voor Geneeskunde 2015;159:A9022

Chapter 3 Point-of-care tests in general practice:

Current use and future needs

Nederlands Tijdschrift voor Geneeskunde 2014;158:A8210

Chapter 4 International definition of a point-of-care test in family

practice: a modified e-Delphi procedure

Family Practice 2018;35:475-408

Chapter 5 General practitioners' experiences with out-of-hours

cardiorespiratory consultations: a qualitative study BMJ Open 2016;6:e012136

Chapter 6 Point-of-care testing in primary care patients with acute cardiopulmonary symptoms: a systematic review Family Practice 2018;35:4-12

Chapter 7 GP-use of D-dimer in suspected venous thromboembolism: historical cohort study in one geographical region Submitted 
Chapter 8 Point-of-care testing in general practice:

just what the doctor ordered?

British Journal of General Practice 2018;68:362-363

Chapter 9 A clinical decision rule for suspected acute coronary syndrome: nationwide flash mob study in family medicine Submitted

Chapter 10 General discussion 173

Summary 195

Samenvatting 203

Valorisation 211

Dankwoord

Curriculum Vitae 



\section{Chapter 1}

General introduction

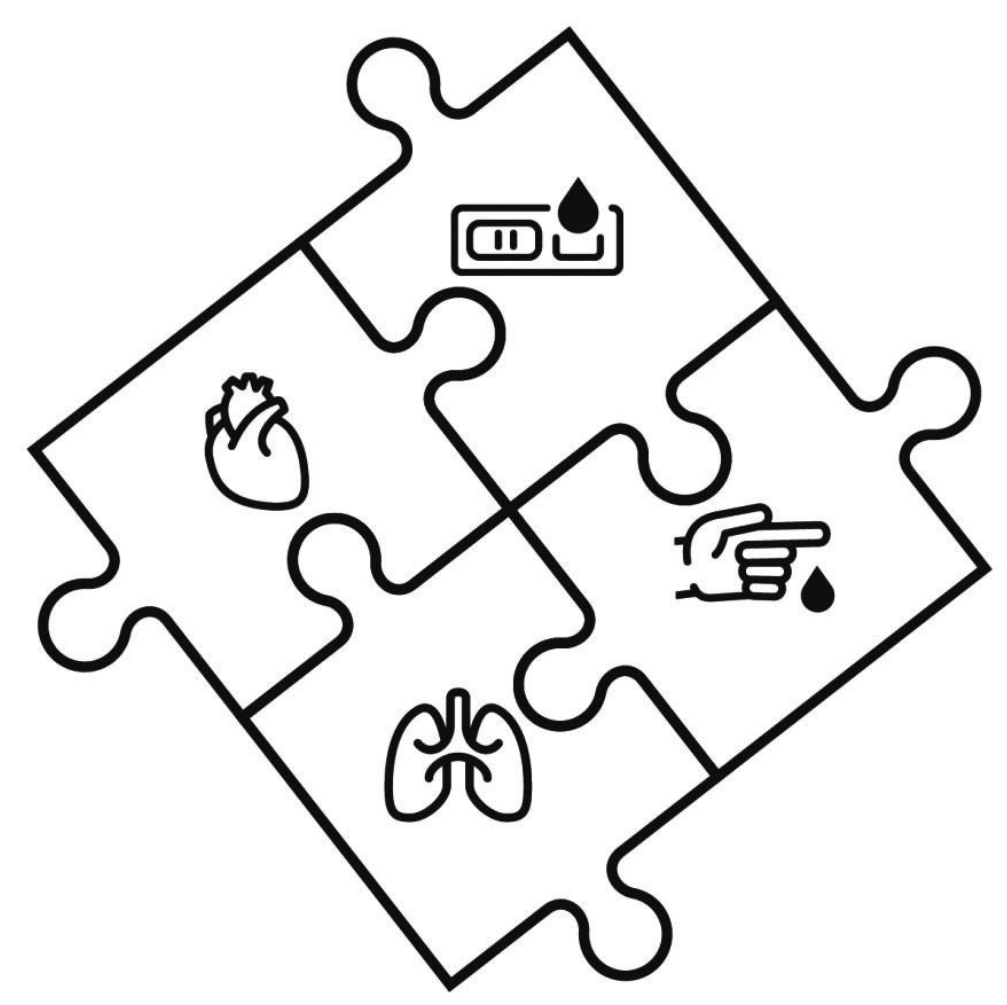





\section{GENERAL INTRODUCTION}

\section{Diagnostics in general practice}

In general practice, patients often present with undifferentiated and sometimes vague symptoms. ${ }^{1-3}$ A core competence of general practitioners (GPs) is to make rapid decisions in these patients and tolerate the high diagnostic uncertainty, unpredictability and ambiguity that come along with these decisions. ${ }^{2,4-6}$ A vital task is to identify patients with a high probability of serious disease and exclude serious conditions, while minimizing unnecessary diagnostics, over-referrals to secondary care and missed cases. ${ }^{4,7}$

Diagnostic tests can assist GPs in the clinical decision-making process. ${ }^{8}$ During office hours, GPs typically have access to most medical imaging, laboratory tests and a variety of point-of-care tests (POCTs) without referral to secondary care. ${ }^{9}$ As the a priori chance of serious or acute conditions is higher during out-ofhours care than during office hours and patients are often unknown to the GP on call, one would expect diagnostics to play a more central role in the decisionmaking process during out-of-hours care. ${ }^{10}, 11$ However, knowledge on GPs' access to diagnostic tests during out-of-hours care in the Netherlands is mostly lacking.

\section{Point-of-care testing in general practice}

Given that diagnostic tests can assist GPs in the decision-making process in patients with ill-defined problems and symptoms, POCTs may be especially useful in general practice and particularly in patients presenting with acute symptoms, because the results may influence the clinical decision-making during the consultation. ${ }^{12}$ There is no widely supported international definition of POCTs in general practice, so various definitions and alternative names for POCTs exist. Alternative names include rapid tests, bedside tests, near patient tests, all putting a different emphasis on as to what these sort of tests are. ${ }^{13}$ Since professionals working in one discipline may define POCTs differently than those 
working in other disciplines, variations in definitions may lead to misconceptions and confusion.

The number of available POCTs has increased exponentially during the past few decades and POCTs are increasingly used and wanted by GPs. ${ }^{14}$ Research has shown that these kind of tests have many potential benefits, e.g. POCTs may save patients' and physicians' time, optimize management, reduce the number of referrals to secondary care, reduce health care costs, improve patient satisfaction and adherence to treatment. ${ }^{15-21}$ Nevertheless, GPs also have some concerns with regard to increasing use of POCTs, such as worries about test accuracy, over-reliance on diagnostics, the use of diagnostics without a proper indication, cost-effectiveness, a lack of skills to safely use these diagnostics and interpret test results. ${ }^{12,22-24}$

\section{Evaluation of diagnostic tests}

It is vital that diagnostic tests are evaluated thoroughly before implementation in clinical practice. They should preferably only be implemented after they have proven to have a positive effect on health related outcomes. To establish whether a new diagnostic test assists the decision-making process and changes health related outcomes, it must be examined as part of a broader clinical pathway, because individual diagnostic tests rarely improve health related outcomes directly. ${ }^{25,} 26$

\section{Framework}

There is no definite consensus on the terminology or approach for diagnostic test evaluation. At least 19 different test evaluation frameworks exist, and all describe the evaluation of tests as a linear process. ${ }^{27} \mathrm{~A}$ few years ago, a multidisciplinary group of the European Federation of Clinical Chemistry and Laboratory Medicine described a more dynamic and cyclical approach, hereby preventing discussion on the precise relationship between, and hierarchy of the 
different elements in test evaluation (Figure 1.1). ${ }^{25}$ Although this framework was originally designed focusing on in vitro diagnostic tests only, biomarkers specifically, it can be applied to the evaluation of many diagnostic tests and diagnostic strategies in general practice, including POCTs and clinical decision rules.

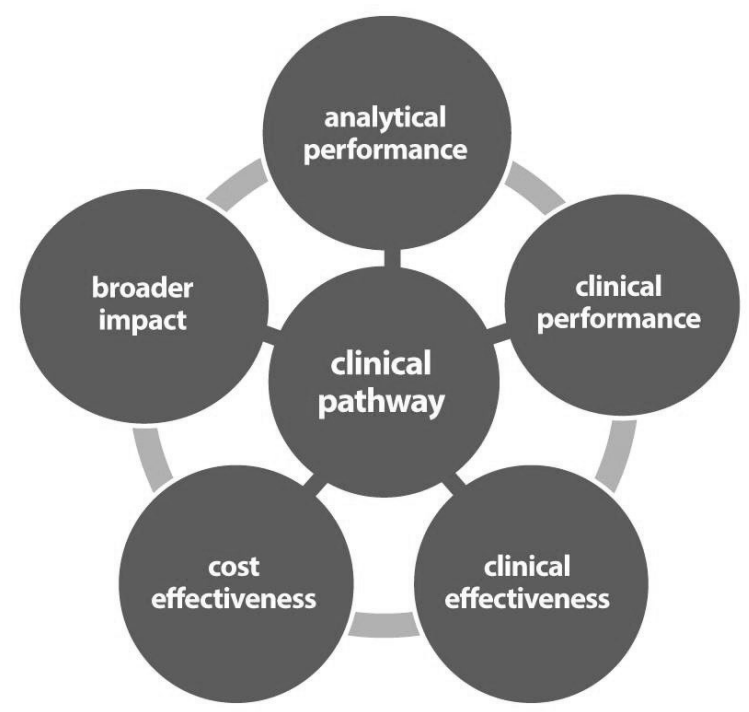

Figure 1.1 Cyclical framework and components of test evaluation.

Reprinted from Clinica Chimica Acta, volume 427, Horvath AR, Lord SJ, St John A, et al, From biomarkers to medical tests: The changing landscape of test evaluation, 49-57, 2014, with permission from Elsevier. ${ }^{25}$

In this dynamic approach, five key components can be distinguished that are connected to the clinical pathway: (i) analytical performance, (ii) clinical performance, (iii) clinical effectiveness, (iv) cost-effectiveness, and (v) broader impact. Analytical performance refers to the ability of a test to conform to predefined technical specifications, including analytical sensitivity and specificity, and measurement range and accuracy. Clinical performance refers to the ability of a test to detect patients with a particular clinical condition or psychological state. The capacity of a test to improve health outcomes that are relevant to the 
individual being tested, is regarded the clinical effectiveness. In the costeffectiveness component, the increase or reduction of the use of resources with the introduction of a test are being evaluated. Finally, the broader impact of a test goes beyond the clinical- and cost-effectiveness and refers to its broader effects on social, psychological, legal, ethical, societal, organizational and other consequences. The availability of POCTs, for example, can lead to organizational changes in the provision of health care, with a shift from secondary to primary care. $^{25}$

At the start of the test evaluation process, the test's potential purpose and role in the clinical pathway should be addressed in detail. The intended clinical application of the test and how the test result will be used to improve clinical management in practice should be clearly defined. ${ }^{25}$ For example, one purpose of a test may be to safely 'rule out' a serious disease in primary care to eventually reduce referrals. The role of a test describes how the test will be positioned to alter the current clinical pathway, by (i) replacement of the existing test, (ii) acting as a triage instrument before the existing test, or (iii) acting as an add-on alongside or after the existing test. At the same time, the relevant patient population for each testing application should be defined. ${ }^{25,} 28$ Given that the test evaluation process is cyclical and dynamic, the originally intended purpose and role of the test can be redefined if an alternative purpose and role becomes apparent. ${ }^{25}$

\section{Acute cardiopulmonary symptoms in general practice}

Patients with acute cardiopulmonary symptoms are fairly common in general practice, yet accurately diagnosing these patients is often considered challenging. ${ }^{29-31}$ Particularly in this field, GPs indicated a desire to use POCTs. ${ }^{14}$

According to national figures, the incidence rate of symptoms of the chest in Dutch general practice is approximately 33 per 1000 patient years, of pain attributed to the heart 5 per 1000 patient years, and of dyspnoea 13 per 1000 
patient years. ${ }^{32}$ Chest pain alone accounts for about $0.7 \%$ to $2.7 \%$ of all general practice consultations. ${ }^{33-36}$

Acute chest symptoms, possibly involving the heart or lungs, could be caused by many different underlying diseases, of which some could have serious consequences if left untreated. Most patients with these symptoms will have minor conditions like mild respiratory conditions, gastro-intestinal conditions, musculoskeletal or psychiatric causes. 33, 35, 36 However, distinguishing the potentially serious and life-threating causes of these symptoms from minor conditions, is a challenging task for GPs, due to overlapping signs and symptoms and often non-specific, atypical or even vague symptoms. ${ }^{31,37,38}$ Pulmonary embolism and acute coronary syndrome are considered notoriously difficult to exclude. POCTs may be useful in the decision-making process of patients with these kind of acute cardiopulmonary symptoms.

\section{Pulmonary embolism}

Acute pulmonary embolism (PE) is a form of venous thromboembolism and refers to an obstruction in the pulmonary arteries by a substance - often a thrombus - originating from elsewhere in the body. ${ }^{39-41}$ According to national figures, the annual incidence rate of $P E$ in Dutch general practice is approximately 1.1 per 1000 patient years. ${ }^{32}$ To reduce the associated morbidity and mortality, it is vital to quickly recognize a PE and initiate treatment. ${ }^{42,43}$ The most common symptom at presentation is dyspnoea, but symptoms like chest pain, coughing, and signs and symptoms of deep vein thrombosis are also prevalent. Nevertheless, patients may present with a wide range of non-specific symptoms, ranging from no symptoms at all to sudden death, making diagnosing PE challenging. ${ }^{40,41,44-47}$

The current clinical diagnostic pathway for suspected PE starts with an assessment of the clinical pretest probability, which can be estimated by using the Wells clinical prediction rule. In patients with a low clinical pretest probability for $\mathrm{PE}$, it is recommended that GPs perform a D-dimer test. A low Wells score 
combined with a D-dimer value below $500 \mu \mathrm{g} / \mathrm{L}$ can safely exclude a PE. ${ }^{48-53}$ Over the past few years, the results of several studies have shown that using an age-adjusted $D$-dimer cut-off in patients $\geq 50$ years seems to be safe. ${ }^{54-58}$ However, if the pretest probability of PE is moderate to high, patients should immediately be referred to secondary care.

At the moment, Dutch GPs have access to D-dimer testing through routine laboratory tests with results available within a few hours. D-dimer POCTs are limited available and have been on and off the market. A D-dimer POCT might expedite the diagnostic process and referral to secondary care, as the results can immediately support clinical decision-making during the consultation.

\section{Acute coronary syndrome}

Acute coronary syndrome (ACS) applies to patients suspected of having ischemia or necrosis of the heart muscle, including patients suspected of myocardial infarction, characterized by a typical rise and/or fall in cardiac biomarker values, and unstable angina, without elevated cardiac biomarkers. ${ }^{59}$, 60 The annual incidence rate of acute myocardial infarction in Dutch general practice is approximately 4.1 per 1000 patient years, with a higher incidence in men (5.8) than in women (2.5). ${ }^{32}$ Comparable to patients with PE, patients with ACS can present with a wide range of symptoms, such as typical ischemic-type chest pain or discomfort, dyspnoea, nausea, unexplained weakness, or a combination of these and other symptoms. ${ }^{61,62}$ And alike PE it is vital to rapidly diagnose ACS and initiate treatment, but diagnosing ACS can be a challenge. ${ }^{61}$

The current diagnostic pathway for suspected ACS is less well-defined as in the case of suspected PE. The pathway consists of the clinical evaluation of the patient through history taking and physical examination, sometimes followed by an electrocardiogram (ECG) if available in practice, and sporadically by biochemical testing via an external laboratory. However, additional tests like an ECG and biochemical testing are currently not recommended by the Dutch GP guideline. Depending on the severity of the clinical situation and the differential diagnostic considerations, this diagnostic pathway may be more or less 
elaborate. ${ }^{63}$ If we take the diagnostic pathway of PE as an example, two kind of add-on tests might aid the decision-making process in patients suspected of ACS, namely a clinical decision rule and a POCT for cardiac biomarkers. As far as we know, there currently is no POCT that can safely rule out a myocardial infarction in general practice. However, there is a potentially suitable clinical decision rule, the Marburg Heart Score, that may support the clinical decisionmaking in patients suspected of ACS. This score consists of only five items that can be assessed without any additional diagnostic test and it showed promising results in a German general practice setting. ${ }^{64-66}$

\section{Aim and research objectives}

The general aim of this thesis is to assess the current state of point-of-care tests in general practice in general and in acute cardiopulmonary symptoms specifically. This thesis focusses on the following research objectives:

1. To assess the availability of diagnostics at GP out-of-hours services.

2. To assess current use, future wishes and attitudes of GPs towards POCTs in general practice.

3. To develop an international multidisciplinary consented definition of a POCT in general practice.

4. To explore the challenges in cardiopulmonary consultations at GP out-ofhours services.

5. To systematically review the literature on POCTs in patients with acute cardiopulmonary symptoms.

6. To evaluate the current clinical pathway and role of D-dimer in patients with a venous thromboembolism.

7. To evaluate the diagnostic value of a clinical decision rule in patients with symptoms of a possible acute coronary syndrome. 


\section{Outline of this dissertation}

Chapter 2 provides an overview of current GP access to diagnostic tests imaging, function tests, laboratory tests and POCTs - during GP out-of-hours care in the Netherlands and whether or not access to diagnostic facilities differs between services located adjacent to or separate from an accident and emergency department. Chapter 3 describes the current GP use, future needs and GPs' attitudes toward POCTs in the Netherlands. In chapter 4 we describe a modified international e-Delphi procedure of four rounds among expert panel members from different professional backgrounds, aiming to reach consensus on an international definition of a POCT in general practice. Chapter 5 discusses a qualitative study, consisting of 15 face-to-face semi-structured interviews with Dutch GPs, on their experiences with out-of-hours cardiopulmonary consultations. In chapter 6 we present the results of a systematic review on point-of-care testing in primary care patients with acute cardiopulmonary symptoms. The objective of this review was to assess whether using POCTs in primary care patients with acute cardiopulmonary symptoms leads to more accurate diagnosis and affects clinical management. Chapter 7 provides the results of a retrospective analyses of patients in whom the GP determined a Ddimer value or who had a diagnostic work-up for suspected venous thromboembolism in a non-academic hospital in 2015. The aim of this study was to investigate the (urgent) referral pathway of patients with venous thromboembolism diagnoses and to analyse the current role of laboratory Ddimer testing in those referred with suspected venous thromboembolism. Chapter 8 is an editorial wherein we argue that more point-of-care does not necessarily mean better care; we address several concerns with regard to the evaluation and implementation of POCTs. In chapter 9, we present the results of a novel and innovative nationwide flash mob study of two weeks, called 'Huisarts HART Week'. The primary aim of this study was to externally validate the Marburg Heart Score or to develop an adapted clinical decision rule for GPs to safely rule out ACS in patients referred to secondary care for suspected ACS. Moreover, we wanted to evaluate the feasibility of using this new flash mob method for large scale, relatively inexpensive and fast research in general practice. Finally, in the general discussion in chapter 10, we discuss the main 
findings of this thesis and their implications, and we elaborate on recruitment challenges and a novel research method in general practice research. 


\section{REFERENCES}

1. Thomson GH. Tolerating uncertainty in family medicine. The Journal of the Royal College of General Practitioners. 1978;28:343-6.

2. Rosser WW. Approach to diagnosis by primary care clinicians and specialists: is there a difference? J Fam Pract. 1996;42:139-44.

3. Knottnerus JA. Medical decision making by general practitioners and specialists. Fam Pract. 1991;8:305-7.

4. Green C, Holden J. Diagnostic uncertainty in general practice. A unique opportunity for research? Eur J Gen Pract. 2003;9:13-5.

5. Hewson MG, Kindy PJ, Van Kirk J, Gennis VA, Day RP. Strategies for managing uncertainty and complexity. J Gen Intern Med. 1996;11:481-5.

6. Dixon AS. 'There's a lot of it about': clinical strategies in family practice. $J R$ Coll Gen Pract. 1986;36:468-71.

7. Owen P. Clinical practice and medical research: bridging the divide between the two cultures. Br J Gen Pract. 1995;45:557-60.

8. Heneghan $C$, Glasziou $P$, Thompson $M$, et al. Diagnostic strategies used in primary care. BMJ. 2009;338:b946.

9. Giesen P, Huibers L, Padros Goossens M, Willekens M. [Between dream and achievement. GPs' future vision of their position in acute care]. Medisch Contact. 2007;62:653-5.

10. Giesen P, Braspenning ]. [GP out-of-hours service: common symptoms of acute nature]. Huisarts en wetenschap. 2004;47:735-6.

11. Huibers LA, Moth G, Bondevik GT, et al. Diagnostic scope in out-of-hours primary care services in eight European countries: an observational study. BMC Fam Pract. 2011;12:30.

12. Cals J, van Weert H. Point-of-care tests in general practice: hope or hype? Eur J Gen Pract. 2013;19:251-6.

13. Farrance I; (on behalf of the RCPA Quality Assurance Programs). Review: Policies, procedures and guidelines for point-of-care testing. April 2012. [cited 2017 May]. Available from: http://www.aacb.asn.au/documents/item/635.

14. Howick J, Cals JW, Jones C, et al. Current and future use of point-of-care tests in primary care: an international survey in Australia, Belgium, The Netherlands, the UK and the USA. BMJ Open. 2014;4:e005611.

15. Laurence $\mathrm{CO}$, Gialamas A, Bubner $\mathrm{T}$, et al. Patient satisfaction with point-of-care testing in general practice. Br J Gen Pract. 2010;60:e98-104. 
16. Gialamas A, Yelland LN, Ryan P, et al. Does point-of-care testing lead to the same or better adherence to medication? A randomised controlled trial: the PoCT in General Practice Trial. Med J Aust. 2009;191:487-91.

17. Price $\mathrm{CP}$, Kricka $\mathrm{L}$. National Institute of Biomedical Imaging and Bioengineering/National Heart, Lung, and Blood Institute/National Science Foundation Workshop Faculty. Improving healthcare accessibility through point-of-care technologies. Clin Chem. 2007;53:1665-75.

18. Gialamas A, St John A, Laurence CO, et al. PoCT Management Committee. Point-ofcare testing for patients with diabetes, hyperlipidaemia or coagulation disorders in the general practice setting: a systematic review. Fam Pract. 2010;27:17-24.

19. Cals JW, Butler CC, Hopstaken RM, Hood K, Dinant GJ. Effect of point of care testing for $C$ reactive protein and training in communication skills on antibiotic use in lower respiratory tract infections: cluster randomised trial. BMJ. 2009;338:b1374.

20. Cals JW, Schot MJ, de Jong SA, Dinant GJ, Hopstaken RM. Point-of-care C-reactive protein testing and antibiotic prescribing for respiratory tract infections: a randomized controlled trial. Ann Fam Med. 2010;8:124-33.

21. Geersing GJ, Janssen KJ, Oudega R, et al. Excluding venous thromboembolism using point of care $\mathrm{D}$-dimer tests in outpatients: a diagnostic meta-analysis. BMJ. 2009;339:b2990.

22. Jones $\mathrm{CH}$, Howick J, Roberts NW, et al. Primary care clinicians' attitudes towards point-of-care blood testing: a systematic review of qualitative studies. BMC Fam Pract. 2013;14:117.

23. Hardy V, Thompson M, Alto W, et al. Exploring the barriers and facilitators to use of point of care tests in family medicine clinics in the United States. BMC Fam Pract. 2016;17:149.

24. Butler CC, Simpson S, Wood F. General practitioners' perceptions of introducing nearpatient testing for common infections into routine primary care: a qualitative study. Scand J Prim Health Care. 2008;26:17-21.

25. Horvath AR, Lord SJ, StJohn A, et al. From biomarkers to medical tests: The changing landscape of test evaluation. Clinica Chimica Acta. 2014;427:49-57.

26. Ferrante di Ruffano L, Hyde CJ, McCaffery KJ, Bossuyt PM, Deeks JJ. Assessing the value of diagnostic tests: a framework for designing and evaluating trials. BMJ. 2012;344:e686.

27. Lijmer JG, Leeflang M, Bossuyt PMM. Proposals for a Phased Evaluation of Medical Tests. Medical Decision Making. 2009;29:E13-E21.

28. Bossuyt PM, Irwig L, Craig J, Glasziou P. Comparative accuracy: assessing new tests against existing diagnostic pathways. BMJ. 2006;332:1089-92. 
29. McConaghy JR, Oza RS. Outpatient diagnosis of acute chest pain in adults. Am Fam Physician. 2013;87:177-82.

30. Willemsen RT, Kietselaer BL, Kusters R, Buntinx F, Dinant G]. [Diagnostic tools for acute coronary syndrome (ACS): a challenge for general practitioners and cardiologists]. Ned Tijdschr Geneeskd. 2014;158:A8078.

31. Body R, Carley S, Wibberley C, McDowell G, Ferguson J, Mackway-Jones K. The value of symptoms and signs in the emergent diagnosis of acute coronary syndromes. Resuscitation. 2010;81:281-6.

32. Nielen M, Flinterman L, Kroneman M, Verheij R. [Incidence and prevalence of health problems in Dutch general practice]. From: NIVEL Zorgregistraties eerste lijn [Internet]. 2018 [cited 2018 January 1]. Available from: www.nivel.nl/node/4309.

33. Hoorweg BBN, Willemsen RT, Cleef LE, et al. Frequency of chest pain in primary care, diagnostic tests performed and final diagnoses. Heart. 2017;103:1727-32.

34. Nilsson S, Scheike M, Engblom $D$, et al. Chest pain and ischaemic heart disease in primary care. Br J Gen Pract. 2003;53:378-82.

35. Bosner S, Becker A, Haasenritter J, et al. Chest pain in primary care: epidemiology and pre-work-up probabilities. Eur J Gen Pract. 2009;15:141-6.

36. Verdon F, Herzig L, Burnand B, et al. Chest pain in daily practice: occurrence, causes and management. Swiss Med Wkly. 2008;138:340-7.

37. Bruyninckx R, Aertgeerts B, Bruyninckx P, Buntinx F. Signs and symptoms in diagnosing acute myocardial infarction and acute coronary syndrome: a diagnostic meta-analysis. Br J Gen Pract. 2008;58:105-11.

38. Swap CJ, Nagurney JT. Value and limitations of chest pain history in the evaluation of patients with suspected acute coronary syndromes. JAMA. 2005;294:2623-9.

39. Thompson BT, Kabrhel C. Overview of acute pulmonary embolism in adults. 2018 [updated 2016 Dec 16; cited 2018 Feb 2]. Available from: https:// www.uptodate.com/contents/overview-of-acute-pulmonary-embolism-in-adults? search=pulmonary\%20embolism\&source $=$ search_result\&selectedTitle $=1 \sim 150 \&$ usage _type=default\&display_rank=1.

40. Lapner ST, Kearon C. Diagnosis and management of pulmonary embolism. BMJ. 2013;346:f757.

41. Meyer G, Roy PM, Gilberg S, Perrier A. Pulmonary embolism. BMJ. 2010;340:c1421.

42. Cohen AT, Agnelli G, Anderson FA, et al. Venous thromboembolism (VTE) in Europe. The number of VTE events and associated morbidity and mortality. Thromb Haemost. 2007;98:756-64.

43. Smith SB, Geske JB, Maguire JM, Zane NA, Carter RE, Morgenthaler TI. Early anticoagulation is associated with reduced mortality for acute pulmonary embolism. Chest. 2010;137:1382-90. 
44. Stein PD, Terrin ML, Hales CA, et al. Clinical, laboratory, roentgenographic, and electrocardiographic findings in patients with acute pulmonary embolism and no preexisting cardiac or pulmonary disease. Chest. 1991;100:598-603.

45. Stein PD, Beemath A, Matta F, et al. Clinical characteristics of patients with acute pulmonary embolism: data from PIOPED II. Am J Med. 2007;120:871-9.

46. Thompson BT, Kabrhel C, Pena C. Clinical presentation, evaluation, and diagnosis of the nonpregnant adult with suspected acute pulmonary embolism. 2018 [updated 2018 May 03; cited 2018 Jun 24]. Available from: https://www.uptodate.com/ contents/clinical-presentation-evaluation-and-diagnosis-of-the-nonpregnant-adultwith-suspected-acute-pulmonary-embolism?topicRef $=8253 \&$ source=see_link.

47. Cohen AT, Dobromirski M, Gurwith MM. Managing pulmonary embolism from presentation to extended treatment. Thromb Res. 2014;133:139-48.

48. Konstantinides SV, Torbicki A, Agnelli G, et al. 2014 ESC guidelines on the diagnosis and management of acute pulmonary embolism. Eur Heart J. 2014;35:3033-80.

49. Dupras D, Bluhm J, Felty C, et al. Institute for Clinical Systems Improvement. Venous Thromboembolism Diagnosis and Treatment. [updated 2013 Jan]. Available from: http://bit.ly/VTE0113.

50. Qaseem A, Snow V, Barry P, et al. Current Diagnosis of Venous Thromboembolism in Primary Care: A Clinical Practice Guideline from the American Academy of Family Physicians and the American College of Physicians. Ann Fam Med. 2007;5:57-62.

51. National Institute for Health and Care Excellence (NICE). Diagnosing venous thromboembolism in primary, secondary and tertiary care. [cited 2017 August]. Available from: https://pathways.nice.org.uk/pathways/venous-thromboembolism \#path=view\%3A/pathways/venous-thromboembolism/diagnosing-venousthromboembolism-in-primary-secondary-and-tertiary-care. $x m l \& c o n t e n t=v i e w$-index.

52. The Dutch College of General Practitioners' working group deep vein thrombosis and pulmonary embolism. [GP guideline Deep vein thrombosis and pulmonary embolism (second partial revision)] Utrecht: Dutch College of General Practitioners. [cited 2018 April 24]. Available from: https://www.nhg.org/standaarden/volledig/nhg-standaarddiepe-veneuze-trombose-en-longembolie.

53. Geersing GJ, Erkens PM, Lucassen WA, et al. Safe exclusion of pulmonary embolism using the Wells rule and qualitative $\mathrm{D}$-dimer testing in primary care: prospective cohort study. BMJ. 2012;345:e6564.

54. Righini M, Van Es J, Den Exter PL, et al. Age-adjusted D-dimer cutoff levels to rule out pulmonary embolism: the ADJUST-PE study. JAMA. 2014;311:1117-24.

55. Schouten HJ, Geersing GJ, Koek HL, et al. Diagnostic accuracy of conventional or age adjusted D-dimer cut-off values in older patients with suspected venous thromboembolism: systematic review and meta-analysis. BMJ. 2013;346:f2492. 
56. Andro M, Righini M, Le Gal G. Adapting the D-dimer cutoff for thrombosis detection in elderly outpatients. Expert Rev Cardiovasc Ther. 2013;11:751-9.

57. Fuchs E, Asakly S, Karban A, Tzoran I. Age-Adjusted Cutoff D-Dimer Level to Rule Out Acute Pulmonary Embolism: A Validation Cohort Study. Am J Med. 2016;129:872-8.

58. Flores J, Garcia de Tena J, Galipienzo J, et al. Clinical usefulness and safety of an age-adjusted $\mathrm{D}$-dimer cutoff levels to exclude pulmonary embolism: a retrospective analysis. Intern Emerg Med. 2016;11:69-75.

59. Thygesen K, Alpert JS, Jaffe AS, et al. Third universal definition of myocardial infarction. Circulation. 2012;126:2020-35.

60. Reeder GS, Kennedy HL. Criteria for the diagnosis of acute myocardial infarction. [updated 2016 Jul 05; cited 2018 Jun 24]. Available from: https:// www.uptodate.com/contents/criteria-for-the-diagnosis-of-acute-myocardialinfarction?search=acute\%20myocardial\%20infarction\&source=search_result\&selecte dTitle=2 150\&usage_type=default\&display_rank=2.

61. Anderson JL, Morrow DA. Acute Myocardial Infarction. N Engl J Med. 2017;376:205364.

62. Smith JN, Negrelli JM, Manek MB, Hawes EM, Viera AJ. Diagnosis and management of acute coronary syndrome: an evidence-based update. J Am Board Fam Med. 2015;28:283-93.

63. Rutten F, Bakx J, Bruins Slot M, et al. [GP guideline Acute coronary syndrome (first revision)]. Huisarts en wetenschap 2012;55:564-70.

64. Bosner S, Haasenritter J, Becker A, et al. Ruling out coronary artery disease in primary care: development and validation of a simple prediction rule. CMAJ. 2010;182:1295-300.

65. Haasenritter J, Bosner S, Vaucher $\mathrm{P}$, et al. Ruling out coronary heart disease in primary care: external validation of a clinical prediction rule. $\mathrm{Br} J$ Gen Pract. 2012;62:e415-21.

66. Haasenritter J, Donner-Banzhoff N, Bosner S. Chest pain for coronary heart disease in general practice: clinical judgement and a clinical decision rule. $\mathrm{Br} J$ Gen Pract. 2015;65:e748-53. 


\title{
Chapter 2
}

Access to diagnostic tests during GP out-ofhours care: A cross-sectional study of all GP out-of-hours services in the Netherlands

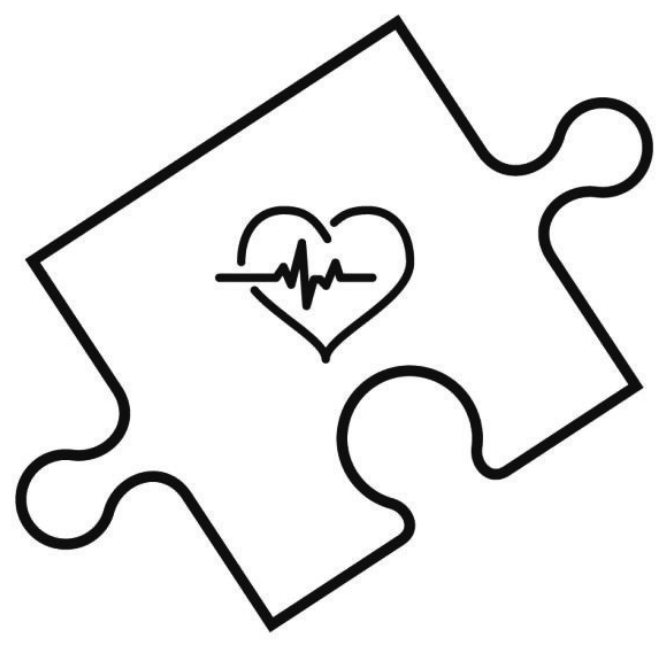

\author{
Angel Schols \\ Femke Stevens \\ Camiel Zeijen \\ Geert-Jan Dinant \\ Christel van Vugt \\ Jochen Cals
}

European Journal of General Practice 2016;22:176-81 Nederlands Tijdschrift voor Geneeskunde 2015;159:A9022 


\section{ABSTRACT}

Background In general practice, excluding serious conditions is one of the cornerstones of the consultation. Diagnostic tests are widely used to assist the decision-making process in these cases. Little is known about general practitioners' (GPs) access to diagnostic tests at GP out-of-hours services.

Objectives To determine GPs' access to diagnostic tests - imaging, function tests, laboratory tests, and point-of-care tests (POCT) - during GP out-of-hours care and to assess whether access to diagnostic facilities differs between services located adjacent to or separate from an accident and emergency (A\&E) department.

Methods Cross-sectional survey of all 117 GP out-of-hours services in the Netherlands in 2014.

Results One-hundred-seventeen GP out-of-hours services participated in the survey; response rate $100 \%$. Access to diagnostic tests during GP out-of-hours care varied across services, although generally there was limited access. Electrocardiography was available in 26\% (30/117) of all services, conventional radiography in $19 \%$ (22/117), laboratory tests between $37 \%$ (43/117) and 65\% (76/117). All services had glucose POCT and urine dipstick tests available while none utilized troponin POCT. We observed no relevant differences in access to diagnostic tests between services adjacent to or separate from an $A \& E$ department.

Conclusion GPs in the Netherlands had limited and varying access to diagnostic tests during GP out-of-hours care in 2014. Out-of-hours services adjacent to A\&E departments do not offer wider access to diagnostic tests. Further research on the accessibility of diagnostic tests in other European countries with similar and different GP out-of-hours care systems could shed further light on the effects of accessibility to diagnostic tests. 


\section{INTRODUCTION}

European GP out-of-hours services seem highly comparable when looking at the diagnostic scope of patients presenting to these services, with new and/or acute conditions largely contributing to the workload. ${ }^{1-3}$ Although the incidence of urgent and acute life-threatening health problems is low, the a priori chance of serious or acute conditions is higher than during routine day care. ${ }^{1,2}$ In general practice, excluding serious conditions is one of the cornerstones of the consultation and diagnostic tests are widely used to assist the decision-making process in these cases. ${ }^{4}$ During routine consultations general practitioners (GPs) typically have access to most medical imaging, laboratory tests and varying point-of-care tests (POCT) without referral to secondary care. ${ }^{5}$ Given the higher a priori chance of assessing a patient with a serious or acute disease during outof-hours care, one would expect that access to diagnostic tests would be at least as widely available as during routine day care.

Yet, it is unknown what the availability of diagnostic tests is during GP out-ofhours care. In the past decade, many countries with a developed primary care system have shifted from GPs providing care in small-call rotations from their own practice to large-scale out-of-hours GP cooperatives often located on a central location. ${ }^{3,6-8}$ During this shift, many GP out-of-hours services in the Netherlands relocated near an accident and emergency (A\&E) department, ${ }^{6}, 9$ which could be a decisive factor in having access to diagnostic tests.

The primary aim of this cross-sectional study is to determine GPs' access to diagnostic tests, including imaging, function tests, laboratory tests, and POCT, during GP out-of-hours care in the Netherlands. Furthermore, we aim to assess whether location, adjacent to or separate from an A\&E department, affects access to diagnostic tests. 


\section{METHODS}

\section{The Dutch GP out-of-hours system}

The Dutch GP out-of-hours system was reorganized around the year 2000; care shifted from small-call GP rotation groups to large-scale GP cooperatives, with generally 40-250 GPs practising in one region, taking care of populations ranging from 100000 to 500000 inhabitants. ${ }^{3,6,8}$ At the time of the survey, there were 124 GP out-of-hours services in the Netherlands, which were managed by 50 coordinating large-scale GP cooperatives. All out-of-hours services have a telephone triage centre in which trained nurses conduct telephone triage under supervision of a GP and divide all contacts into telephone advice, GP consultation, and home visits by GPs. The services are accommodated with a specially equipped car and a driver that are available to GPs for home visits. More than $95 \%$ of GPs provide out-of-hours care through this system. ${ }^{3,6}$

\section{Participants and data collection}

In January and February 2014 we invited the managers from all GP cooperatives in the Netherlands to participate in a survey assessing GPs' access to diagnostic tests during GP out-of-hours care. Two investigators (FS and CZ) performed the surveys by telephone. Respondents were enabled to elaborate on their answers and they were allowed to return the questionnaire by email if they did not know the answer to a specific question. We also permitted managers to refer us to a GP colleague more capable of answering the questions.

The survey was developed using existing literature and was partly based on a previous international POCT survey that our group co-led. ${ }^{10}$ The questionnaire consisted of 24 main questions on baseline characteristics, access to imaging and function tests (slit lamp, electrocardiography (ECG), conventional radiography, ultrasonography), access to laboratory tests (regular blood tests, urine sediment, cultures), access to POCT (glucose, C-reactive protein (CRP), haemoglobin, troponin, D-dimers, urine dipstick, pregnancy test, dip slide) at 
the out-of-hours services and during home visits, and future plans concerning GPs' access to diagnostic tests. We defined regular blood tests as routine blood analyses (complete blood count, liver, and kidney function), of which the results were available during the GP's out-of-hours shift. Conventional radiography included frequently ordered X-rays of one or more body parts, including skeletal imaging, plain chest or abdomen X-rays, during the complete out-of-hours shift or a certain timeframe. The availability of and access to diagnostic tests were defined as access to diagnostic tests without referral to secondary care. We piloted the questionnaire to check face-validity and changed it according to the comments.

Baseline characteristics of the GP out-of-hours services were provided by the national organization of GP out-of-hours services (InEen). In some cases, the exact population per service was unknown. In these cases, we calculated the population size by dividing the population of the large-scale GP cooperative by the number of services that fell under the coordination of that specific cooperative.

\section{Statistical analyses}

We performed descriptive analyses. To assess the difference between services adjacent to an A\&E department and services at a separate location, we divided the services into two groups. Services adjacent to an A\&E department were defined as services in a hospital with an A\&E department or legally on the grounds of a hospital with an A\&E department. This information was provided as benchmark data by the national organization of GP out-of-hours services. We tested differences using Pearson chi-square or Fisher's Exact Tests, as appropriate. A $P$-value $\leq 0.05$ was considered significant. We analysed the data using SPSS Statistics 21. 


\section{RESULTS}

Of all 124 GP out-of-hours services registered in the Netherlands, we excluded seven services; three services had stopped their activities at the moment of data collection, and four provided care at variable locations using the traditional model of small-call rotations. All remaining $117 \mathrm{GP}$ out-of-hours services completed the survey ( $85 \%$ by phone and $15 \%$ by email); response rate was $100 \%$. The median number of patients per GP out-of-hours service was 130000 (IQR 85 000-183 000). Seventy-four (63\%) services were located adjacent to an A\&E department and $43(37 \%)$ at a separate location.

\section{GPs' access to diagnostic tests}

ECG was available in 26\% (30/117) of all services and conventional radiography in 19\% (22/117). Of the 30 services having access to ECG, 25 were assisted by a cardiologist in interpreting the ECG, and of the 22 services having access to radiography, 13 were assisted by a radiologist in interpreting the $\mathrm{X}$-rays. Laboratory tests were available between 37\% (43/117) and 65\% (76/117) of services for various analyses. All services had glucose POCT and urine dipstick tests available while none utilized troponin POCT. During home visits, $10 \%$ $(11 / 116)$ of GPs had access to ECG. The availability of different POCT varied considerably; $100 \%$ of GPs had access to glucose POCT and none of them to troponin POCT (Table 2.1). We observed no significant differences in access to diagnostic tests between services adjacent to or separate from an $A \& E$ department, except for a significant difference in CRP POCT during home visits (Table 2.1). 
Table 2.1 GPs' access to diagnostic tests during GP out-of-hours care in the Netherlands.

\begin{tabular}{|c|c|c|c|}
\hline $\begin{array}{l}\text { GPs' access to diagnostic test at } \\
\text { GP out-of-hours services }(n, \%)\end{array}$ & $\begin{array}{l}\text { All GP out-of- } \\
\text { hours services } \\
\quad(n=117)\end{array}$ & $\begin{array}{l}\text { Adjacent to an } \\
\text { A\&E department } \\
(n=74)\end{array}$ & $\begin{array}{c}\text { Separate } \\
\text { location } \\
(n=43)\end{array}$ \\
\hline \multicolumn{4}{|l|}{ Imaging and function tests } \\
\hline Slit lamp & $36(31)$ & $25(34)$ & $11(26)$ \\
\hline Electrocardiography & $30(26)$ & $19(26)$ & $11(26)$ \\
\hline $\begin{array}{l}\text { Assessment by cardiologist without } \\
\text { referral }\end{array}$ & $25(83)$ & $17(90)$ & $8(73)$ \\
\hline Conventional radiography & $22(19)$ & $15(20)$ & $7(16)$ \\
\hline $\begin{array}{l}\text { Assessment by radiologist without } \\
\text { referral }\end{array}$ & $13(59)$ & $9(60)$ & $4(57)$ \\
\hline Ultrasonography & $1(1)$ & $1(1)$ & $0(0)$ \\
\hline \multicolumn{4}{|l|}{ Laboratory tests } \\
\hline Regular laboratory blood tests & $43(37)$ & $30(41)$ & $13(30)$ \\
\hline Urine sediment & $68(58)$ & $47(64)$ & $21(49)$ \\
\hline Cultures (urine, faeces, wound) & $76(65)$ & $51(69)$ & $25(58)$ \\
\hline \multicolumn{4}{|l|}{ Point-of-care tests } \\
\hline Glucose & $117(100)$ & $74(100)$ & $43(100)$ \\
\hline Urine dipstick & $117(100)$ & $74(100)$ & $43(100)$ \\
\hline Pregnancy test & $114(97)$ & $73(99)$ & $41(95)$ \\
\hline Haemoglobin & $85(73)$ & $55(74)$ & $30(70)$ \\
\hline C-reactive protein (CRP) & $50(43)$ & $27(37)$ & $23(54)$ \\
\hline Dip slide (urine culture) & $47(40)$ & $29(39)$ & $18(42)$ \\
\hline D-dimers & $25(21)$ & $19(26)$ & $6(14)$ \\
\hline Troponin & $0(0)$ & $0(0)$ & $0(0)$ \\
\hline $\begin{array}{l}\text { GPs' access to diagnostic test } \\
\text { during out-of-hours home visits } \\
(n, \%)\end{array}$ & $\begin{array}{l}\text { All GP out-of- } \\
\text { hours services } \\
\quad(n=116)^{\mathrm{b}}\end{array}$ & $\begin{array}{l}\text { Adjacent to an } \\
\text { A\&E department } \\
(n=74)\end{array}$ & $\begin{array}{l}\text { Separate } \\
\text { location } \\
(n=42)^{b}\end{array}$ \\
\hline Electrocardiography & $11(10)$ & $8(11)$ & $3(7)$ \\
\hline $\begin{array}{l}\text { Assessment by cardiology without } \\
\text { referral }\end{array}$ & $1(9)$ & $1(13)$ & $0(0)$ \\
\hline \multicolumn{4}{|l|}{ Point-of-care tests } \\
\hline Glucose & $116(100)$ & $74(100)$ & $42(100)$ \\
\hline Urine dipstick & $106(91)$ & $68(92)$ & $38(91)$ \\
\hline Pregnancy test & $56(48)$ & $36(49)$ & $20(48)$ \\
\hline Haemoglobin & $42(36)$ & $26(35)$ & $16(38)$ \\
\hline D-dimers & $19(16)$ & $14(19)$ & $5(12)$ \\
\hline C-reactive protein (CRP) & $3(3)$ & $0(0)$ & $3(7)^{a}$ \\
\hline Troponin & $0(0)$ & $0(0)$ & $0(0)$ \\
\hline
\end{tabular}




\section{Future plans concerning GPs' access to diagnostic tests}

More than half (56\%) of GP out-of-hours services expressed plans to expand their diagnostic facilities. These plans mainly concerned adding conventional radiography and $\mathrm{POCT}$ for CRP.

\section{DISCUSSION}

\section{Main findings}

Our study shows that in 2014, GPs in the Netherlands had limited and varying access to diagnostic tests during GP out-of-hours care. In contradiction to our expectations, GP out-of-hours services adjacent to A\&E departments do not offer wider access to diagnostic tests.

\section{Strengths and limitations}

We performed a telephone survey to achieve a high response rate. Although this research method is prone to reporting bias, this direct method facilitated clarification and elaboration on answers given by respondents. Even though we approached managers to take part in this study, we permitted them to refer us to a GP colleague more capable of answering the questions if they felt unable to do so or to return the questionnaire by email to enable them to consult colleagues on certain questions. The results of this study are an actual representation of GPs' access to diagnostic tests during GP out-of-hours care in the Netherlands, since we included all GP out-of-hours services and obtained a response rate of $100 \%$. However, generalizability of the results to other countries may be challenging as not all GP out-of-hours services are organized in the same manner and different countries may have different views on the use of diagnostic tests in primary care and the position of primary care itself. 


\section{Impact of the accessibility of diagnostic tests on out-of-hours care}

European GP out-of-hours services seem highly comparable with regards to the diagnostic scope of patients presenting to these services and, as stated by the European research network for out-of-hours primary care (EurOOHnet), face similar challenges concerning the organization of out-of-hours primary care. ${ }^{2,11}$ Demographic changes and other developments put a strain on services and imply safety risks. ${ }^{11}$ It may be argued that access to diagnostic tests including radiography, ECG and blood tests, may influence the utilization of GP out-ofhours care and that improved access to diagnostic tests could reduce unscheduled secondary care use and increase the efficiency of out-of-hours care in general. ${ }^{7}$ Reduction of unscheduled secondary care use is particularly important in countries were the annual number of unscheduled attendances at A\&E departments has markedly risen over the past years, e.g. the UK. ${ }^{12,13}$ One of the main reasons why patients with apparently less urgent conditions present to $A \& E$ departments is to see a doctor and have diagnostic tests done in the same place. ${ }^{14}$ For example, it is known that the patients' belief that radiography is necessary, is an important factor for attending an A\&E department instead of an out-of-hours primary care facility. ${ }^{15}$ Our study shows that GPs in less than $20 \%$ of GP out-of-hours services in the Netherlands have direct access to radiography. Therefore, if radiography were more widely available to GPs during out-of-hours care, this could reduce self-referrals and unscheduled care in A\&E departments, especially since a relatively large number of out-of-hours contacts involve musculoskeletal injuries. ${ }^{2,16}$ The same may be argued for laboratory tests. ${ }^{17}$ Other research has shown, that GPs taking care of 'non-emergency' patients in an A\&E department request fewer diagnostic tests while working as safe as and more cost-effective than the hospital A\&E physicians and with equal or higher patient satisfaction. ${ }^{18-20}$ Finally, improved access to diagnostic tests may also reduce unnecessary referrals to $A \& E$ departments, because serious diagnoses may be excluded more reliably. Alternatively, having diagnostic test facilities available could also drive patients to attend out-of-hours care to get non-urgent diagnostic tests done. Also, when more diagnostic facilities are available to GPs, physicians should be aware of misuse of these facilities. 


\section{Availability of diagnostic tests during GP out-of-hours care}

As far as we know, there is only one other study worldwide on the availability of diagnostic tests during GP out-of-hours care. This study is published in a Norwegian national journal, and shows that GPs in Norway have more access to ECG (26\% versus 99\%), but less to conventional radiography (19\% versus $13 \%)$, while differences for laboratory tests are less unequivocal. ${ }^{21}$ These differences may partially be explained by differences in the organization of GP out-of-hours care, financial structures, geographical organization and the perspective of physicians towards diagnostic tests. A further comparison of more (European) countries with similar healthcare systems would shed more light on this matter.

\section{GPs' perspective and Dutch guidelines}

From the GPs' perspective, there is a desire to have more diagnostic facilities, e.g. more POCT, available at GP out-of-hours services. ${ }^{5,10,22}$ Although we found a similar accessibility of POCT during out-of-hours care compared to a recent Dutch study on POCT use during routine day care, this study also showed that GPs desire more access to POCT during GP out-of-hours care, with a percentage as high as $93 \%$ of GPs wanting access to POCT for CRP and 92\% to POCT for Ddimers. ${ }^{10,22}$ This seems logical, as the use of POCT is most promising in acute conditions, and these conditions are more prevalent during out-of-hours care. ${ }^{23}$ Furthermore, research has shown that patient satisfaction and medication adherence substantially improve when point-of-care tests are used. ${ }^{24,}{ }^{25}$ It is advised by the profession that GPs should have sufficient access to diagnostic facilities not only during routine day care, but also during out-of-hours care, including interpretation of test results if necessary. ${ }^{26}$ In current Dutch guidelines, the use of several diagnostic tests is incorporated in diagnostic algorithms, for example, CRP in the guideline for acute cough and diverticulitis, D-dimers in the guideline for deep vein thrombosis and pulmonary embolism, and ECG in the guideline for atrial fibrillation. ${ }^{27}$ Since many GPs do not have 
access to these diagnostic facilities during out-of-hours care, they are unable to adhere to the guidelines at those moments.

\section{Future plans of the GP out-of-hours services}

In our current study, more than half of the GP out-of-hours services expressed plans to expand their diagnostic facilities, though some services reported to be satisfied with their current limited access. This may partially be explained by the workload associated with running tests, and the fact that services require all attending GPs to be familiar with the utilization and interpretation of the available tests. The availability of ECG, for example, would require all GPs to be able to interpret common ECG findings. However, merely $25 \%$ of GPs consider interpreting ECGs as one of their job responsibilities. ${ }^{5}$ Furthermore, it is known that older and more experienced GPs use less additional diagnostic tests than younger GPs. ${ }^{28}$ This could explain why only $26 \%$ of all services currently facilitate access to ECG.

\section{Influence of service location}

We hypothesized that the accessibility of diagnostic tests is higher in services adjacent to an A\&E department compared to services at a separate location. However, in our study, we observed no significant differences between the two groups, except for a difference in CRP POCT during home visits. Although statistically significant, this difference is not clinically relevant. The number of services with CRP POCT during home visits is very small (3/116), it is a relatively new test and this was the only significant test in multiple tests. The arbitrary division of services into two groups by legal location adjacent to an A\&E department or not, might have attenuated the differences between groups. Services legally not on the grounds of a hospital, but in walking distance from an A\&E department, may still have relatively easy access to diagnostic tests. Barriers to effective collaboration between GP out-of-hours services and the A\&E departments may be financial incentives, organizational obstacles, differences in 
clinical cultures, legal responsibilities, and technological problems. These barriers need to be overcome if effective and efficient collaboration between outof-hours care providers is a mutual goal.

\section{Implications for research and/or practice}

Diagnostic tests are less available during GP out-of-hours care compared to routine day care, which seems contradictory to the fact that patients presenting out-of-hours have a higher a priori chance of serious diseases. Increased access to diagnostic tests may have an impact on the utilization of GP out-of-hours services and $A \& E$ departments, and may reduce the number of unscheduled $A \& E$ attendances. Further research is necessary to determine the desire and need for more diagnostic tests and on how these tests can be implemented in GP out-ofhours care.

\section{CONCLUSION}

GPs in the Netherlands had limited and varying access to diagnostic tests during GP out-of-hours care in 2014. Contrary to our expectations, GP out-of-hours services adjacent to A\&E departments do not offer wider access to diagnostic tests. Increased access to diagnostic tests may have an impact on the utilization and efficiency of GP out-of-hours services and A\&E departments. Further research on the accessibility of diagnostic tests in other European countries with similar and different GP out-of-hours care systems could shed further light on the effects of accessibility to diagnostic tests. 


\section{REFERENCES}

1. Giesen P, Braspenning J. [GP out-of-hours service: common symptoms of acute nature]. Huisarts en wetenschap. 2004;47:735-6.

2. Huibers LA, Moth G, Bondevik GT, et al. Diagnostic scope in out-of-hours primary care services in eight European countries: an observational study. BMC Fam Pract. 2011;12:30.

3. Giesen P, Smits M, Huibers L, Grol R, Wensing M. Quality of after-hours primary care in the Netherlands: a narrative review. Ann Intern Med. 2011;155:108-13.

4. Heneghan C, Glasziou P, Thompson M, et al. Diagnostic strategies used in primary care. BMJ. 2009;338:b946.

5. Giesen P, Huibers L, Padros Goossens M, Willekens M. [Between dream and achievement. GPs' future vision of their position in acute care]. Medisch Contact. 2007;62:653-5.

6. van Uden CJ, Giesen PH, Metsemakers JF, Grol RP. Development of out-of-hours primary care by general practitioners (GPs) in The Netherlands: from small-call rotations to large-scale GP cooperatives. Fam Med. 2006;38:565-9.

7. Giesen P, Franssen E, Mokkink H, van den Bosch W, van Vugt A, Grol R. Patients either contacting a general practice cooperative or accident and emergency department out of hours: a comparison. Emerg Med J. 2006;23:731-4.

8. Huibers L, Giesen P, Wensing M, Grol R. Out-of-hours care in western countries: assessment of different organizational models. BMC Health Serv Res. 2009;9:105.

9. Thijssen WA, Giesen PH, Wensing M. Emergency departments in The Netherlands. Emerg Med J. 2012;29:6-9.

10. Howick J, Cals JW, Jones C, et al. Current and future use of point-of-care tests in primary care: an international survey in Australia, Belgium, The Netherlands, the UK and the USA. BMJ Open. 2014;4:e005611.

11. Huibers L, Philips $H$, Giesen P, Remmen R, Christensen MB, Bondevik GT. EurOOHnet-the European research network for out-of-hours primary health care. Eur J Gen Pract. 2014;20:229-32.

12. Cowling TE, Harris MJ, Watt HC, Gibbons DC, Majeed A. Access to general practice and visits to accident and emergency departments in England: cross-sectional analysis of a national patient survey. Br J Gen Pract. 2014;64:e434-9.

13. Ismail SA, Gibbons DC, Gnani S. Reducing inappropriate accident and emergency department attendances: a systematic review of primary care service interventions. Br J Gen Pract. 2013;63:e813-20. 
14. Siminski $\mathrm{P}$, Cragg $\mathrm{S}$, Middleton R, et al. Primary care patients' views on why they present to Emergency Departments: Inappropriate attendances or inappropriate policy? Aust J Prim Health. 2005;11:87-95.

15. Coleman P, Irons $R$, Nicholl J. Will alternative immediate care services reduce demands for non-urgent treatment at accident and emergency? Emerg Med $\mathrm{J}$. 2001;18:482-7.

16. van Uden CJ, Winkens RA, Wesseling GJ, Crebolder HF, van Schayck CP. Use of out of hours services: a comparison between two organisations. Emerg Med J. 2003;20:184-7.

17. Sturm JJ, Hirsh DA, Lee EK, Massey R, Weselman B, Simon HK. Practice characteristics that influence nonurgent pediatric emergency department utilization. Acad Pediatr. 2010;10:70-4.

18. Murphy AW, Bury G, Plunkett PK, et al. Randomised controlled trial of general practitioner versus usual medical care in an urban accident and emergency department: process, outcome, and comparative cost. BMJ. 1996;312:1135-42.

19. Dale J, Lang H, Roberts JA, Green J, Glucksman E. Cost effectiveness of treating primary care patients in accident and emergency: a comparison between general practitioners, senior house officers, and registrars. BMJ. 1996;312:1340-4.

20. Bosmans JE, Boeke AJ, van Randwijck-Jacobze ME, et al. Addition of a general practitioner to the accident and emergency department: a cost-effective innovation in emergency care. Emerg Med J. 2012;29:192-6.

21. Rebnord IK, Thue G, Hunskar S. [Equipment for diagnostics, laboratory analyses and treatment in out-of-hours services]. Tidsskr Nor Laegeforen. 2009;129:987-90.

22. Cals JW, Schols AM, van Weert HC, et al. [Point-of-care testing in family practices: present use and need for tests in the future]. Ned Tijdschr Geneeskd. 2014;158:A8210.

23. Cals JWL, Geersing GJ. Near-patient testing holds most promise for acute conditions. Brit J Gen Pract. 2010;60:450-1.

24. Laurence $\mathrm{CO}$, Gialamas $\mathrm{A}$, Bubner $\mathrm{T}$, et al. Patient satisfaction with point-of-care testing in general practice. Br J Gen Pract. 2010;60:e98-104.

25. Gialamas A, Yelland LN, Ryan $P$, et al. Does point-of-care testing lead to the same or better adherence to medication? A randomised controlled trial: the PoCT in General Practice Trial. Med J Aust. 2009;191:487-91.

26. Dutch College of General Practitioners. [Dutch College of General Practitioners' position on GPs and acute care] Utrecht; 2013 [cited 2016 March 14]. Available from: https://www.nhg.org/themas/publicaties/nhg-standpunt-huisarts-en-spoedzorg-juni2013. 
27. Dutch College of General Practitioners guidelines [Internet]. Utrecht: Dutch College of General Practitioners. [cited 2016 March 14]. Available from: https://www.nhg.org/nhg-standaarden.

28. Rebnord IK, Sandvik H, Hunskaar S. Use of laboratory tests in out-of-hours services in Norway. Scand J Prim Health Care. 2012;30:76-80. 



\title{
Chapter 3
}

\section{Point-of-care tests in general practice: \\ Current use and future needs}

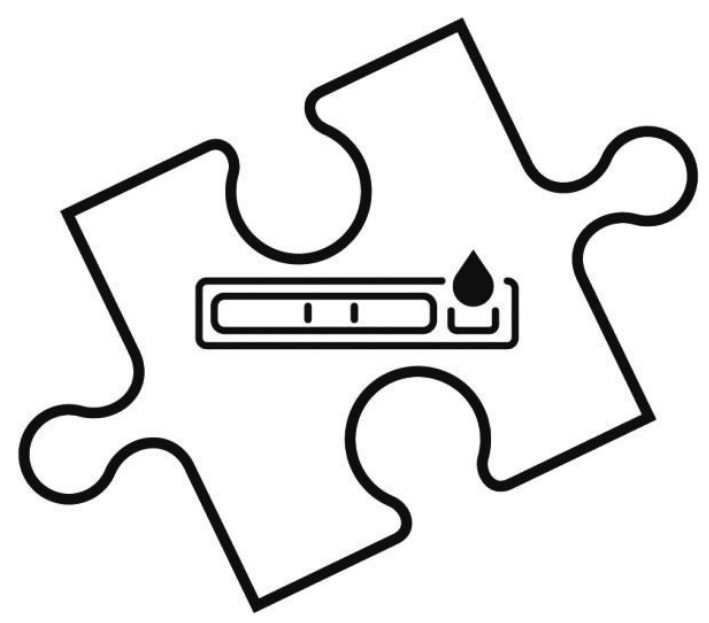

\author{
Jochen Cals \\ Angel Schols \\ Henk van Weert \\ Femke Stevens \\ Camiel Zeijen \\ Gea Holtman \\ Wim Lucassen \\ Marjolein Berger
}

Nederlands Tijdschrift voor Geneeskunde 2014;158:A8210 (translation) 


\section{ABSTRACT}

Objective To determine the current use, and future needs and attitudes of Dutch general practitioners (GPs) with regard to point-of-care tests (POCTs).

Design Cross-sectional survey using online questionnaires.

Method We conducted a survey among 2129 Dutch GPs, asking them about their current use and desired use of POCTs, the frequency of use, their opinions regarding aspects of POCTs and the effects of POCT use on practice, the acceptable waiting time for a test result, whether they wish to use POCTs at GP out-of-hours services, and for which health conditions they wish to use POCTs.

Results Six-hundred-and-thirty-nine GPs responded to the survey (response rate: $30 \%$ ). At present, the most commonly used POCTs are used for blood glucose $(96 \%)$, urine nitrite and leucocytes (96\%), pregnancy $(94 \%)$, haemoglobin $(58 \%)$ and CRP $(48 \%)$. The most desired POCTs are for D-dimer $(70 \%)$, troponin $(65 \%)$, B-type natriuretic peptide (BNP) (62\%), Chlamydia $(60 \%)$ and INR (54\%). GPs feel that POCTs primarily have a positive effect on patient satisfaction (93\%), diagnostic certainty (89\%), use of antibiotics $(84 \%)$ and substitution to primary care $(78 \%)$. They feel that reliability $(35 \%)$ and a proven effect on the immediate decision-making in general practice $(46 \%)$ are key aspects of a POCT. GPs primarily wish for POCTs to be available for acute diseases, such as acute thromboembolic diseases ( $D$-dimer), heart problems (troponin, BNP) and infections (CRP, Chlamydia).

Conclusion Currently, a small number of POCTs are used in general practice. In the future, GPs want to use more POCTs, mainly for patients with a health condition wherein the GP needs to make a diagnostic decision during the consultation. 


\section{INTRODUCTION}

Point-of-care tests (POCTs), or near-patient tests, are biomedical tests that are carried out on bodily materials, such as blood, urine, and faeces, and for which the results are returned very quickly - often within minutes. ${ }^{1}$ The nitrite dipstick for urine, the blood glucose finger-prick and the pregnancy test are examples of POCTs that have been used in daily practice for decades.

In recent years, a number of POCTs have been included in the Dutch College of General Practitioners practice guidelines based on Dutch research. ${ }^{2-4}$ The Ddimer test, for example, was included in the GP guideline 'Deep-vein thrombosis', whereas the C-Reactive Protein test (CRP) was included in the GP guideline 'Acute cough'. 5, 6 Recent studies carried out in general practices in the Netherlands showed that the same D-dimer test, in conjunction with a prediction rule, can also be used to reliably exclude a pulmonary embolism. ${ }^{7}$ The use of POCTs may result in fewer referrals to secondary care or prescriptions, greater patient satisfaction and improved treatment compliance. ${ }^{8,9}$

The foregoing developments seem to have led to an increase in the application of POCTs in Dutch general practices, however no exact figures exist on this subject as yet. In addition, there is no information regarding which POCTs general practitioners (GPs) may need and for which health conditions they wish to use them. We carried out a cross-sectional survey using questionnaires among Dutch GPs in order to identify and map out the current use of, and future needs and attitudes with regard to POCTs.

\section{METHOD}

This survey is part of an international survey into the use of POCTs by GPs in the Netherlands, Belgium, the United Kingdom, the United States and Australia. The results of this international comparative survey were published elsewhere. ${ }^{10}$ In addition to the questions regarding the use of POCTs that were put to respondents in all countries, we asked Dutch GPs an additional set of questions, 
which is described under the 'Survey' heading. In the current study we will be presenting the results of all the questions we asked Dutch GPs.

\section{Research population and sample size calculation}

Assuming a total of 10851 Dutch GPs, we calculated that we would need 371 responding GPs to be able to make a valid claim regarding the use of POCTs in Dutch general practice with a confidence interval of $5 \% .{ }^{10,11}$ Taking into account a conservative response, we sent 2129 GPs an email in February 2013, with the request to complete an online survey regarding the use of and attitude towards POCTs. These GPs were all affiliated with the networks of the departments of Family Medicine of Maastricht University or the Universities of Groningen or Amsterdam in some way. After two weeks, we sent the group a one-off reminder by email.

\section{Survey}

The survey consisted of eight main questions specifically about POCTs and eight questions that dealt with characteristics of the respondents and their practice. We digitised the survey and collected the answers in collaboration with Flycatcher Internet Research's Academic Support Centre (in Maastricht). The eight main questions focused on the current and desired use of POCTs, the frequency of use, GPs' opinions regarding aspects of POCTs and the effects of their use on practice, the acceptable waiting time for a test result, how GPS would wish to use POCTs at GP out-of-hours services, and for which health conditions they would wish to use POCTs. The survey is available via www.flycatcherpanel.nl/surveys/F29AC_1.qms. 
In collaboration with the international working group, we first identified the laboratory tests that were requested most frequently and subsequently classified these tests into six main categories for blood tests (cardiovascular, endocrine, haematology, infection-related, liver and other blood tests) and three other main categories for tests on respiratory samples, urinary or genital fluids and faeces.

GPs were able to give one of the following answers per test:

- The test is available as a POCT in my practice and I use it (current use).

- The test is available as a POCT in my practice, but I do not use it. The test is not available as a POCT in my practice, but I would use it if it were available (desired use).

- The test is not available as a POCT in my practice and I would not use it if it were available.

If GPs indicated they currently used or desired to use a POCT, we asked them how often they used or desired to use the test (at least once daily, weekly, monthly, once a year or less).

We asked Dutch GPs a number of additional questions. The attitude of GPs regarding the effect of POCTs was investigated by asking them to respond to 11 statements on a 5-point scale, ranging from very negative to very positive. We also asked the GPs to rank eight aspects of POCTs, such as simplicity, effectiveness and cost, in order of importance and to indicate an acceptable waiting time for the result of a POCT upon suspicion of six acute health conditions (pneumonia, pulmonary embolism, deep vein thrombosis, acute coronary syndrome, urinary tract infection and Chlamydia). We based these questions on previous publications on POCTs. ${ }^{1}$

The respondents were required to provide an answer to each of the questions referred to above. As such, no answers were omitted. Finally, we asked the GPs to identify five health conditions for which they wished to use a POCT if it were available. This was the only optional, open question and the question was asked in all countries. We grouped the answers according to International Classification of Primary Care (ICPC) codes and in cases of ambiguity three researchers applied the most appropriate ICPC code by way of consensus. 


\section{RESULTS}

\section{Study population}

Of the 2129 GPs we asked to take part in the survey, 639 (30\%) responded. Groningen had a response rate of $24 \%$ (217/900), Amsterdam of $31 \%$ (126/410) and Maastricht of $36 \%$ (296/819). The characteristics of the corresponding GPs and their practices were representative of the overall population of Dutch GPs (table 3.1). ${ }^{12,13}$

\section{Current and future use of POCTs}

Currently, the most commonly used POCTs in general practice (table 3.2) are tests for blood glucose (96\%), urine leucocytes and nitrite (96\%), pregnancy (94\%), haemoglobin (58\%) and CRP (48\%). GPs primarily cite the need for POCTs for D-dimer (70\%), troponin (65\%), B-type natriuretic peptide (BNP) $(62 \%)$, Chlamydia (60\%) and INR (54\%). Table 3.2 also shows the user frequency for each of the tests. At present, the majority of GPs only use the blood glucose finger-prick test and the urine dipstick for leucocytes and nitrites daily ( $69 \%$ and $89 \%$ respectively). 
Table 3.1 Basic characteristics of responding GPs and practices in a survey on the use point-of-care tests.

\begin{tabular}{|c|c|c|}
\hline Characteristic & $\begin{array}{l}\text { Respondents } \\
(n=639)\end{array}$ & $\begin{array}{l}\text { National } \\
\text { figures* }\end{array}$ \\
\hline \multicolumn{3}{|l|}{ General practitioners } \\
\hline Sex, male; \% (n) & $62.6(400)$ & 57.4 \\
\hline Average age in years (SD) & $48.9(9.48)$ & 48.5 \\
\hline Year of graduation; mean (SD) & $1991(9.42)$ & - \\
\hline Average number of working hours per week & 44 & 44 \\
\hline \multicolumn{3}{|l|}{ Position } \\
\hline Self-employed general practitioner; \% (n) & $82.0(524)$ & 78.5 \\
\hline Employed general practitioner; \% (n) & $17.5(112)$ & 7.8 \\
\hline General practitioner trainee; \% (n) & $0.5(3)$ & 13.7 \\
\hline \multicolumn{3}{|l|}{ Practices } \\
\hline $\begin{array}{l}\text { Number of patients registered at practice; median } \\
\text { (IQR) }\end{array}$ & $\begin{array}{l}3000 \\
(2482-5200)\end{array}$ & - \\
\hline \multicolumn{3}{|l|}{ Location of practice ${ }^{+}$} \\
\hline Rural area; \% (n) & $43.8(280)$ & 32.5 \\
\hline Urban area; \% (n) & $56.2(359)$ & 67.5 \\
\hline $\begin{array}{l}\text { Kilometres to nearest hospital with } \\
\text { emergency department (average) }\end{array}$ & 8.6 & - \\
\hline \multicolumn{3}{|c|}{$\begin{array}{l}\text { IQR = Interquartile range. } \\
\text { * National figures were retrieved from publications of the NIVEL (Netherlands Institute for Health } \\
\text { Services Research). }{ }^{12,13} \\
\text { †'Rural area' for the respondents was defined as 'rural area + semi-rural area', whereas the NIVEL } \\
\text { publication defined it as 'non-urban + not very urban'; the term 'urban area' for the respondents was } \\
\text { defined as 'urban area + suburban area', whereas the NIVEL publications defined the term as 'very } \\
\text { strongly urban + very urban + moderately urban'. }\end{array}$} \\
\hline
\end{tabular}


Table 3.2 Current use, desired use, and potential future use of point-of-care tests in general practice and most frequently cited users frequency $(n=639)$.

\begin{tabular}{|c|c|c|c|c|}
\hline Point-of-care test & $\begin{array}{l}\text { Current } \\
\text { use* } \\
\%\end{array}$ & $\begin{array}{l}\text { Desired } \\
\text { uset } \\
\%\end{array}$ & $\begin{array}{l}\text { Potential } \\
\text { future use } \\
\% \text { (n) }\end{array}$ & $\begin{array}{l}\text { Most frequently } \\
\text { cited users } \\
\text { frequency }\end{array}$ \\
\hline Glucose & 96.4 & 2.0 & $98.4(629)$ & $\begin{array}{l}\text { At least once a day } \\
68.5 \%(431 / 629)\end{array}$ \\
\hline $\begin{array}{l}\text { Nitrite/leukocytes } \\
\text { (urine dipstick) }\end{array}$ & 95.6 & 1.6 & $97.2(621)$ & $\begin{array}{l}\text { At least once a day } \\
89.4 \%(555 / 621)\end{array}$ \\
\hline Pregnancy test & 94.4 & 2.3 & $96.7(618)$ & $\begin{array}{l}\text { Weekly } \\
41.9 \%(259 / 618)\end{array}$ \\
\hline CRP & 47.7 & 47.3 & $95.0(607)$ & $\begin{array}{l}\text { Weekly } \\
46.5 \%(282 / 607)\end{array}$ \\
\hline D-dimer & 17.8 & 70.1 & $87.9(562)$ & $\begin{array}{l}\text { Monthly } \\
54.4 \%(306 / 562)\end{array}$ \\
\hline Haemoglobin & 58.1 & 26.3 & 84.4 (539) & $\begin{array}{l}\text { Weekly } \\
49.7 \%(268 / 539)\end{array}$ \\
\hline Troponin & 1.9 & 65.4 & $67.3(430)$ & $\begin{array}{l}\text { Monthly } \\
43.5 \%(187 / 430)\end{array}$ \\
\hline BNP & 0.6 & 62.3 & $62.9(402)$ & $\begin{array}{l}\text { Monthly } \\
46.8 \%(188 / 402)\end{array}$ \\
\hline Chlamydia & 0.8 & 59.8 & $60.6(387)$ & $\begin{array}{l}\text { Weekly } \\
47.0 \%(182 / 387)\end{array}$ \\
\hline $\begin{array}{l}\text { Helicobacter pylori } \\
\text { (blood or exhaled air) }\end{array}$ & 0.8 & 52.9 & $53.4(341)$ & $\begin{array}{l}\text { Monthly } \\
46.9 \%(160 / 341)\end{array}$ \\
\hline INR & 0.9 & 54.3 & $55.2(353)$ & $\begin{array}{l}\text { Monthly } \\
41.6 \%(147 / 353)\end{array}$ \\
\hline Gonorrhoea & 0.6 & 51.0 & $51.6(330)$ & $\begin{array}{l}\text { Weekly } \\
42.4 \%(140 / 330)\end{array}$ \\
\hline ESR & 20.8 & 28.6 & $49.4(316)$ & $\begin{array}{l}\text { Weekly } \\
48.7 \%(154 / 316)\end{array}$ \\
\hline Faecal occult blood & 2.2 & 43.5 & $45.7(292)$ & $\begin{array}{l}\text { Monthly } \\
45.2 \%(132 / 292)\end{array}$ \\
\hline HCG (quantitative) & 21.6 & 23.3 & $44.9(287)$ & $\begin{array}{l}\text { Monthly } \\
39.2 \%(113 / 287)\end{array}$ \\
\hline $\mathrm{HbA}_{1 \mathrm{c}}$ & 5.9 & 37.4 & $43.3(277)$ & $\begin{array}{l}\text { At least once a day } \\
46.6 \%(129 / 277)\end{array}$ \\
\hline
\end{tabular}


Table 3.2 (Continued).

\begin{tabular}{|c|c|c|c|c|}
\hline Point-of-care test & $\begin{array}{l}\text { Current } \\
\text { use* } \\
\%\end{array}$ & $\begin{array}{l}\text { Desired } \\
\text { uset } \\
\%\end{array}$ & $\begin{array}{l}\text { Potential } \\
\text { future use } \neq \\
\% \text { (n) }\end{array}$ & $\begin{array}{l}\text { Most frequently } \\
\text { mentioned users } \\
\text { frequency }\end{array}$ \\
\hline Leukocytes (WBC) & 0.9 & 40.1 & $41.0(262)$ & $\begin{array}{l}\text { Weekly } \\
55.0 \%(144 / 262)\end{array}$ \\
\hline $\begin{array}{l}\text { Influenza } \\
\text { (nose/throat swab) }\end{array}$ & 0.3 & 36.2 & $36.5(234)$ & $\begin{array}{l}\text { Weekly } \\
33.5 \%(78 / 234)\end{array}$ \\
\hline $\begin{array}{l}\text { Group A Streptococcus } \\
\text { (throat swab) }\end{array}$ & 0.6 & 32.6 & $33.2(212)$ & $\begin{array}{l}\leq \text { once a year } \\
35.4 \%(75 / 212)\end{array}$ \\
\hline Potassium & 0.0 & 32.9 & $32.9(210)$ & $\begin{array}{l}\text { Weekly } \\
44.3 \%(93 / 210)\end{array}$ \\
\hline $\begin{array}{l}\text { MRSA } \\
\text { (nose swab) }\end{array}$ & 3.3 & 29.4 & 32.7 (209) & $\begin{array}{l}\leq \text { once a year } \\
55.0 \%(115 / 209)\end{array}$ \\
\hline Leukocytes differentiation & 0.8 & 28.2 & $29.0(185)$ & $\begin{array}{l}\text { Weekly } \\
50.8 \%(94 / 185)\end{array}$ \\
\hline Creatinine & 0.0 & 27.7 & $27.7(177)$ & $\begin{array}{l}\text { Weekly } \\
41.8 \%(74 / 177)\end{array}$ \\
\hline Urine total proteins & 13.5 & 13.6 & $27.1(173)$ & $\begin{array}{l}\text { Weekly } \\
39.9 \%(69 / 173)\end{array}$ \\
\hline TSH & 0.3 & 26.8 & $27.1(173)$ & $\begin{array}{l}\text { Weekly } \\
46.2 \%(80 / 173)\end{array}$ \\
\hline Uric acid & 0.0 & 26.1 & $26.1(167)$ & $\begin{array}{l}\text { Monthly } \\
54.5 \%(91 / 167)\end{array}$ \\
\hline \multicolumn{5}{|c|}{$\begin{array}{l}\text { CRP = C-reactive protein, BNP = B-type natriuretic peptides, INR = International Normalised Ratio, } \\
\text { ESR = Erythrocyte sedimentation rate, HCG = Human Chorionic Gonadotropin, HbA1c = Haemoglobin } \\
\text { A1c, WBC = white blood cell count, MRSA = Methicillin-resistant Staphylococcus aureus, TSH = Thyroid } \\
\text { stimulating hormone. } \\
\text { *Current use implies that the GP has the POCT and also uses it. } \\
\text { †Desired use implies that the GP does not have the POCT, but would like to use it. } \\
\text { fPotential future use is the current use and desired use combined. } \\
\text { Point-of-care tests of which the potential future use is <25\%: } \\
24.9 \% \text { - } 20.1 \% \text { : free T4 or T3, urine protein/creatinine ratio. } 20.0 \%-10.1 \%: \text { HDL/LDL cholesterol, } \\
\text { albumin/creatinine ratio, sodium, total cholesterol, thrombocytes, vitamin D, Borrelia Burgerdorfi } \\
\text { (Lyme), PSA, gamma-glutamyltransferase (gamma GT), Coxiella Burnetii (Q fever), vitamin B12, } \\
\text { ASAT/ALAT, heart-type fatty-acid binding protein (H-FABP), bilirubin, triglyceride. <10\%: folic acid, } \\
\text { faecal calprotectin, alkaline phosphatase, calcium, HIV, rheumatoid factor, hepatitis B, albumin, } \\
\text { hepatitis C, anti-nuclear antibodies (ANA), CA125, procalcitonin. }\end{array}$} \\
\hline
\end{tabular}




\section{Attitudes toward point-of-care tests}

Virtually all GPs (93\%) feel that the use of POCTs has a positive effect on patient satisfaction. In addition, $89 \%$ of respondents feel that POCTs improve diagnostic certainty in the GP practice, reduce antibiotics use (83\%) and induce substitution to primary care (78\%) (table 3.3). GPs feel that a proven impact on the immediate decision-making in the GP practice (46\%) and reliability of the POCT (35\%) are key requirements that any POCT should meet (table 3.4 ).

Table 3.3 General practitioners' attitude with regard to POCTs.

\begin{tabular}{|c|c|c|}
\hline \multirow{2}{*}{$\begin{array}{l}\text { Aspect } \\
(n=639)\end{array}$} & \multicolumn{2}{|l|}{ Attitude* } \\
\hline & $\begin{array}{l}\text { Positive } \\
\% \text { (n) }\end{array}$ & $\begin{array}{l}\text { Neutral or negative } \\
\%(n)\end{array}$ \\
\hline Diagnostic certainty & $88.6(566)$ & $11.4(73)$ \\
\hline Patient satisfaction & $93.1(595)$ & $6.9(44)$ \\
\hline Doctor-patient communication & $72.5(463)$ & $27.5(176)$ \\
\hline Doctor-patient relationship & $71.5(457)$ & $28.5(182)$ \\
\hline Patient safety & $57.6(368)$ & $42.4(271)$ \\
\hline Treatment compliance & $60.9(389)$ & $39.1(250)$ \\
\hline Job satisfaction & $76.2(487)$ & $23.8(152)$ \\
\hline Use of medication in general & $52.0(332)$ & $48.0(307)$ \\
\hline Use of antibiotics in particular & $82.6(528)$ & $17.4(111)$ \\
\hline Health care costs & $59.8(382)$ & $40.2(257)$ \\
\hline Substitution to primary care & $78.2(500)$ & $21.8(139)$ \\
\hline
\end{tabular}


Table 3.4 Aspects of a POCT, ordered according to the importance attached to that aspect by general practitioners.

\begin{tabular}{ll}
\hline Most important aspect of POCTs* & \% \\
\hline The proven effectiveness on the immediate decision-making in general practice & 45.9 \\
The reliability of the POCT (compared to conventional lab tests) & 34.7 \\
The speed with which I obtain the result after carrying out the POCT & 7.2 \\
The reimbursement of the POCT by the health care insurer & 5.2 \\
The simplicity with which the POCT can be carried out & 4.5 \\
The quality control with which the quality of the POCT can be guaranteed & 1.3 \\
The costs of the POCT and potential equipment & 0.9 \\
The frequency with which I can use the POCT & 0.3 \\
\hline
\end{tabular}

*The importance placed on the foregoing aspects was measured using an online survey completed by 639 GPs. The percentages above reflect the proportion of GPs that scored that specific aspect as the most important aspect.

\section{Most commonly cited health conditions}

The open question regarding health conditions for which POCTs could be useful was answered by 611 GPs who provided a total of 3146 answers. GPs mainly feel that POCTs for thromboembolic disease, acute coronary syndrome, respiratory tract infections and urinary tract infections could be useful in increasing diagnostic certainty (table 3.5 ).

\section{Waiting times and the GP out-of-hours service}

GPs would like the result of a POCT to be delivered within the time slot of a double consultation ( $20 \mathrm{~min}$ ). The median of acceptable waiting times is 6 minutes for acute coronary syndrome (interquartile range (IQR): 4-11) and a urinary tract infection (IQR: 4-16), 11 minutes upon suspicion of pneumonia (IQR: 6-16), pulmonary embolism (IQR: 6-16), deep vein thrombosis (IQR: 621) and anaemia (IQR: 6-21) and 16 minutes (IQR: 11-61) upon suspicion of a Chlamydia infection. At GP out-of-hours services, $93 \%$ of GPs wish to have a 
POCT for CRP. This percentage is $92 \%$ for D-dimer, $81 \%$ for haemoglobin, $71 \%$ for troponin, $68 \%$ for the INR, $59 \%$ for BNP and $31 \%$ for creatinine.

Table 3.5 Most frequently cited health conditions for which GPs would want to use POCTs.

\begin{tabular}{|c|c|c|}
\hline Health condition or diagnosis & ICPC code & $\begin{array}{l}\text { Number of times } \\
\text { cited; } n(\%) \\
(n=611) *\end{array}$ \\
\hline Thromboembolic diseasest & K93/K94 & $651(106.5)$ \\
\hline Pulmonary embolism & & $293(48.0)$ \\
\hline Deep vein thrombosis & & $271(44.3)$ \\
\hline $\begin{array}{l}\text { Undefined or pulmonary embolism and thrombosis } \\
\text { in } 1 \text { box }\end{array}$ & & $87(14.2)$ \\
\hline Acute coronary syndrome & K74/K75/K76 & $383(62.7)$ \\
\hline Respiratory tract infections & & $416(68.1)$ \\
\hline Pneumonia or acute lower respiratory tract infection & R81/R78/R05 & $334(54.7)$ \\
\hline Acute upper respiratory tract infection & $\mathrm{R} 72 / \mathrm{R} 74 / \mathrm{R} 75$ & $72(11.8)$ \\
\hline Other‡ & R71/R80/R83 & $10(1.6)$ \\
\hline Urinary tract infection & U70/U71 & $159(26.0)$ \\
\hline Heart failure & K77 & $140(22.9)$ \\
\hline Anaemia & $\mathrm{B} 78 / 80 / 81 / 82$ & $122(20.0)$ \\
\hline Diabetes nos & T89/T90/T87 & $90(14.7)$ \\
\hline Infections general & & $80(13.1)$ \\
\hline Appendicitis & D88 & $66(10.8)$ \\
\hline Sexually transmitted diseases & & $55(9.0)$ \\
\hline
\end{tabular}

ICPC = International Classification of Primary Care.

*28 respondents did not provide answers.

IIn the case of thromboembolic diseases, more answers were provided than the number of respondent general practitioners taking part. This is the result of the questions being open questions, where many general practitioners cited pulmonary embolism as one answer and gave deep vein thrombosis as one answer.

$\neq$ Other respiratory tract infections include: respiratory syncytial virus, influenza virus, whooping cough and $\mathrm{Q}$ fever. 


\section{DISCUSSION}

In the Netherlands, a limited number of POCTs is used by the majority of GPs in practice. Nevertheless, GPs feel that POCTs have a positive effect on patient satisfaction and that POCTs increase diagnostic certainty in general practice. GPS stated the desire for POCTs to be available for acute thromboembolic diseases (D-dimer), heart problems (troponin, BNP) and infections (CRP, Chlamydia). Dutch GPs seem to want to use POCTs primarily for cases where the result has an immediate influence on the decision-making of the GP.

\section{Interpretation of the results}

The blood glucose, nitrite and pregnancy tests are three long-established POCTs that are used by almost all GPs (see table 3.2). The haemoglobin test is still used by a majority of GPs, despite the reported doubts regarding the accuracy of the measurement. ${ }^{14}$ The CRP POCT is used by nearly half of the respondents. This percentage will undoubtedly have risen since the publication of the Dutch GP guideline 'Acute cough' and other scientific publications on the role of this POCT in relation to cough symptoms. ${ }^{6,15-17}$ A D-dimer POCT is currently used by $18 \%$ of respondents, while as much as $88 \%$ of respondents state that they wish to use this POCT in the future. We expect an increase in use of this POCT, as it is suitable to exclude both deep vein thrombosis and pulmonary embolism. ${ }^{5,18}$

In this study, health conditions for which the GP needs to make a clinical decision during the consultation - often in relation to either treatment or referral - are cited most often: pulmonary embolism, deep vein thrombosis, myocardial damage and respiratory and urinary tract infections. It is precisely upon suspicion of one of these conditions that the POCT must be able to reliably exclude the condition. The use of the foregoing POCTs will directly affect primarily emergency secondary care, due to the changing referral behaviour of GPs.

Although respondents indicated that they wish to use certain POCTs if they were available, this does not imply that they would also immediately implement that POCT in daily practice. Implementation of POCTs is determined by multiple 
factors. The GPs in this survey feel that POCTs must have a proven effectiveness on the immediate decision-making and that the reliability of the POCT must be significant.

Strikingly, the costs of POCTs are ascribed a far less significant role in the decision whether or not to use a test. There are, however, various barriers that inhibit the implementation of POCTs in daily practice - mostly financial and organisational ones. In addition, cost-effectiveness in daily practice has not yet been demonstrated for many POCTs, with the exception of the CRP test for cough and the D-dimer test for deep vein thrombosis. ${ }^{19,} 20$

Issues such as quality control and analytical accuracy are also key factors that must be guaranteed before any large-scale implementation can be recommended. For that reason, collaboration with laboratories would be a logical step to ensure implementation, quality and maintenance of the equipment. ${ }^{21}$

From an organisational and practical point of view, the availability of multiple POCTs integrated into one device would be more suitable than individual devices and procedures for each individual POCT. Finally, we must be cautious that indications do not broaden once a POCT is available. Clear protocols will have to be drafted, in collaboration with secondary care providers, regarding whether a POCT is or is not indicated in general practice.

\section{Strengths and limitations}

In this study, which is part of a larger international survey into the use of POCTs, we asked the Dutch GPs an additional set of questions. As Dutch group, we explicitly chose to ask these additional questions because we wanted to ascertain why and on the basis of which indications GPs would want to use POCTs and which factors they consider to be important in relation thereto. When interpreting the data of this study, it is vital that we exercise caution.

As with any survey, selection bias may skew the results. GPs with an interest in diagnostics that is above average - regardless of the use of POCTs - will potentially have responded to the survey more quickly based on that interest. 
Therefore, the percentages that we found potentially may be an overestimation of the current use and the future need for POCTs. Nevertheless, we believe that by selecting three large regions, both peripheral and central within the Netherlands, we have been able to reach a representative group of GPs.

The basic characteristics of the responding GPs were similar to the national figures available on primary care provided by the NIVEL. Although the response rate was not high, a response rate of $30 \%$ matches previous surveys conducted among GPs. ${ }^{22,} 23$ In addition, the number of respondents achieved, i.e. 639, was well above the required 371 GPs from the sample size calculation, resulting in minimal uncertainty regarding the reported percentages.

In any case, our results show for which health conditions GPs experience diagnostic uncertainty and where additional point-of-care diagnostics may be useful. We asked respondents to not only consider existing tests, but also envisage potential future POCTs. It goes without saying that the properties and added value of these tests must be demonstrated first. This should be taken into account when interpreting the data.

\section{CONCLUSION}

Our study shows that GPs wish to use more POCTs in the future, primarily in cases where the result has a direct effect on diagnostic or treatment decisions of the GP during a consultation. Future POCTs should be able to exclude acute thromboembolic conditions, myocardial damage and various types of infections in a safe and simple way in general practice. A key element is that a POCT should never stand on its own merits, but should always be an addition to the findings of the medical history and the physical examination. ${ }^{1}$

If general practice studies have shown that POCTs, as an additional diagnostic tool, have a proven impact on GPs' daily practice and if these POCTs are sufficiently reliable, then there seems to be a consensus among GPs that these POCTs should be used in daily practice. 


\section{REFERENCES}

1. Cals J, van Weert H. Point-of-care tests in general practice: hope or hype? Eur J Gen Pract. 2013;19:251-6.

2. Geersing GJ, Janssen $\mathrm{KJ}$, Oudega $\mathrm{R}$, et al. Excluding venous thromboembolism using point of care $\mathrm{D}$-dimer tests in outpatients: a diagnostic meta-analysis. BMJ. 2009;339:b2990.

3. Buller HR, Ten Cate-Hoek AJ, Hoes AW, et al. Safely ruling out deep venous thrombosis in primary care. Ann Intern Med. 2009;150:229-35.

4. Cals JW, Butler CC, Hopstaken RM, Hood K, Dinant GJ. Effect of point of care testing for $\mathrm{C}$ reactive protein and training in communication skills on antibiotic use in lower respiratory tract infections: cluster randomised trial. BMJ. 2009;338:b1374.

5. Oudega $R$, van Weert $H$, Stoffers $H E J H$, et al. [Dutch GP guideline Deep vein thrombosis]. Huisarts en wetenschap. 2008;51:24-37.

6. Verheij TJM, Hopstaken RM, Prins JM, et al. [Dutch GP guideline Acute cough]. Huisarts en wetenschap. 2011;54:68-92.

7. Geersing GJ, Erkens PM, Lucassen WA, et al. Safe exclusion of pulmonary embolism using the Wells rule and qualitative D-dimer testing in primary care: prospective cohort study. BMJ. 2012;345:e6564.

8. Laurence $\mathrm{CO}$, Gialamas A, Bubner $\mathrm{T}$, et al. Patient satisfaction with point-of-care testing in general practice. Br J Gen Pract. 2010;60:e98-104.

9. Gialamas A, Yelland LN, Ryan P, et al. Does point-of-care testing lead to the same or better adherence to medication? A randomised controlled trial: the PoCT in General Practice Trial. Med J Aust. 2009;191:487-91.

10. Howick J, Cals JW, Jones C, et al. Current and future use of point-of-care tests in primary care: an international survey in Australia, Belgium, The Netherlands, the UK and the USA. BMJ Open. 2014;4:e005611.

11. www.nss.gov.au/nss/home.nsf/pages/Sample+size+calculator [cited 2014 Nov 12].

12. Van Hassel DTP, Kenens RJ. Cijfers uit de registratie van huisartsen. Peiling 2012. Utrecht: NIVEL; 2013. [cited 2014 Nov 12]. Available from: www.nivel.nl/brochures.

13. Van den Berg MJ, Kolthof ED, de Bakker DH, van der Zee J. Tweede Nationale Studie naar ziekten en verrichtingen in de huisartsenpraktijk. De werkbelasting van huisartsen. Utrecht: NIVEL; 2004.

14. Eekhof JA, Groeneveld Y. [Determining the haemoglobin concentration in general practice using the HemoCue method: useful but not completely reliable]. Ned Tijdschr Geneeskd. 2008;152:2294-7.

15. Cals J, Francis N. [Acute cough in adults]. Huisarts en wetenschap. 2010;53:510. 
16. Hopstaken RM, Verdijk N, van den Broek N, et al. [CRP point-of-care test in daily practice]. Huisarts en wetenschap. 2012;55:388-92.

17. Francis N, Gillespie D, Nuttall ], et al. [Antibiotic treatment adherence in cough symptoms in 13 European countries]. Huisarts en wetenschap. 2013;56:384-7.

18. Lucassen WA, Erkens PM, Geersing G]. [Diagnostics in pulmonary embolism]. Huisarts en wetenschap. 2013;56:264-8.

19. Cals JW, Ament AJ, Hood K, et al. C-reactive protein point of care testing and physician communication skills training for lower respiratory tract infections in general practice: economic evaluation of a cluster randomized trial. J Eval Clin Pract. 2011;17:1059-69.

20. Ten Cate-Hoek AJ, Toll DB, Buller HR, et al. Cost-effectiveness of ruling out deep venous thrombosis in primary care versus care as usual. J Thromb Haemost. 2009;7:2042-9.

21. Kleinveld HA, Raijmakers MT, Vermeer HJ, Oosterhuis WP. [Vision document NVKC Point-of-care tests in primary care]. Utrecht: NVKC; 2012. [cited 2018 Jun 28]. Available from: https://www.nvkc.nl/sites/default/files/visiedocument_POCT_def\% 286\%29.pdf.

22. Swart S], Rietjens JA, Brinkkemper $\mathrm{T}$, et al. [Palliative sedation largely in accordance with Dutch national guideline]. Ned Tijdschr Geneeskd. 2011;155:A2857.

23. Schoots $M$, Honkoop $P$, Dunselman $H$, Joziasse I. [Were does 'the new general practitioner' want to settle down?]. Huisarts en wetenschap. 2012;55:494-9. 



\section{Chapter 4}

International definition of a point-of-care test in family practice: a modified e-Delphi procedure

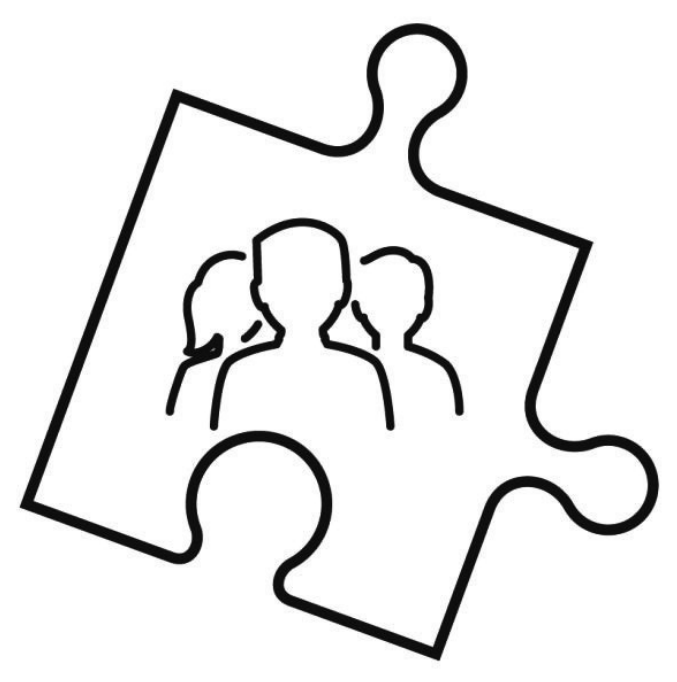

Angel Schols Geert-Jan Dinant Rogier Hopstaken Christopher Price Ron Kusters Jochen Cals

Family Practice 2018;35:475-480 


\section{ABSTRACT}

Background The use of point-of-care tests (POCTs) in family practice is increasing, and the term POCT is often used in medical literature and clinical practice. Yet, no widely supported definition by several professional fields exists.

Objective To reach consensus on an international definition of a POCT in family practice.

Methods We performed a modified international e-Delphi procedure of four rounds among expert panel members from different professional backgrounds family practitioners, laboratory specialists, policymakers, researchers and manufacturers.

Results Of 27 panel members from seven different countries, 26 participated in all rounds. Most panel members were active in POCT research or policymaking and $70 \%$ worked in family medicine. After choosing important components, structuring of answers and feedback, the following definition was chosen as the best or second best definition by $81 \%$ of panel members: a point-of-care test in family practice is a test to support clinical decision making, which is performed by a qualified member of the practice staff nearby the patient and on any part of the patient's body or its derivatives, during or very close to the time of consultation, to help the patient and physician to decide upon the best suited approach, and of which the results should be known at the time of the clinical decision making.

Conclusion The definition emerging from this study can inform family practitioners, laboratory specialists, policymakers and manufacturers on the most widely supported and recognized definition and could act as a clear starting point for the organization and execution of professional point-of-care testing in family practice worldwide. 


\section{INTRODUCTION}

The term point-of-care test (POCT) is often used throughout the medical literature and in clinical practice. In family practice, in particular, POCTs are increasingly used and wanted by physicians to assist clinical decision making. ${ }^{1}$ There are various definitions and alternative names that have been used for a POCT. $^{2}$ Yet no widely supported and recognized international definition of a POCT in family practice exists. Differences in definitions may lead to misconceptions and confusion, especially since those working in family practice may define a POCT differently from those coming from a laboratory background.

A suitable approach for seeking consensus on a definition is the Delphi technique, in which a series of questionnaires is used to collect data from a panel of selected experts. This technique uses multiple iterations designed to develop a consensus of opinions concerning a specific topic. The controlled feedback process allows and encourages the selected panel members to reassess their initial judgements, while doing this without the direct influence of other panel members, as anonymity and confidentiality are facilitated by the research team. ${ }^{3,4}$ In this study, we performed a modified e-Delphi procedure to reach consensus on an international definition of a POCT in family practice, supported and recognized by those professions working with POCTs in family practice.

\section{METHOD}

\section{Participants}

We compiled an international expert panel using purposive sampling combined with the quota and snowball method; ${ }^{5}$ the research group compiled an international list of potential panel members (purposive sampling) and we asked all potential panel members who responded to our invitation to provide the name of another potential panel member (snowball method). We purposely aimed to include panel members from four different fields (quota method): (i) family practitioners directly involved in POCT research or policymaking (35\%); 
(ii) family practitioners without special involvement in point-of-care testing (35\%); (iii) laboratory specialists (15\%) and (iv) manufacturers of POCTs (15\%). In total, we invited 40 potential panel members via a personal e-mail, aiming to include about 25 to 30 panel members to be able to have at least three panel members representing their field.

\section{Data collection and analyses per round}

We performed four rounds of an online questionnaire - each questionnaire based on the analysis of the previous round - starting with a completely open questionnaire, supplemented with some questions on personal characteristics, followed by an increasingly more specific questionnaire. We allowed panel members the opportunity to write down free comments in each round. We piloted all questionnaires by asking at least two family physician trainees to fill out the questionnaires - checking if all instructions and questions were clear and adjusted the questionnaires when needed. At the start of every round, panel members were given feedback on the previous round. We aimed for an agreement proportion of $80 \%$ by the last round. ${ }^{6,7}$ Data of each round were analysed by three researchers (AS, GD, JC). Quantitative and qualitative data analyses were discussed in a consensus meeting, in which decisions - based on the analysis - were made for the next round. When discussion points remained, the other co-authors were asked to comment on these points. We used Survey Monkey to distribute the questionnaires. After the last round, an English language expert evaluated the final definition to provide possible languagerelated suggestions for the definition as a whole.

\section{Round 1 (divergence)}

We wanted to explore ideas for different components of the definition. As a framework we used the $\mathrm{W}_{5} \mathrm{H} 1$ Kipling problem-solving model, ${ }^{8}$ asking respondents open questions on the 'who, what, where, when, why and how' of a POCT and providing one common example per question from the literature. 
Hence, we performed a modified e-Delphi procedure. ${ }^{9}$ We asked all panel members to give their best answer to the questions, provide any relevant alternatives and add any relevant questions we might have missed.

During the analysis of this round, we organized and discussed all suggested answers, after which we clustered and excluded answers if necessary. Excluded answers were misspellings or general remarks given by the respondent not related to that particular question.

\section{Round 2 (convergence)}

We aimed to determine which components from the first round should be included in the final definition and which descriptions per component were preferred. The questionnaire consisted of one main question per component; each question consisting of a long list of possible descriptions. Possible descriptions were arranged according to the frequency of the answers given in the previous round and/or by logical order. We asked panel members to carefully read all descriptions, choose the best description and indicate the importance of a specific component being part of the final definition, on a scale of 1 to 5 ( 1 being not important - 5 being very important).

At the end of this round, we included all components that were considered by at least $80 \%$ of the panel members to be at least moderately important $(\geq 3)$. If this percentage was not met, we performed a qualitative analysis of the chosen answers and free comments to confirm that the component should not be included in the definition. With regard to the different descriptions per component, any option that was chosen by more than $25 \%$ of respondents was included in the third questionnaire. Other descriptions were only included after qualitative analyses of the answers and comments. 


\section{Round 3 (convergence)}

We wanted to reach consensus on which description per component best fitted the definition. We again asked panel members to choose the best option out of two or three possible descriptions most often chosen by the panel in the second round. All the most frequently chosen answers were added to the possible definitions of round 4 . When the quantitative data were not convincing, the qualitative data were used to make a final decision or both descriptions were added in the candidate definitions.

Round 4 (convergence)

We presented four candidate definitions. We asked the panel members to grade these possible definitions on a scale of 1 to 10 (<6 being insufficient, 6-7 sufficient, 8-9 good and 10 excellent) and to prioritize the four definitions based on their preference. We combined the analysis of the individual grades and ranking of definitions as well as the free comments, to assess if one of the definitions would be preferred by at least $80 \%$ of the panel.

\section{RESULTS}

\section{Participants}

In total, 27 panel members from seven different countries - the Netherlands, USA, Belgium, Germany, UK, Australia and Finland - were included in this Delphi study. Seven (26\%) participants were included via snowballing. About two-thirds of the panel members were active in POCT research or policymaking. Nineteen (70\%) participants were active in family medicine, of which about $60 \%$ were active in POCT research or policymaking. Eight (30\%) participants were active in other fields like laboratory medicine and POCT development. The panel consisted of seven females, the average age was 50 years, and on average they had 20 years of working experience. In the second round one person dropped-out, 
because he moved to another position within his company. We performed the four Delphi rounds between October 2015 and August 2016.

\section{Round 1}

On average, 53 answers (range 35-67) per question were given. All answers were carefully discussed by our research team and most answers were included in the second questionnaire unchanged. To reduce the list of possible options per question, we clustered a few very similar answers and excluded a small number of answers; for example, we clustered the answers 'before visit' with 'before consultation' and 'bodily fluid' with 'body fluids'. After discussion with all coauthors, we decided to not add any extra questions in the second round.

\section{Round 2}

Table 4.1 shows the most important results of the second round. The components 'Where should the test NOT be performed and analysed?' and 'How should the test results be fed back to the user of the test?' were not included in the next round, as only $77 \%(<80 \%)$ of panel members considered these components at least moderately important to be included. Qualitative data supported the exclusion of these elements (Table 4.1). With regard to the question 'When should the results be known?', panel members convincingly preferred the answer 'at the time of clinical decision making'. This element was included in the candidate definitions of the last round. 
Table 4.1 Summary of the qualitative and quantitative results of Delphi round 2 on the definition of a point-of-care test performed in 2016 (January-March).

\begin{tabular}{|c|c|c|}
\hline Component & $\begin{array}{l}\text { Percentage whom considered this component to } \\
\text { be at least moderately important to be included } \\
\text { and most important qualitative comments }\end{array}$ & $\begin{array}{l}\text { Most frequently chosen } \\
\text { answer(s) }\end{array}$ \\
\hline $\begin{array}{l}\text { 1: On what } \\
\text { entity/elements } \\
\text { should the test } \\
\text { be performed? }\end{array}$ & $\begin{array}{l}85 \% \\
\text { - } \quad \text { Replace it's by its } \\
\text { - } \quad \text { Also include (exhaled) breath }\end{array}$ & $\begin{array}{l}\text { Blood, urine, saliva, sputum, } \\
\text { faeces } \\
\text { - Any element/part of the body } \\
\text { or it's derivatives/secretions }\end{array}$ \\
\hline $\begin{array}{l}\text { 2: By whom } \\
\text { should the test } \\
\text { be performed? }\end{array}$ & $\begin{array}{l}81 \% ; \\
-\quad \text { Add qualified or authorized }\end{array}$ & $\begin{array}{l}\text { - Authorized medical } \\
\text { professional } \\
\text { - By any member of the } \\
\text { medical staff (physician, } \\
\text { nurse, auxiliaries) }\end{array}$ \\
\hline $\begin{array}{l}\text { 3: Where should } \\
\text { the test be } \\
\text { performed and } \\
\text { analysed? }\end{array}$ & $92 \%$ & $\begin{array}{l}\text { - Nearby the patient/near } \\
\text { patient side/next to the } \\
\text { patient } \\
\text { - In any room/premises where } \\
\text { there is sufficient hygiene and } \\
\text { safety precautions for the } \\
\text { patient and the POC tester }\end{array}$ \\
\hline $\begin{array}{l}\text { 4: Where should } \\
\text { the test NOT be } \\
\text { performed and } \\
\text { analysed? }\end{array}$ & $\begin{array}{l}77 \%(<80 \%) \text {; } \\
\text { Also qualitative analysis supported the exclusion of this } \\
\text { component, e.g. the most frequently chosen option was } \\
\text { 'in situations negatively affecting the reliability of the } \\
\text { outcome', which overlapped with the most frequently } \\
\text { chosen option of component } 3 \text {. Also free comments } \\
\text { confirmed that this component could better be excluded, } \\
\text { e.g. 'There is an overlap with element } 3 \text {. There are too } \\
\text { many options to exclude...' . }\end{array}$ & Not included in definition \\
\hline $\begin{array}{l}\text { 5: When should } \\
\text { the test be } \\
\text { performed? }\end{array}$ & $\begin{array}{l}92 \% \text {; } \\
\text { - Combine both components in one option and add } \\
\text { 'and physician' in the second part of this component } \\
\text { (comment). } \\
\text { - For the component 'at the time of the clinical decision } \\
\text { making' also see component } 6 \text {. }\end{array}$ & $\begin{array}{l}\text { - During or very close to the } \\
\text { time of the consultation } \\
\text { - When it helps the patient to } \\
\text { get the answer required to } \\
\text { take the best suited action }\end{array}$ \\
\hline $\begin{array}{l}\text { 6: When should } \\
\text { the result be } \\
\text { known? }\end{array}$ & $\begin{array}{l}96 \% \text {; } \\
\text { - For the component 'during consultation' also see } \\
\text { component } 5 \text {. }\end{array}$ & $\begin{array}{l}\text { - At the time of clinical decision } \\
\text { making }\end{array}$ \\
\hline $\begin{array}{l}\text { 7: Why should } \\
\text { the test be } \\
\text { performed } \\
\text { (expectations of } \\
\text { test)? }\end{array}$ & $\begin{array}{l}92 \% \text {; } \\
\text { - 'To support' might be better than 'to inform' } \\
\text { (comment). }\end{array}$ & $\begin{array}{l}\text { - To inform clinical decision } \\
\text { making } \\
\text { - Exclude or confirm diagnosis, } \\
\text { assess disease severity, } \\
\text { monitor disease or therapy }\end{array}$ \\
\hline $\begin{array}{l}\text { 8: How should } \\
\text { the test results } \\
\text { be fed back to } \\
\text { the user of the } \\
\text { test? }\end{array}$ & $\begin{array}{l}77 \%(<80 \%) \text {; } \\
\text { Also qualitative analysis supported the exclusion of this } \\
\text { component, e.g. most frequently chosen option 'depends } \\
\text { on the test...' added nothing of interest to the definition, } \\
\text { and comments like 'doesn't matter..., 'this really depends } \\
\text { on what you are testing', 'many options are quite fine...' } \\
\text { made by respondents supported this decision. }\end{array}$ & Not included in definition \\
\hline
\end{tabular}




\section{Round 3}

Table 4.2 shows the quantitative results of round 3 . The following answers to the 'what, whom and why questions' were most frequently chosen and included in the definition of the last round: 'any part of the body or its derivatives', 'by any qualified member of the medical staff', 'to support clinical decision making'. Some comments were made about the element 'medical staff'. After consideration of these comments and advice from a linguist, 'medical staff' was replaced by 'practice staff', as this better reflected the most chosen answers in all rounds. The preferred answers to the 'where and when questions' were less convincing, and, therefore, candidate definitions were made for both answer options.

Table 4.2 Summary of the quantitative results of Delphi round 3 on the definition of a point-of-care test performed in 2016 (March-June).

\section{On what entity/elements should the test be performed?}

any part of the body or its derivatives

blood, urine, saliva, sputum, faeces, (exhaled) breath

\section{By whom should the test be performed?}

by any member of the medical staff

by any qualified member of the medical staff

$\mathbf{8 0 . 7 7 \%}$

\section{Where should the test be performed and analysed?}

in any room where there is sufficient hygiene and safety precautions precautions (combination of the two answers above)

\section{When should the test be performed?}

during or very close to the time of the consultation

during or very close to the time of the consultation, when it helps the patient and physician to the answer required to take the best suited action

\section{Why should the test be performed (expectations of test)?}

exclude or confirm diagnosis, assess disease severity, monitor disease or therapy 


\section{Round 4}

Table 4.3 shows the candidate definitions of round 4 and a summary of the responses. Three of four definitions were considered sufficient by at least $88 \%$ of panel members and one definition insufficient by more than $20 \%$ of the panel. The final definition, see Box 4.1, was chosen as the best or second best definition by $81 \%$ of the panel and was considered sufficient by $88 \%$ with a median grade of 8 (range 5-10).

Box 4.1 Final definition of a point-of-care test in family practice.

A point-of-care test in family practice is a test to support clinical decision making, which is performed by a qualified member of the practice staff nearby the patient and on any part of the patient's body or its derivatives, during or very close to the time of consultation, to help the patient and physician to decide upon the best suited approach, and of which the results should be known at the time of the clinical decision making. 
Table 4.3 Quantitative results of the preference of four candidate definitions; Delphi round 4 on the definition of a point-of-care test performed in 2016 (JuneAugust).

\begin{tabular}{|c|c|c|}
\hline Definition & $\begin{array}{c}\text { Panel members } \\
\text { considering this } \\
\text { definition as the best or } \\
\text { second best definition }\end{array}$ & $\begin{array}{c}\text { Median } \\
\text { grade } \\
\text { (range) }\end{array}$ \\
\hline $\begin{array}{l}\text { A test to support clinical decision making in family } \\
\text { practice, that is performed by any qualified member of } \\
\text { the practice staff, during or very close to the time of } \\
\text { the consultation, nearby the patient and on any part of } \\
\text { the patient's body or its derivatives, and of which the } \\
\text { results should be known at the time of the clinical } \\
\text { decision making. }\end{array}$ & $54 \%$ & $8(4-10)$ \\
\hline $\begin{array}{l}\text { A test to support clinical decision making in family } \\
\text { practice, that is performed by a qualified member of } \\
\text { the practice staff, during or very close to the time of } \\
\text { consultation, and nearby the patient in a room where } \\
\text { there is sufficient hygiene and safety precautions, on } \\
\text { any part of the patient's body or its derivatives, and of } \\
\text { which the results should be known at the time of the } \\
\text { clinical decision making. }\end{array}$ & $15 \%$ & $7(4-10)$ \\
\hline $\begin{array}{l}\text { A test to support clinical decision making in family } \\
\text { practice, that is performed by a qualified member of } \\
\text { the practice staff, nearby the patient and on any part of } \\
\text { the patient's body or its derivatives, during or very } \\
\text { close to the time of consultation, when it helps the } \\
\text { patient and physician to an answer required to take the } \\
\text { best suited action, and of which the results should be } \\
\text { known at the time of the clinical decision making. }\end{array}$ & $81 \%$ & $8(5-10)$ \\
\hline $\begin{array}{l}\text { A test to support clinical decision making in family } \\
\text { practice, that is performed by a qualified member of } \\
\text { the practice staff, nearby the patient in a room where } \\
\text { there is sufficient hygiene and safety precautions, on } \\
\text { any part of the patient's body or its derivatives, during } \\
\text { or very close to the time of consultation, when it helps } \\
\text { the patient and physician to an answer required to take } \\
\text { the best suited action, and of which the results should } \\
\text { be known at the time of the clinical decision making. }\end{array}$ & $50 \%$ & $8(4-10)$ \\
\hline
\end{tabular}




\section{DISCUSSION}

\section{Summary}

With a multidisciplinary international panel of POCT experts consisting of family practitioners, laboratory specialists, policymakers, researchers and manufacturers, we reached consensus on a widely supported and recognized international definition of a POCT in family practice, with $88 \%$ of panel members considering this definition sufficient with a median grade of 8 : a POCT in family practice is a test to support clinical decision making, which is performed by a qualified member of the practice staff nearby the patient and on any part of the patient's body or its derivatives, during or very close to the time of consultation, to help the patient and physician to decide upon the best suited approach, and of which the results should be known at the time of the clinical decision making.

\section{Strengths and limitations}

This is the first study that developed a widely supported and recognized international definition among expert panel members from different professional backgrounds, all involved in point-of-care testing in family practice. Even though the diversity in the panel made it more difficult to reach agreement on the best definition, it was important to evaluate the ideas of all professionals involved because of the multidisciplinary nature of point-of-care testing. The dropout rate was low, with only 1 in 27 panel members dropping out before the last round. Although the Delphi technique is prone to influences of the researcher, we tried to reduce this by analysing the results in a team of at least three researchers, and if in doubt by all co-authors, to ensure that the data were interpreted as objectively as possible.

A limitation of this study might be the framework for the questionnaire in the first round, which was based on a general problem-solving model. We initially piloted a first Delphi round based on different components of definitions found in the existing literature. However, during pilot testing it proved difficult to have an open first round to explore additional options for the definition. Therefore, we 
chose to have a completely open first round. This made it more complicated to strictly follow the rules of the Delphi technique when aiming for consensus in four rounds. Furthermore, differences in languages across healthcare systems sometimes proved challenging and not all panel members were native English speakers. Therefore, some minor alterations by the research team and an English language expert were necessary.

\section{Comparison with existing literature}

In daily clinical practice and medical literature, many alternative names for a POCT exist. However, these alternative names might lead to confusion as to what in essence sets a POCT apart from any other test, as it is not the speed (rapid test), or the location (at the bedside, near the patient), or the aspect of the device (handheld or not) that differentiates a POCT from other tests. It is in fact the immediate influence of the test result on the clinical decision making during the consultation that sets it apart. The same kind of confusion is seen in the definition of a POCT in the literature. Definitions range from mainly defining the location where the test is being performed, 'any pathology testing performed outside a hospital laboratory where the result is available without the sample being sent to a laboratory for analysis', ${ }^{10}$ to defining its role in the clinical decision making of the doctor, 'any test taken by or on behalf of the treating doctor on-site at the time of consultation that allows the test result to be used to make immediate decisions about patient treatment ${ }^{\prime 1}{ }^{11}$ During this Delphi procedure, we reached agreement on all relevant aspects of the definition.

\section{Implications for research and practice}

With the increasing use of POCTs in the past few decades, many point-of-care testing guidelines have been published. ${ }^{2}$ Recently, a Dutch multidisciplinary working group on point-of-care testing in family practice suggested in its guideline that it is important to consider point-of-care testing as a process, in which all elements of the chain - including indication, execution, interpretation, 
documentation and follow-up - need to be taken into account. ${ }^{12,13}$ So, although the definition of a POCT in this study is clear as to what test should be considered a POCT, the process of point-of-care testing entails a broader multidisciplinary concept.

Several considerations are important with regard to this process. First of all, before implementation, the clinical need for a POCT should be assessed, different devices should be evaluated for quality and a clinical diagnostic pathway should be developed to prevent misuse and overuse. When using a biochemical or biophysical POCT, a quality management system should be implemented. Responsibility and accountability need to be discussed with all professionals involved. As also described in the final definition of this study, adequate training and certification - including basic health and safety issues and standard operating procedures - are important to make sure that the user of a POCT is qualified to adequately and safely use a POCT. It is vital that results of a POCT are clearly documented and connectivity with GP patient record systems should aid correct documentation. Family practices using a POCT should participate in appropriate internal quality control and external quality assurance to make sure that the test outcomes are precise and accurate. ${ }^{2,14-19}$ Cooperation with medical laboratories and manufacturers is important to support family practitioners in the implementation of point-of-care testing, training and certification of staff and to ensure quality control and device maintenance.

\section{CONCLUSION}

With the increase of POCTs in family practice, it is important to have a clear definition of a POCT that is supported and recognized by all professional fields involved in the use and development of POCTs. Such a definition informs stakeholders as to how a POCT can be part of a clinical diagnostic work-up of a patient. In so doing, it can help researchers and manufacturers in the design of a POCT, and family practitioners and patients in regard to expected clinical, process and economic outcomes. It is important to realize that the benefit of a POCT is only achieved if the test result is known and acted upon at the time of 
the clinical decision making. The definition emerging from this Delphi study can inform family practitioners, laboratory specialists, policymakers, researchers and manufacturers on the most widely supported international definition and could act as a clear starting point for the organization and execution of professional point-of-care testing worldwide. 


\section{REFERENCES}

1. Howick J, Cals JW, Jones C, et al. Current and future use of point-of-care tests in primary care: an international survey in Australia, Belgium, The Netherlands, the UK and the USA. BMJ Open. 2014;4:e005611.

2. Farrance I; (on behalf of the RCPA Quality Assurance Programs). Review: Policies, procedures and guidelines for point-of-care testing. April 2012. [cited 2017 May]. Available from: http://www.aacb.asn.au/documents/item/635.

3. Hsu C-C, Sandford BA. The Delphi technique: making sense of consensus. Practical assessment, research \& evaluation. 2007;12:1-8.

4. Jones J, Hunter D. Consensus methods for medical and health services research. BMJ. 1995;311:376-80.

5. Burns KEA, Duffett $M$, Kho $M E$, et al. A guide for the design and conduct of selfadministered surveys of clinicians. CMAJ. 2008;179:245-52.

6. Keeney S, Hasson F, McKenna H. Consulting the oracle: ten lessons from using the Delphi technique in nursing research. J Adv Nurs. 2006;53:205-12.

7. Hasson F, Keeney S, McKenna H. Research guidelines for the Delphi survey technique. J Adv Nurs. 2000;32:1008-15.

8. Creatingminds.org [Internet]. The Kipling Method (5W1H). [cited 2015 Jan]. Available from: http://creatingminds.org/tools/kipling.htm.

9. Hasson F, Keeney S. Enhancing rigour in the Delphi technique research. Technological Forecasting and Social Change. 2011;78:1695-704.

10. Hobbs FD, Delaney BC, Fitzmaurice DA, et al. A review of near patient testing in primary care. Health Technol Assess. 1997;1:1-229.

11. Gialamas A, St John A, Laurence CO, et al. PoCT Management Committee. Point-ofcare testing for patients with diabetes, hyperlipidaemia or coagulation disorders in the general practice setting: a systematic review. Fam Pract. 2010;27:17-24.

12. Hopstaken RM, Kleinveld HA, Balen van JAM, et al. [Guideline Point of care testing (POCT) in general practice]. 2015. [cited 2017 May]. Available from: https://www.nhg.org/sites/default/files/content/nhg_org/uploads/final_richtlijnpoct_2 015Imlres.pdf.

13. Hopstaken RM, van Balen JA, Kusters R. [Point-of-care-testing in general practice]. Ned Tijdschr Geneeskd. 2015;159:A9475.

14. New Zealand Point-of-Care Testing Advisory Group. New Zealand Best Practice Guidelines for Point-of-Care Testing. 2014. [cited 2017 May]. Available from: https://www.nzimls.org.nz/nz-point-of-care-testing-guidelines-2013.html.

15. Medicines and Healthcare Products Regulatory Agency. Management and use of IVD point of care test devices. December 2013 [cited 2017 May]. Available from: 
http://www.viapath.co.uk/sites/default/files/upload/POCT/Management\%20and\%20us e\%20of\%20IVD\%20point\%20of\%20care\%20test\%20devices.pdf

16. ISO 22870. International standard Point-of-care testing (POCT) - Requirements for quality and competence. ISO 2006. [cited 2016 October]. Available from: https://www.iso.org/standard/35173.html.

17. Junker R, Schlebusch H, Luppa PB. Point-of-care testing in hospitals and primary care. Dtsch Arztebl Int. 2010;107:561-7.

18. Price CP. Point of care testing. BMJ. 2001;322:1285-8.

19. de Vries C, Doggen C, Hilbers E, et al. Results of a survey among GP practices on how they manage patient safety aspects related to point-of-care testing in every day practice. BMC Fam Pract. 2015;16:9. 



\title{
Chapter 5
}

General practitioners' experiences with outof-hours cardiorespiratory consultations:

a qualitative study

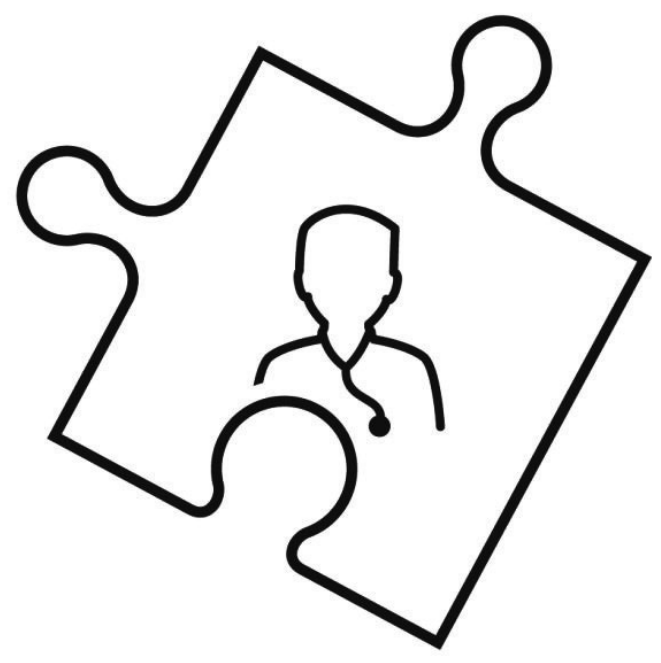

\author{
Angel Schols \\ Tessa van Boekholt \\ Lex Oversier \\ Geert-Jan Dinant \\ Jochen Cals
}




\section{ABSTRACT}

Objectives To explore general practitioners' (GPs') experiences with and views on the diagnosis and management of patients with cardiorespiratory symptoms during GP out-of-hours care. We also aimed to identify ways of (diagnostic) support during these consultations.

Design Qualitative study; face-to-face semistructured interviews.

Setting GP out-of-hours care in the Netherlands.

Participants 15 GPs in the province of Limburg, the Netherlands.

Results Overall, GPs find cardiorespiratory consultations challenging and difficult. Tension and uncertainty as well as defensive behaviour were the key themes that characterised GPs' experiences. We identified several subthemes underlying the key themes: setting, potentially severe consequences, absence of a pre-existing relationship and little knowledge of the patient's background, difficulties differentiating between possible causes of symptoms, changed public opinion and patient population, and previous experiences. GPs approach cardiorespiratory consultations differently and their threshold for referring patients and performing diagnostic tests is lower. We identified differing views on the use of additional diagnostic tests at GP out-of-hours services.

Conclusions This study sheds further light on how GPs experience cardiorespiratory consultations during out-of-hours care and how this leads to a high number of cardiorespiratory referrals. GPs relate cardiorespiratory consultation during out-of-hours care with tension and uncertainty leading to defensive behaviour, which can be translated into a different approach towards cardiorespiratory consultations and a lower threshold for referring patients and performing diagnostic tests. Opinions on the possible added value of additional diagnostics in reducing the number of referrals should be further investigated, as we identified differing views on the use of additional diagnostic tests at GP out-of-hours services. 


\section{INTRODUCTION}

Patients with cardiorespiratory symptoms visiting general practitioner (GP) outof-hours services are often referred to secondary care. ${ }^{1}$ Although cardiorespiratory symptoms can be caused by serious underlying conditions, that could have severe consequences if left untreated; often, no serious underlying conditions are found and patients are discharged the same day. ${ }^{2}$ 3-6

Previous research has shown that GPs find the diagnosis and management of patients with chest pain and heart failure difficult, because serious conditions are frequently masked by other conditions and symptoms are often non-specific or vague, which makes them diagnostically challenging. ${ }^{3-5,7,8}$ When investigating GPs' perceptions, attitudes and experiences with patients with chest pain or dyspnoea in general practice, most of the existing literature focuses on GPs' experiences with the diagnosis and management of specific cardiorespiratory conditions, for example, heart failure or specific care for patients with advanced chronic obstructive pulmonary disease. ${ }^{8-10}$ Little is known about GPs' experiences with patients with cardiorespiratory symptoms in general and during out-of-hours care. Differences between out-of-hours care and office hours care can be expected, as previous research suggests that GPs incorporate background knowledge about the patient, discrepancies between previous and current consultation, knowledge on individual symptom presentation, the physician's own ideas and gut feelings in the management and referral of patients in daytime practice, ${ }^{11-13}$ whereas GPs generally lack a prior relationship with patients and relevant background information during out-of-hours care.

The aim of this study was to explore GPs' experiences with and views on the diagnosis and management of patients with cardiorespiratory symptoms during GP out-of-hours care. The secondary aim was to identify ways of (diagnostic) support during these consultations. 


\section{METHODS}

\section{The Dutch GP out-of-hours system}

In the Netherlands, every citizen is registered with one GP practice. GPs act as a gatekeeper to secondary care. GP out-of-hours care is organised by large-scale GP cooperatives, with generally 40-250 GPs practising at one GP out-of-hours service in one region, taking care of 100 000-500 000 citizens. ${ }^{14}$ Therefore, patients are usually unknown to the doctor on call, especially since GPs often have no to very limited access to patient records. All out-of-hours services have a telephone triage centre in which trained nurses conduct telephone triage under supervision of a GP and the services are accommodated with a specially equipped car and a driver that are available to GPs for home visits. ${ }^{14}$ Access to diagnostic tests is limited and varies between services. ${ }^{15}$ Out-of-hours services are open all evenings, nights and weekends. GP shifts are typically 6-10 hours.

\section{Sampling and participants}

We selected a purposive sample of 38 GPs from a database of all GPs in the province of Limburg, the Netherlands. GPs were selected according to differences in age, sex, and location of the GP out-of-hours service, since previous research has shown that not all GP out-of-hours services have the same diagnostic facilities, which may affect GPs' experiences. ${ }^{15}$ GPs were first invited by email and when no response followed, we contacted them by phone. Sampling continued until 15 GPs agreed to participate. We offered the participating GPs a reimbursement of $€ 30$ in vouchers.

\section{Data collection}

Two trained researchers (TB and LO) carried out 15 semistructured face-to-face interviews using a topic guide, which was developed based on existing literature. The topic guide consisted of questions on GPs' experiences with and views on the diagnosis and management of patients with cardiorespiratory symptoms and 
explored the need for support and additional diagnostic tools in these consultations. We predefined cardiorespiratory as signs and symptoms that could indicate heart or lung disease. The topic guide was pilot tested in audio taped interviews with two GP trainees from our research department. During the study, we performed minor modifications to the topic guide as new insights emerged. All interviews were conducted and audio taped in GPs' surgeries in the spring of 2015. On average, the interviews lasted 36 min with a range from 23 to $49 \mathrm{~min}$. GPs were aware that the purpose of the study was to explore experiences and opinions and not to audit practice. We encouraged them to talk freely about what they considered to be important.

Prior to the interviews, participants were asked to read and sign a consent form and fill in a short questionnaire about personal and background characteristics. The interviews were equally divided among the two interviewers. One interviewer conducted the interview, while the other observed. After 13 interviews, we felt we had reached data saturation. Hereafter, we conducted two more interviews to confirm data saturation, defined as the identification of no new relevant codes in the last two interviews.

\section{Data analysis}

The interviews and analyses were conducted in parallel. TAvB and LMRO transcribed the audio taped interviews verbatim. The anonymised transcripts were used as a basis for the thematic content analysis and were read in detail by TAvB, LMRO and AMRS. The transcripts were entered into Nvivo V.9 software to assist analysis and coding. The first 10 transcripts were independently coded by both interviewers and the last five transcripts were coded by one interviewer and checked and supplemented by the other. All new codes were discussed with a third coder (AS). Disagreement among the three coders was resolved by discussion. The thematic content analysis consisted of familiarisation with the data, indexing the material, charting and interpretation to form the key themes. ${ }^{16}$ Themes were shared and debated by the team to reach a concordance of views on common themes. 


\section{Trustworthiness}

Reliability of the analysis was strived for by double coding all interviews. We tried to enhance the reliability of the interpretation of the data by observing all interviews - one interviewer conducted the interview, while the other one observed - and taking notes on the interviewing process. Furthermore, peer debriefing sessions were held with the research team, to reflect on the research process as a whole and specifically on the analysis and interpretation of the data. In these sessions, we discussed the content of the interviews, coding of the interviews and the thematic content analysis, reviewed the topic guide, and assessed whether data saturation was achieved. Transferability was strived for by providing descriptive data on the study population, information on the sampling and interviewing process, and quotes from participants. Moreover, we kept a detailed record of the recruitment process and interview schedule.

\section{RESULTS}

Characteristics of the 15 participating GPs are described in table 5.1. Twice as many male GPs as female GPs were interviewed; their mean age was 49 years and, on average, the GPs worked 27 out-of-hours shifts in the past 12 months.

Table 5.1 General practitioner characteristics $(n=15)$.

\begin{tabular}{ll}
\hline Gender, male, $\mathrm{n}$ & 11 \\
Age, mean (range) & $49(37-58)$ \\
Years since qualifying, mean (range) & $16(5-25)$ \\
Average working hours per week, mean (range) & $41(25-65)$ \\
Out-of-hours shifts in the past 12 months, mean (range) & $27(16-35)$ \\
\hline
\end{tabular}




\section{Experiences with cardiorespiratory consultation during out-of-hours care}

Most GPs considered the cardiorespiratory consultation at GP out-of-hours services to be difficult. Tension and uncertainty as well as defensive behaviour were the key themes that characterised GPs' experiences; tension and uncertainty led to a defensive decision-making style, resulting in a different approach towards these consultations and a lower threshold for referring patients and performing diagnostic tests. Although the majority of GPS expressed a desire for additional tests to reduce diagnostic uncertainty, all GPs emphasised that the patient's background and taking a thorough medical history are most important and some GPs were even very critical towards adding additional diagnostic tests. We identified several subthemes underlying the key themes (see figure 5.1).

- Out-of-hours care setting

- Potentially severe consequences

- Absence of pre-existing relationship / little knowledge on patient's background

- Difficulties differentiating between possible causes of symptoms

- Changed public opinion and patient population

- Previous experiences

\section{1}

\section{Tension and uncertainty}

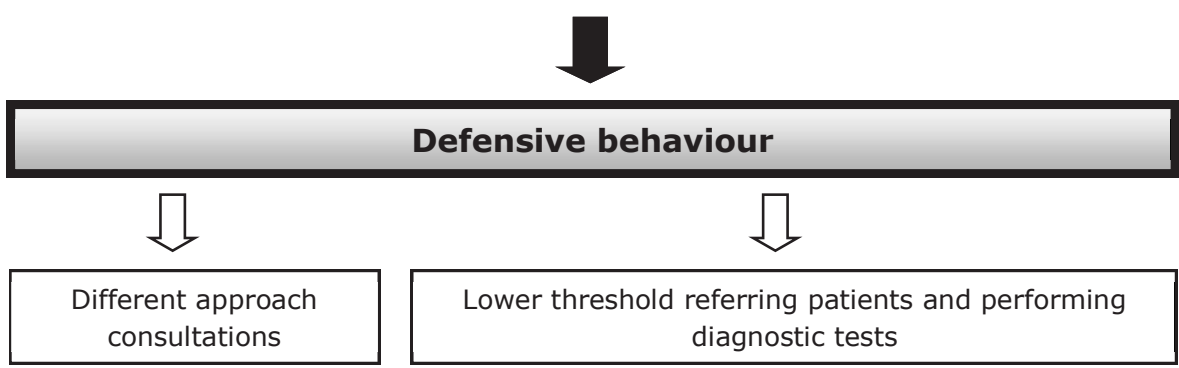

Figure 5.1 Overview of the key themes relating to cardiopulmonary consultations during out-of-hours care. 
Out-of-hours care setting

GPs were more likely to be faced with patients with acute symptoms during outof-hours care and patients were generally more worried:

'I do get the impression that people at the out-of-hours service are clearly more worried about their symptoms than patients who come to the regular surgery with the same complaints, but I think that has to do with the whole setting, as there's a certain barrier to be overcome before you decide to see a different GP or go to the out-of-hours service.' (GP9)

'Well, what you see is, you see mostly patients you don't know, you see mostly urgent cases, whereas in our everyday practice, we're mostly dealing with chronic matters.' (GP6)

This caused a sense of urgency among GPs, which prompted them to act faster and more defensively. A higher workload during out-of-hours care was identified as one of the reasons to refer more easily. One GP said:

'(...) the speed at which things happen, the speed with which you have to make decisions. It's the pressure, of course, the waiting room full of patients. The pressure from the triage nurses, having to plan in another patient, that sort of thing. Well, that's just not very pleasant. You'd like to take all the time you need for what you're faced with, without feeling the pressure, but that's just not possible.' (GP10)

GPs also stressed the importance of getting it right the first time as there will be no second chance, because there is little opportunity for follow-up during their shifts at the GP out-of-hours service: 
'(...) you just have to get it right at the first consultation, be on the right track. In your own practice you're more in control, you can ask the patient to return; it gives you more opportunities for a second chance.' (GP3)

'(...) if you want to do a reassessment, you'll have to do it within your own shift, otherwise a colleague will be dealing with the case.' (GP9)

Potentially severe consequences

The setting makes GPs feel there is no second chance; moreover, the nature of the disease itself also urges GPs to get it right the first time. Cardiorespiratory symptoms were associated with potentially life-threatening conditions. GPs mentioned a certain apprehension of making mistakes in the diagnoses, as these conditions may have severe consequences when misdiagnosed or not treated properly. Hence, GPs acted more defensively. Two GPs said:

'Well, because they're often more life-threatening. So you can't, if you get it completely wrong, you can't have another look the next day. I think, yeah, that makes a difference.' (GP6)

'(...) very rarely, but never with cardiorespiratory patients. I use different criteria then, making me more cautious. Purely because of the acute problem and the potential consequences if you get it wrong.' (GP13)

Absence of a pre-existing relationship and little knowledge of the patient's background

Absence of a pre-existing relationship between the doctor and the patient and little to no knowledge of the patient's background were considered complicating factors. First of all, it makes it more difficult for GPs to assess a patient's current state, since the previous state is unknown to the doctor on call: 
'And if you don't know a patient, you become more cautious, and well, it makes the assessment considerably more difficult, really.' (GP4)

The absence of a relationship of trust makes it more difficult for GPs to discuss their management with patients, since the latter are unfamiliar with the capacities of the doctor on call. Furthermore, some GPs mentioned that it is harder to justify a misdiagnosis if there is no pre-existing relationship with the patient:

'Things can always go wrong, but such things are perceived differently at the outof-hours service, by patients as well. They have less trust in the doctor than at my own practice. And that makes you a bit more cautious.' (GP11)

As a result, GPs stated that the cardiorespiratory consultation takes more time during out-of-hours care:

'And if you don't know the patient, that makes you more cautious and well it just makes the assessment that much more difficult, really, taking more time, and well you don't always have enough time.' (GP4)

Difficulties differentiating between possible causes of symptoms

The tension and uncertainty experienced by GPs can partially be explained by the difficulty in differentiating between possible causes of the symptoms. The strongly divergent and sometimes vague symptoms of patients complicate the identification of serious pathology: 
'If people present with vague symptoms, like being a bit dyspneic, vague chest pains, for instance. And then they cough a little. That's enough to start wondering what might this be.' (GP11)

Furthermore, GPs struggle with diagnostic uncertainties. Most of them, for instance, found it difficult to interpret ECGs:

'I'm glad in a way that our protocol says that the cardiologist must also look at it. As I think that the correct interpretation of an ECG is actually too difficult for a GP, in the case of acute or potentially acute problems. I wouldn't consider myself fully qualified to do that without some back-up of a specialist.' (GP5)

Moreover, the absence of a typical clinical presentation, normal physical examination and a normal ECG, does not exclude severe underlying pathology:

'I can listen to a heart, but that says nothing at all. You can even have an ECG made; that doesn't say it all either. (...) Or how ill a patient is; I've had patients walking in calmly and saying to me: well, I have such and such, and I thought oh well I might as well see a doctor. And he turned out to have an acute myocardial infarction.' (GP4)

Most GPs stated that they find it harder to diagnose and manage patients with cardiac symptoms compared to pulmonary symptoms, with the exception of a pulmonary embolism:

'Of course we haven't talked about pulmonary embolism yet, but that remains very difficult to diagnose. It can take all sorts of forms, and patients may or may not be very ill.' (GP4) 
'Yeah, that's (...) a problem that's sometimes disguised. You hear nothing, you see nothing on the ECG, except occasionally a strained atrium or ventricle. No, I really think that's a difficult one.' (GP1)

Changed public opinion and patient population

According to the GPs, the public opinion and the expectations of patients have changed over time. This has had an effect on the tension and uncertainty experienced by GPs. Four GPs stated that, unlike in the past, society seems to accept medical errors or mistakes to a lesser extent. The fear of a complaint or reprimand by the Disciplinary Board was an important incentive to act more cautiously:

'Everyone makes mistakes of course. But society is now such that people no longer accept errors in medical care, nor in other areas. And, well, that's made me a lot more cautious.' (GP4)

This is accompanied by an ever more demanding patient, who expects GPs to perform additional tests. As a consequence, GPs stated to refer more easily and to attach great importance to justifying management decisions, in particular to patients or the Disciplinary Board. GPs also encountered a change in patient population over the past decade. In particular, they mentioned an increased medical complexity:

\footnotetext{
'What I've noticed in recent years at the out-of-hours service is increased comorbidity, so people with a range of pathologies, the really chronic patient with all kinds of problems, the geriatric patient with all kinds of problems, with contraindications for certain medications, certain therapies, with interactions. And that can also make it more difficult, making you think: what do I need to do for this patient? What would be good for them and what would not be good?' (GP7)
} 


\section{Previous experiences}

Some GPs mentioned a form of misdiagnosis or mistake when taking care of a patient with chest symptoms in the past. They explained that this has influenced subsequent decisions, making them more defensive than before:

'(...) Ten years ago I got a reprimand from the Disciplinary Board as I was said to have missed a cardiac infarction. (...) For the first years after that I did feel more insecure. You notice that you tend to adopt a very defensive attitude as a GP.' (GP3)

'Because I 'burnt my fingers' a few times (...) got it wrong (...) as a doctor you gradually learn from your mistakes.' (GP6)

Also, experiences of colleagues caused some GPs to become more defensive:

'(...) I've also noticed and heard, you hear from colleagues from time to time, how things can develop differently from your on-the-spot assessment. That's made me more cautious.' (GP11)

This was strengthened by the notion that possible consequences of a misdiagnosis can be serious, especially with potential cardiac pathology.

\section{Influence of defensive behaviour on the decision-making process}

The defensive behaviour of GPs influences the decision-making process in several ways. GPs have a different approach towards these consultations. They rely less on their gut feelings and try to take only objective symptoms into account: 
'At my own practice I can afford to trust my intuition more. If I see the same patient at the out-of-hours service I may have the same intuition, but I'd tend not to take it into account unless I can objectify it.' (GP3)

Furthermore, their threshold for referring patients and performing diagnostic tests is lower. For example, GPs use ECG more often during out-of-hours care:

'(...) In any case I'm a bit more defensive than usually at the out-of-hours service. That's got to do with the factors I just mentioned. Not knowing the patients well and of course not wanting to make mistakes and wanting...at least, that's what I call more defensive. That you perform diagnostic tests more easily and perhaps refer sooner, yes.' (GP2)

Some GPs stated that the relatively large number of patients sent back home after referral to secondary care is inherent to the organization of the out-ofhours care and the possibly severe underlying pathology in patients with cardiorespiratory symptoms.

\section{Possible improvements in support during cardiorespiratory consultation}

GPs expressed a desire for more time available for cardiorespiratory consultations, immediate consultation of a cardiologist to aid them in the interpretation of an ECG and improving the availability as well as the quality of patients' medical records. Furthermore, GPs requested improvements of the current triage system, which sometimes leads to higher urgency categories than necessary:

'The triage nurses have to assess the urgency, and they very often classify it too high. I can understand that, as they're facing the same problem as we: when in doubt, refer to a higher tier. But that greatly increases the workload, especially with 
this group of patients. So you often see clusters of high-urgency cases for cardiorespiratory problems, which makes matters more difficult for us too.' (GP7)

GPs were divided when asked whether or not they wanted more additional diagnostics available. GPs in favour of diagnostic tests expressed a desire for additional diagnostics as these could aid in reassuring the patient and help to motivate management decisions to patients and their relatives. Additional diagnostics could help GPs to rule out acute pathology, allowing them to send patients back home safely. One GP explained his wish for the use of d-dimers and troponin as follows:

'Because when they're negative, that excludes a lot of options. So I can safely leave someone at home and safely discuss follow-up management.' (GP9)

As a result, they would be less likely to refer a patient. Moreover, additional diagnostic facilities could help reduce the GPs' tension and uncertainty. One GP even suggested that it could help to improve the quality of GP out-of-hours care in general:

'Yeah, that would make me very happy. I'm really looking forward to that. So I think we can take further major quality-improvement steps in primary care in that respect.' (GP6)

However, some GPs did not see any added value of additional diagnostic tests. According to them, some tests should be preserved for secondary care only because GPs lack the knowledge and skills to safely use and interpret this kind of diagnostics: 
'What I want to have while on duty at the out-of-hours service is my stethoscope, as I really know how that works, I know what I'm supposed to hear and not to hear. And I very much prefer to leave it to the cardiologist to interpret the patient's troponin.' (GP3)

GPs were concerned that the availability of additional diagnostics would oblige them to use them. Some GPs were apprehensive of overdiagnosis: the use of diagnostics without a proper indication. Furthermore, they had doubts about the validity and reliability of these additional diagnostic tests. Two GPs said:

'(...) What I find is that once patients know it exists, they start to ask for it. So it also involves, like, how am I going to prevent having to do it too often, as you're going to, you have to do it based on a proper indication, I think.' (GP14)

'(...) Well, actually, before you start using a test it must have been thoroughly evaluated, and the test must also be reliable.' (GP15)

\section{DISCUSSION}

\section{Summary}

Most GPs consider the cardiorespiratory consultation during out-of-hours care to be difficult. They relate it with tension and uncertainty leading to defensive behaviour during GP out-of-hours care. GPs have a different approach towards cardiorespiratory consultations at the out-of-hours service compared to their own practice and their threshold for referring patients and performing diagnostic tests is lower. We identified differing views on the use of additional diagnostic tests at GP out-of-hours services. 


\section{Strengths and limitations}

As far as we know, this is the first in-depth qualitative study to explore GPs' experiences with and views on the diagnosis and management of patients with cardiorespiratory symptoms in general during out-of-hours care. We specifically chose to ask GPs about symptoms and not conditions, as typical patients present with symptoms and making an accurate diagnosis within a 10 min consultation is part of the complexity of general practice. We aimed to achieve an in-depth data analysis, as both interviewers were trained; one interviewer observed while the other one conducted the interview; both interviewers who analysed the data were already familiar with the data and all transcripts were double coded. All face-to-face interviews were conducted in the GPs' surgeries, as we assumed GPs felt more comfortable and secure in their daily environment. Given that this kind of research is prone to socially desirable answers, we emphasised that we were interested in the GPs' own experiences and opinions and that we were not auditing practice or assessing knowledge.

A limitation of this study is that three interviews were not observed by the second interviewer, though we found no major differences between the results of these interviews and the other interviews. Moreover, we did not return transcripts to participants for comments and participants did not provide feedback on the findings. Some results may not be applicable to each out-ofhours care setting in Europe, as out-of-hours care is differently organised across European countries. Furthermore, we only included GPs from one province in the South of the Netherlands. This may have influenced the results, because this province has one of the highest mortality rates from cardiovascular pathologies in the Netherlands and GPs have relatively more access to diagnostic tests in this region. ${ }^{15,17}$ Nonetheless, we interviewed several GPs working at an out-ofhours service where hardly any diagnostic tests were available. Although female GPs were under-represented in our research population, we did not identify any major differences in responses of female GPs compared to our main results. 


\section{Comparison with existing literature}

In accordance with the literature on care during office hours, we found that GPs experience cardiorespiratory consultations as difficult. While some of the underlying reasons for this perceived challenge are the same as for cardiorespiratory consultations during office hours, ${ }^{3-5,7,8}$ we found supplemental reasons for why these consultations are notoriously difficult during out-of-hours care. For example, the absence of a pre-existing relationship with the patient and little to no knowledge of the patient's background are of major influence on the cardiorespiratory consultation during out-of-hours care, as it makes it more difficult to assess the patient's current state. It seems logical that a lack of this knowledge complicates the consultation during out-of-hours care, as previous research focusing on care during office hours found that background information and discrepancies between previous and current consultation were important factors in chest pain consultations. ${ }^{12,13}$ Information on the patient's background as well as taking a thorough medical history were considered the most important aspects of the consultation in our study. This is in line with previous research on GPs' diagnostic approach of patients with chest pain during out-of-hours care. ${ }^{18}$ However, the GPs in our study stated that they attach less value to their gut feelings and more to objective signs during out-of-hours care, which is in contradiction with previous research that found that GPs' gut feelings and personal ideas are important in the decision-making process for patients with chest pain during office hours. ${ }^{11,} 12$ This contradiction could again be explained by the difference in setting.

We found that tension and uncertainty play an important role in the cardiorespiratory consultation during GP out-of-hours care, which leads to a lower threshold for referring patients to secondary care. A study that explored variations in GPs' out-of-hours referrals in general found similar reasons for being more cautious during out-of-hours care, such as GPs' anxiety about the consequences of the decision not to refer. ${ }^{19}$ We gained new insight into GPs' views on patients with pulmonary symptoms. Most GPs experience such patients as less difficult than those with cardiac symptoms, with the exception of a pulmonary embolism. 


\section{Implications for research and practice}

This study sheds further light on why referrals for cardiorespiratory symptoms are relatively high during out-of-hours care. Additional diagnostics may be of added value in reducing the number of referrals. However, since we identified differing views on the use of such additional diagnostic tests, further research is necessary to gain a better understanding of GPs' motives to either use or refuse new diagnostic tests. The insights into the cardiorespiratory decision-making process of GPs working at out-of-hours services may aid the development of strategies to reduce the number of referrals and could aid in improving mutual understanding between primary and secondary care physicians. 


\section{REFERENCES}

1. Moll van Charante EP, van Steenwijk-Opdam PC, Bindels PJ. Out-of-hours demand for GP care and emergency services: patients' choices and referrals by general practitioners and ambulance services. BMC Fam Pract. 2007;8:46.

2. Bruins Slot $M H$, Rutten $F H$, van der Heijden GJ, et al. Diagnostic value of a heart-type fatty acid-binding protein (H-FABP) bedside test in suspected acute coronary syndrome in primary care. Int J Cardiol. 2013;168:1485-9.

3. McConaghy JR, Oza RS. Outpatient diagnosis of acute chest pain in adults. Am Fam Physician. 2013;87:177-82.

4. Willemsen RT, Kietselaer BL, Kusters R, Buntinx F, Dinant G]. [Diagnostic tools for acute coronary syndrome (ACS): a challenge for general practitioners and cardiologists]. Ned Tijdschr Geneeskd. 2014;158:A8078.

5. Body R, Carley S, Wibberley C, McDowell G, Ferguson J, Mackway-Jones K. The value of symptoms and signs in the emergent diagnosis of acute coronary syndromes. Resuscitation. 2010;81:281-6.

6. Nilsson $S$, Scheike M, Engblom $D$, et al. Chest pain and ischaemic heart disease in primary care. Br J Gen Pract. 2003;53:378-82.

7. Phillips SM, Marton RL, Tofler GH. Barriers to diagnosing and managing heart failure in primary care. Med J Aust. 2004;181:78-81.

8. Fuat A, Hungin AP, Murphy JJ. Barriers to accurate diagnosis and effective management of heart failure in primary care: qualitative study. BMJ. 2003;326:196.

9. Khunti K, Hearnshaw H, Baker R, Grimshaw G. Heart failure in primary care: qualitative study of current management and perceived obstacles to evidence-based diagnosis and management by general practitioners. Eur J Heart Fail. 2002;4:771-7.

10. Young J, Donahue M, Farquhar M, Simpson C, Rocker G. Using opioids to treat dyspnea in advanced COPD: attitudes and experiences of family physicians and respiratory therapists. Can Fam Physician. 2012;58:e401-7.

11. Stolper $E$, van Bokhoven $M$, Houben $P$, et al. The diagnostic role of gut feelings in general practice. A focus group study of the concept and its determinants. BMC Fam Pract. 2009;10:17.

12. Bruyninckx R, Van den Bruel A, Hannes K, Buntinx F, Aertgeerts B. GPs' reasons for referral of patients with chest pain: a qualitative study. BMC Fam Pract. 2009;10:55.

13. Hani MA, Keller H, Vandenesch J, Sonnichsen AC, Griffiths F, Donner-Banzhoff N. Different from what the textbooks say: how GPs diagnose coronary heart disease. Fam Pract. 2007;24:622-7.

14. Giesen P, Smits M, Huibers L, Grol R, Wensing M. Quality of after-hours primary care in the Netherlands: a narrative review. Ann Intern Med. 2011;155:108-13. 
15. Schols AM, Stevens F, Zeijen C, Dinant G], van Vugt C, Cals JW. [Diagnostic tests in GP out-of-hours services in the Netherlands]. Ned Tijdschr Geneeskd. 2015;159:A9022.

16. Braun V, Clarke V. Using thematic analysis in psychology. Qualitative Research in Psychology. 2006;3:77-101.

17. Plat $A W$, te Wierik MJ, Kroon AA, et al. Regional differences in cardiovascular risk factor profile cannot fully explain differences in cardiovascular morbidity in the Netherlands: a comparison of two urban areas. Neth J Med. 2005;63:309-15.

18. Burman RA, Zakariassen E, Hunskaar S. Chest pain out-of-hours - an interview study of primary care physicians' diagnostic approach, tolerance of risk and attitudes to hospital admission. BMC Fam Pract. 2014;15:207.

19. Calnan M, Payne S, Kemple T, Rossdale M, Ingram J. A qualitative study exploring variations in GPs' out-of-hours referrals to hospital. Br J Gen Pract. 2007;57:706-13. 



\section{Chapter 6}

\section{Point-of-care testing in primary care patients}

with acute cardiopulmonary symptoms:

a systematic review

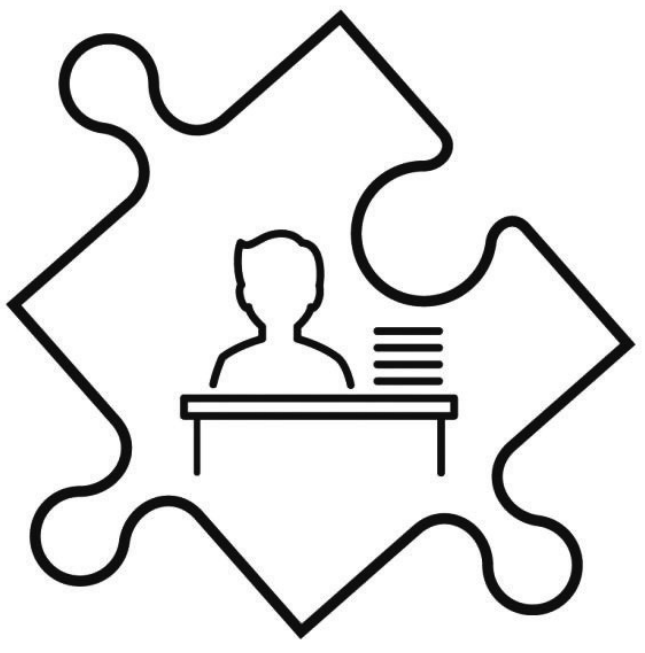

Angel Schols

Jacqueline Stakenborg Geert-Jan Dinant Robert Willemsen Jochen Cals 


\section{ABSTRACT}

Background Point-of-care tests (POCT) can assist general practitioners (GPs) in diagnosing and treating patients with acute cardiopulmonary symptoms, but it is currently unknown if POCT impact relevant clinical outcomes in these patients.

Objective To assess whether using POCT in primary care patients with acute cardiopulmonary symptoms leads to more accurate diagnosis and impacts clinical management.

Methods We performed a systematic review in four bibliographic databases. Articles published before February 2016 were screened by two reviewers. Studies evaluating the effect of GP use of POCT on clinical diagnostic accuracy and/or effect on treatment and referral rate in patients with cardiopulmonary symptoms were included.

Results Our search yielded nine papers describing data from seven studies, on the clinical diagnostic accuracy of POCT in a total of 2277 primary care patients with acute cardiopulmonary symptoms. Four papers showed data on GP use of D-dimer POCT in pulmonary embolism (two studies); two studies on Troponin T in acute coronary syndrome; one on heart-type fatty acid-binding protein $(\mathrm{H}$ FABP) in acute coronary syndrome; one on B-type natriuretic peptide (BNP) in heart failure; one on 3-in-1 POCT (Troponin T, BNP, D-dimer) in acute coronary syndrome, heart failure and/or pulmonary embolism. Only one study assessed the effect of GP use of POCT on treatment initiation and one on actual referral rates.

Conclusion There is currently limited and inconclusive evidence that actual GP use of POCT in primary care patients with acute cardiopulmonary symptoms leads to more accurate diagnosis and affects clinical management. However, some studies show promising results, especially when a POCT is combined with a clinical decision rule. 


\section{INTRODUCTION}

Excluding serious conditions is one of the cornerstones of general practice consultations. General practitioners (GPs) often use diagnostic tests to assist their decision-making process. ${ }^{1}$ A wide range of point-of-care tests (POCT) is currently available to GPs, but at present only few POCT are widely used by GPs. $^{2}$ GPs across countries have expressed a desire to use more POCT in their practice, especially to help them diagnose acute conditions like acute thromboembolic conditions (D-dimers), and heart diseases (Troponin, B-type natriuretic peptide). ${ }^{2}$ This is understandable as patients with cardiopulmonary symptoms are often diagnostically challenging for GPs. POCT could assist GPs in diagnosing and treating patients with these symptoms, but GPs have expressed reservations towards using additional POCT as well, including doubts about the reliability of these tests. ${ }^{3}$ Nonetheless, several studies have shown that the use of POCT may reduce referrals to secondary care or drug prescriptions, and lead to higher patient satisfaction and better adherence to treatment. ${ }^{4-7}$ GPs generally consider the effectiveness of use of a POCT on the decision-making process as the most important aspect in their consideration to use a РОСТ. ${ }^{8}$

Before advocating a widespread use and implementation of GP use of POCT in patients with acute cardiopulmonary symptoms, it is important to determine if GP use of these tests actually affects clinical outcomes of patients. Therefore, the aim of this systematic review is to assess whether using POCT in primary care leads to more accurate diagnosis and impacts clinical management in patients with acute cardiopulmonary symptoms. 


\section{METHOD}

\section{Search strategy}

We performed a systematic electronic literature search in four bibliographic databases: PubMed, EMBASE, CINAHL and the Cochrane library. All articles published before October 2014 were included. We searched the databases for articles on (acute) cardiopulmonary disease and point-of-care testing in primary care. We included several free search terms per category as well as MESH terms. The exact search terms for the PubMed search are shown in Box 6.1. No search limits were applied. We performed a PubMed search update from October 2014 till February 2016. Furthermore, we checked the reference lists of all included articles for other relevant studies. When no full texts were available, e.g. in the case of conference abstracts, we contacted the authors to retrieve a full manuscript when available.

\section{Study selection}

After removing duplicates, two reviewers (JS, AS and in search update AS, JC) independently screened titles and abstracts for predefined PICOS criteria on population and intervention (Box 6.2). In case of disagreement, a third reviewer (JC) independently screened title and abstract and the record was discussed in a consensus meeting. Subsequently, one reviewer (JC) screened and another reviewer (AS) checked the full-texts of the remaining records on all PICOS criteria.

All PICOS criteria were predefined in a study protocol and were defined in more detail during the review process. We excluded all studies that did not agree with the PICOS criteria. During this stage, we decided to also exclude papers on the use of POCT in (acute respiratory)infections, as many articles, including systematic reviews, have been published on this topic. ${ }^{9-11}$ 
Box 6.1 Full Pubmed search (1640 hits).

(((()((()(((()(point of care) OR point-of-care) OR office) OR bedside) OR near patient) OR POC) OR on-site) OR rapid) OR ultra-rapid)) AND (((((((testing) OR test) OR tests) OR assay) OR assays) OR immunoassay) OR immunoassays))) OR "Point-of-Care Systems"[Mesh])) AND (((()(((((primary care) OR primary health care) OR general practice) OR family practice) OR general practitioner) OR GP) OR family doctor) OR family physician)) OR ((((("Primary Health Care"[Mesh] OR "Physicians, Primary Care"[Mesh])) OR "Family Practice"[Mesh]) OR "General Practitioners"[Mesh]) OR "Physicians, Family"[Mesh]))) AND

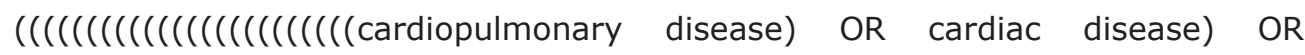
pulmonary disease) OR chest pain) OR chest infections) OR coronary syndromes) OR myocardial infarction) OR thromboembolic event) OR palpitations) OR arrhythmias) OR heart failure) OR pericarditis) OR dyspnoea) OR pulmonary embolism) OR lung embolism) OR pneumonia) OR lower respiratory infection) OR cough) OR bronchitis) OR asthma) OR COPD) OR pleuritis $))$ OR $(((()(((()((()((((" P u l m o n a r y$ Heart Disease"[Mesh]) OR "Heart Diseases"[Mesh]) OR （"Lung Diseases"[Mesh] OR "Lung Diseases, Obstructive"[Mesh])) OR "Chest Pain"[Mesh]) OR ("Acute Coronary Syndrome"[Mesh] OR "Microvascular Angina"[Mesh])) OR ("Myocardial Infarction"[Mesh] OR "Inferior Wall Myocardial Infarction"[Mesh] OR "Anterior Wall Myocardial Infarction"[Mesh])) OR "Thromboembolism"[Mesh]) OR "Arrhythmias, Cardiac"[Mesh]) OR ("Heart Failure"[Mesh] OR "Heart Failure, Systolic"[Mesh] OR "Heart Failure, Diastolic"[Mesh])) OR "Pericarditis"[Mesh]) OR "Dyspnea"[Mesh]) OR "Pulmonary Embolism"[Mesh]) OR ("Pneumonia"[Mesh] OR "Pneumonia, Bacterial"[Mesh] OR "Pneumonia, Viral"[Mesh])) OR "Cough"[Mesh]) OR "Bronchitis"[Mesh]) OR "Asthma"[Mesh]) OR "Pulmonary Disease, Chronic Obstructive"[Mesh]) OR "Pleurisy"[Mesh])) 
Box 6.2 PICOS criteria.

\section{Population}

Patients with acute cardiopulmonary conditions/symptoms in primary care in Western/developed countries. Acute cardiopulmonary was defined as acute conditions or symptoms of either the heart, lungs, or vascular blood supply of these organs at the height of the chest cavity. For example, we excluded studies on non-chest related conditions like deep venous thrombosis or upper respiratory tract infection. Furthermore, we excluded studies on fairly uncommon diseases in Western countries, e.g. tuberculosis and HIV.

\section{Intervention}

All studies that reported on POCT as an intervention. POCT was defined as biomedical tests on patient material, e.g. blood, urine, faeces, performed and analysed at the point-of-care. We excluded tests like electrocardiography, ultrasonography, and spirometry.

\section{Comparator}

Care as usual; no use of a POCT.

\section{Outcomes}

We included studies on clinical effectiveness; clinical diagnostic accuracy and/or effect on treatment and referral rates. We excluded studies on analytical test accuracy or studies with the objective to determine the optimal cut-off value for a POCT.

\section{Study design}

Randomised controlled trials and non-randomised controlled trials, e.g. prospective cohort studies. 


\section{Data extraction and analysis}

Data extraction was performed by one reviewer (AS) and the extracted results were studied by all authors. When diagnostic accuracy outcomes were not presented in the article, we calculated them when possible. The heterogeneity among studies precluded a meta-analysis. Therefore, we undertook a narrative synthesis of the data to explore the evidence for the clinical effectiveness of GP use of POCT in primary care patients with cardiopulmonary symptoms.

\section{Quality assessment}

The internal and external validity of the two trials was assessed using the Cochrane Risk of Bias Tool for randomized trials. ${ }^{12}$ Furthermore, the risk of bias for the diagnostic accuracy outcomes in all studies, was assessed using the QUADAS-2 tool. ${ }^{13}$ All assessments were performed by one reviewer (AS) and checked for accuracy by a second (JC). Quality criteria for inclusion were not set as we intended to be broad-based and only few studies were included on the basis of eligibility. 


\section{RESULTS}

\section{Study selection and study characteristics}

From 3657 records, we identified 3079 unique records; 3078 from the database searches and one additional record through a conference abstract. We assessed 169 full-text articles for eligibility and nine papers met our inclusion criteria (Figure 6.1). ${ }^{14-22}$ Eight of nine papers were published within the past 5 years. Study characteristics of the included papers and accuracy outcomes are shown in Tables 6.1 and 6.2. All studies were prospective and two were randomized trials. The included studies all had domains with high risk of bias using the Cochrane Risk of Bias Tool for both trials and the QUADAS-2 tool for the diagnostic accuracy in all studies (Tables 6.3 and 6.4). Main risks of bias for the diagnostic accuracy outcomes were not all patients receiving the same reference standard and some patients were only followed-up without any extra tests done to confirm absence of the index disease.

\section{Clinical diagnostic accuracy}

The eligible nine papers described data of seven different studies which showed relevant data on the clinical diagnostic accuracy of GP use of POCT in patients with acute cardiopulmonary symptoms in primary care (Tables 6.1 and 6.2). Three papers described the results of one large clinical study (AMUSE-2) evaluating the effect of D-Dimer POCT for pulmonary embolism. ${ }^{14-16}$ We found one additional study on D-dimer POCT. Hence, four papers showed data on GP use of D-dimer POCT, two studies on GP use of Troponin T, one on GP use of heart-type fatty acid-binding protein (H-FABP), one on GP use of B-type natriuretic peptide (BNP) and one on a 3-in-1 POCT (Troponin T, BNP, Ddimer). ${ }^{14-22}$ 


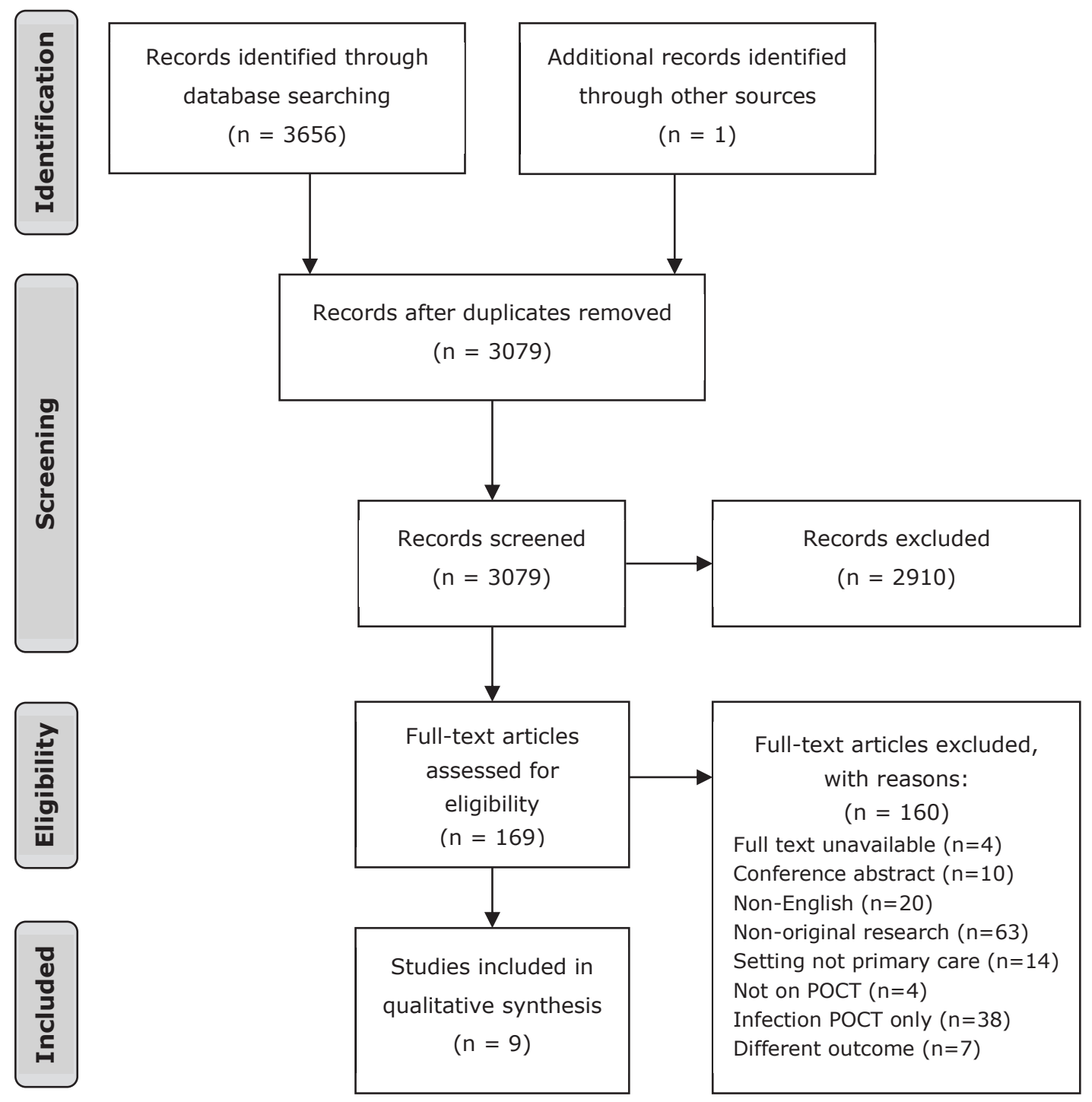

Figure 6.1 Flow diagram of study selection. 


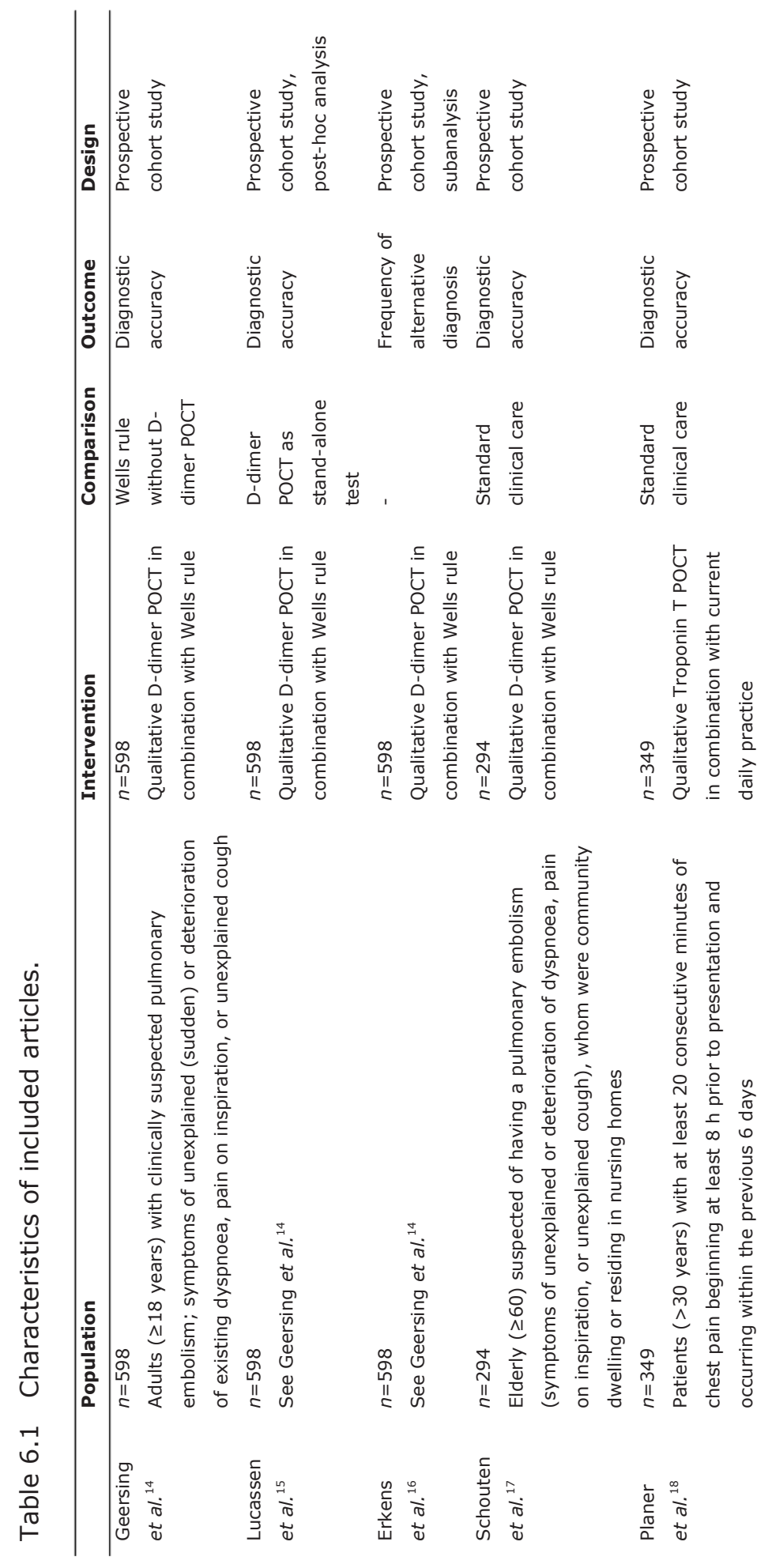




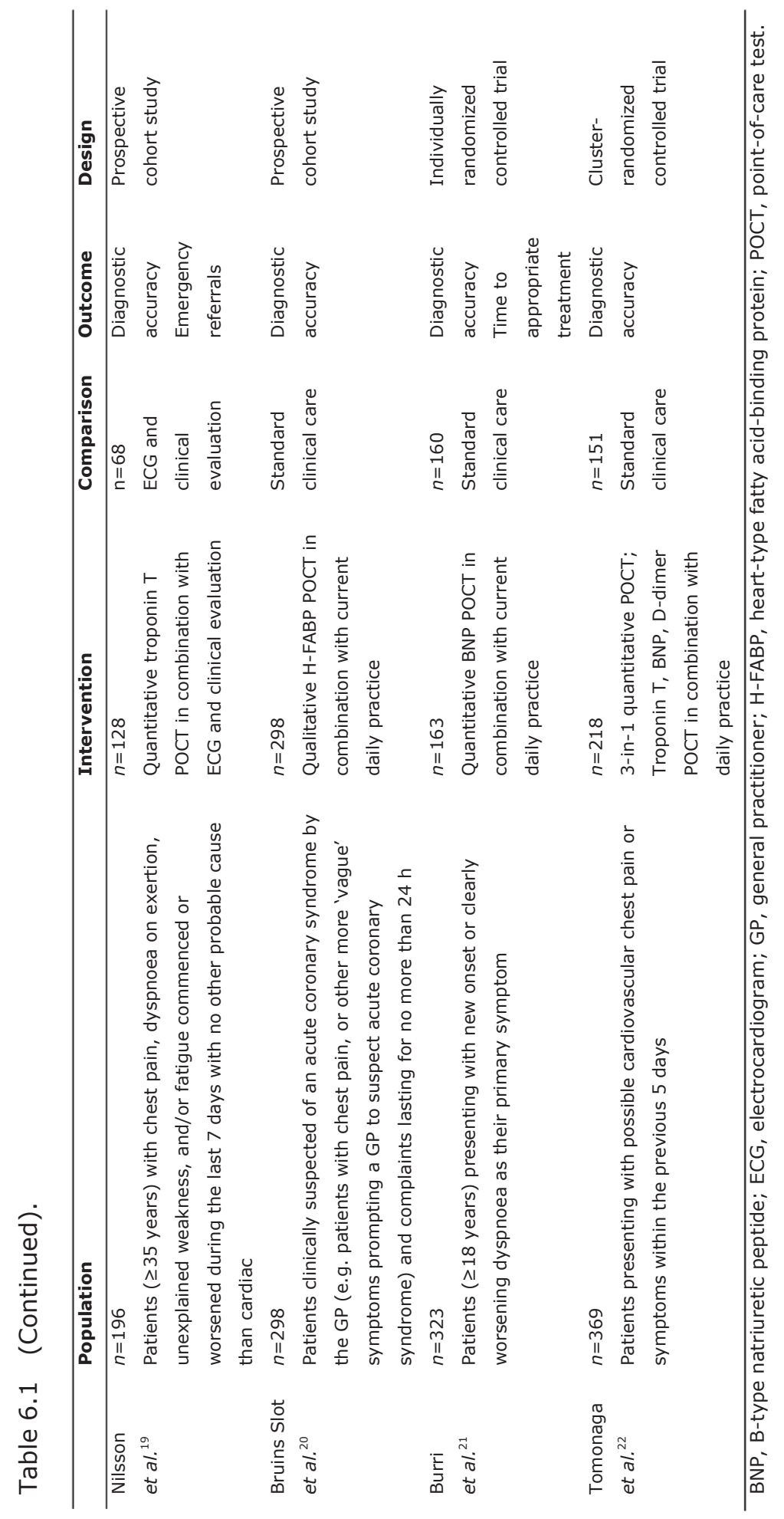




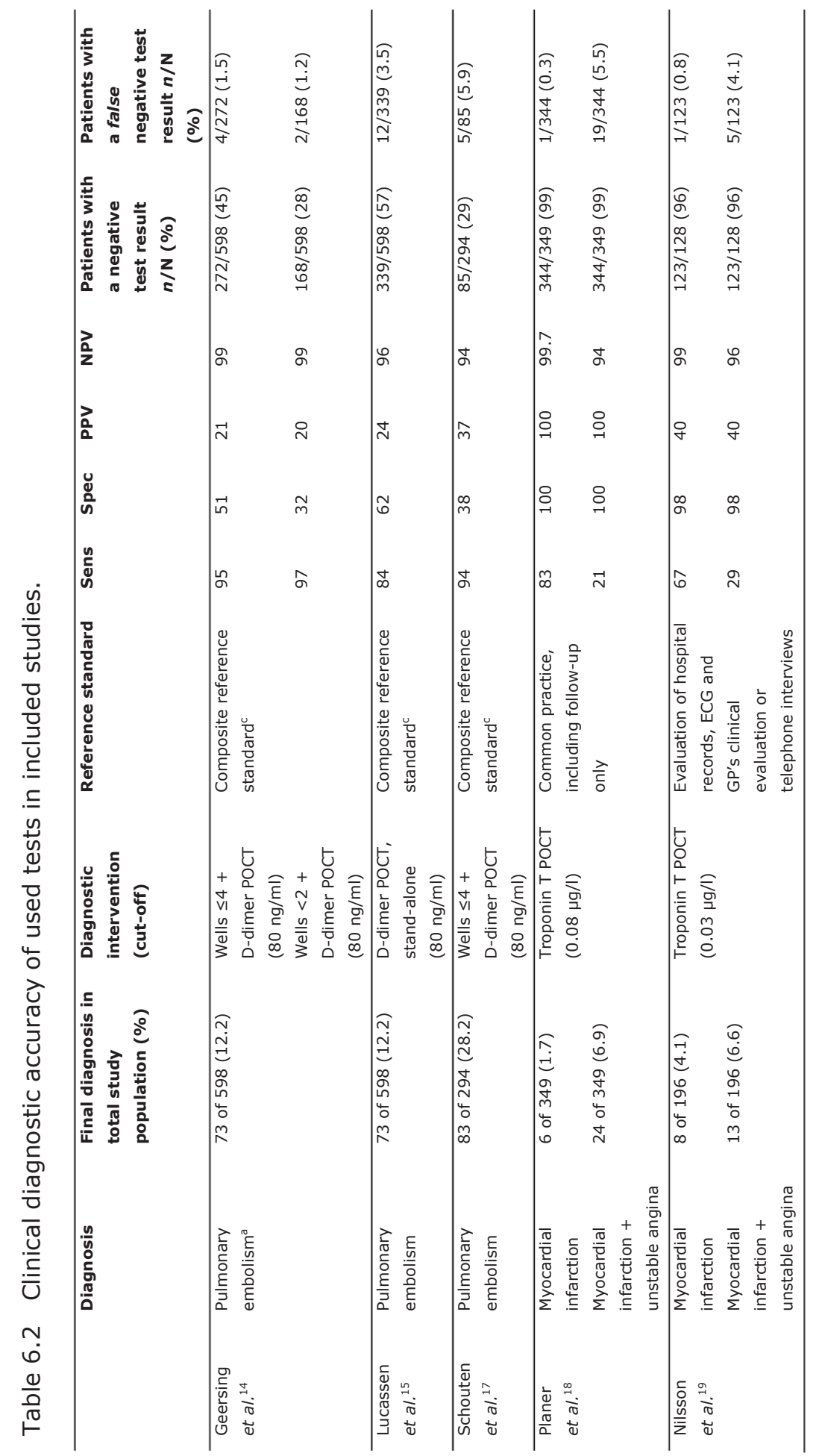




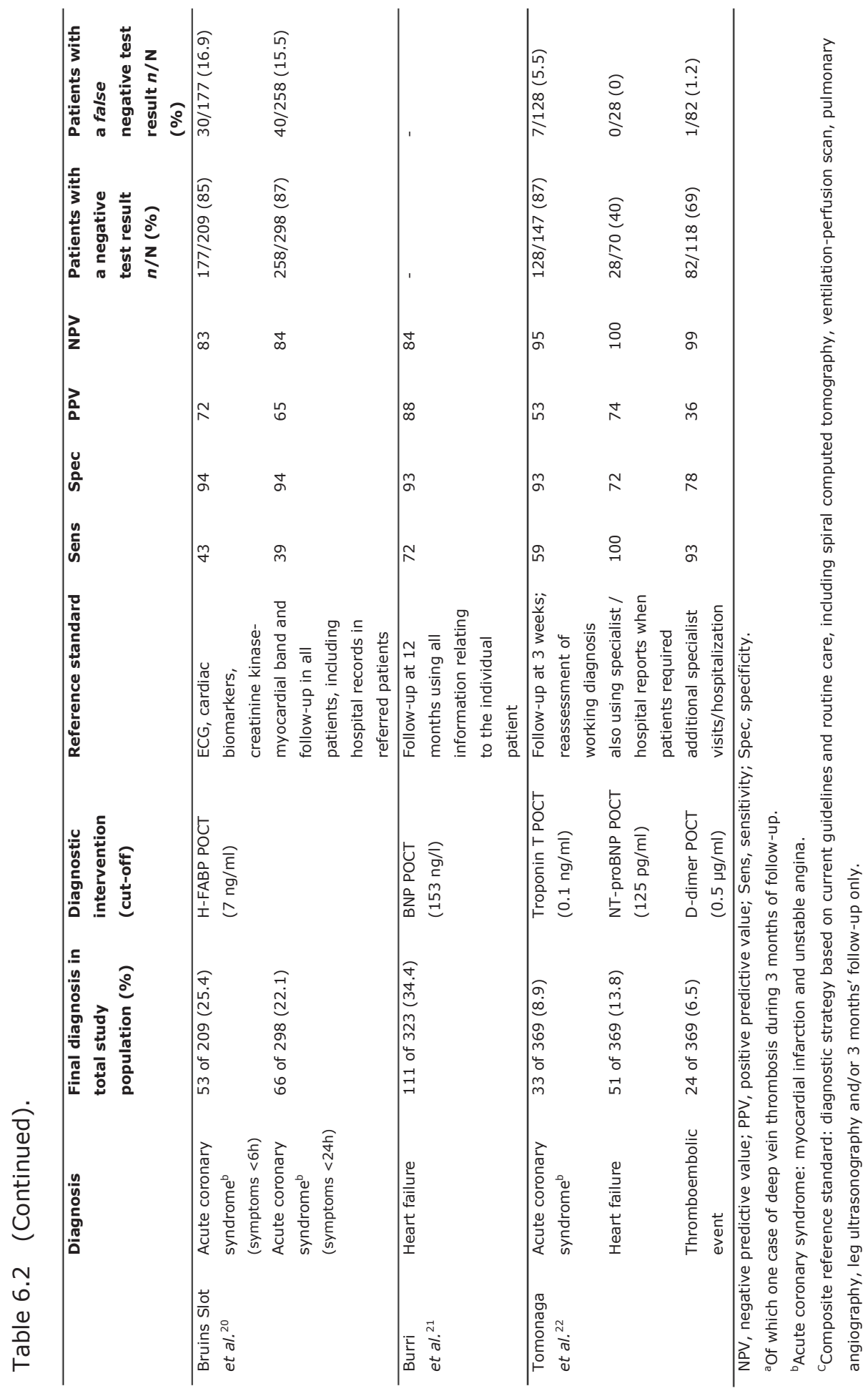


Table 6.3 Risk of bias of randomized controlled trials.

\begin{tabular}{|c|c|c|c|c|c|c|c|}
\hline & $\begin{array}{c}\text { Random } \\
\text { sequence } \\
\text { generation }\end{array}$ & $\begin{array}{c}\text { Allocation } \\
\text { concealment }\end{array}$ & $\begin{array}{l}\text { Blinding of } \\
\text { participants and } \\
\text { researchers }\end{array}$ & $\begin{array}{l}\text { Blinding of } \\
\text { outcome } \\
\text { assessment }\end{array}$ & $\begin{array}{c}\text { Incomplete } \\
\text { outcome } \\
\text { data }\end{array}$ & $\begin{array}{l}\text { Selective } \\
\text { reporting }\end{array}$ & $\begin{array}{c}\text { Other } \\
\text { bias }\end{array}$ \\
\hline $\begin{array}{l}\text { Burri } \\
\text { et al. }{ }^{21}\end{array}$ & (;) & (;) & 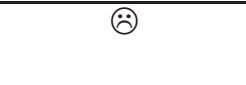 & (;) & $?$ & $?$ & : \\
\hline $\begin{array}{l}\text { Tomonaga } \\
\text { et al. }{ }^{22}\end{array}$ & $?$ & $?$ & : & : & ;) & (;) & ? \\
\hline
\end{tabular}

(;), low risk of bias; $: ;$, high risk of bias; ?, unclear risk of bias.

Table 6.4 Risk of bias regarding diagnostic accuracy (QUADAS-2). ${ }^{a}$

\begin{tabular}{|c|c|c|c|c|}
\hline & Patient selection & Index test & Reference standard & Flow and timing \\
\hline Geersing et al. ${ }^{14}$ & ;) & 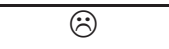 & $\because:$ & 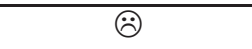 \\
\hline Lucassen et al. ${ }^{15}$ & ;:) & $: ;$ & $: ;$ & $: ;$ \\
\hline Schouten et al. ${ }^{17}$ & $?$ & 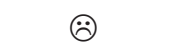 & 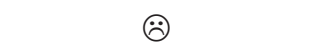 & : : \\
\hline Planer et al. ${ }^{18}$ & : & $?$ & 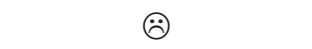 & 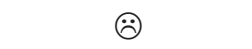 \\
\hline Nilsson et al. ${ }^{19}$ & $?$ & ;) & : & $:$ \\
\hline Bruins Slot et al. ${ }^{20}$ & (:) & 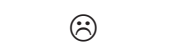 & ;) & ;) \\
\hline Burri et al. ${ }^{21}$ & ;) & : & $?$ & ? \\
\hline Tomonaga et al. ${ }^{22}$ & ;:) & ;:) & $: 0$ & $: ;$ \\
\hline
\end{tabular}

(;), low risk of bias; $: ;$, high risk of bias; ?, unclear risk of bias.

${ }^{a}$ There were no concerns regarding applicability in any of these studies.

\section{Pulmonary embolism}

In a prospective cohort study, Geersing et al. ${ }^{14}$ investigated the diagnostic value of a combination of the Wells clinical decision rule and a D-dimer POCT to safely exclude pulmonary embolism in 598 adult patients clinically suspected of pulmonary embolism. Seventy-three (12\%) patients were diagnosed with a pulmonary embolism. This study concluded that pulmonary embolism can be safely and efficiently excluded on the basis of a Wells score of $\leq 4$ combined with a negative D-dimer POCT result, with a positive and negative predictive value (PPV and NPV) of 21.2 and $98.5 \%$, respectively. Using a Wells threshold of $<2$ 
was even safer, but this was at the expense of the specificity (Table 6.2) ${ }^{14}$ In a post hoc analysis by Lucassen et al. ${ }^{15}$, the D-dimer POCT had a higher specificity as a stand-alone POCT compared to the combination of a D-dimer POCT with the Wells, yet it was less safe with a NPV of $96 \%$. A subanalysis of the same study population by Erkens et al. ${ }^{16}$ showed that a positive Wells rule or a positive Ddimer POCT are not only positively associated with pulmonary embolism, but also with other clinically relevant diseases, for example pneumonia. In another prospective cohort study by Schouten et al. ${ }^{17}$, wherein 150 patients were entered via the AMUSE-2 study, a NPV of $94 \%$ was found when using a combination of the Wells rule ( $\leq 4$ points) and a D-dimer POCT in 294 elderly ambulatory adults ( $\geq 60$ years) suspected of having a pulmonary embolism. The NPV and the specificity in this study was considerately lower than in the study from Geersing et al. ${ }^{14}$ when compared with the same Wells cut-off score. The NPV was also lower when compared to the Wells $<2$ condition in the study by Geersing and compared to the D-dimer as a stand-alone test by Lucassen. A scenario analyses in the study of Schouten showed that lowering the threshold for the Wells rule did not improve the failure rate $(6.3 \%) .{ }^{17}$ The percentage of patients diagnosed with a pulmonary embolism was higher - and the included patients were older - in the study by Schouten (28\%) compared to Geersing et al. ${ }^{14}(12 \%)$.

\section{Acute coronary syndrome and heart failure}

Two prospective cohort studies by Planer et al. ${ }^{18}$ and Nilsson et al. ${ }^{19}$ investigated the diagnostic value of Troponin $\mathrm{T}$ in patients with chest pain or other symptoms clinically suggestive of acute coronary syndrome. Planer studied the diagnostic value of Troponin T POCT for the diagnosis of acute myocardial infarction in 349 patients ( $>30$ years) with at least 20 min consecutive chest pain beginning at least $8 \mathrm{~h}$ prior to presentation and occurring within the previous 6 days. Of all 349 patients, only $6(1.7 \%)$ were diagnosed with a myocardial infarction, of which one was missed by the Troponin T POCT. They calculated a sensitivity of $83 \%$ and a specificity of $100 \%$ for a diagnosis of myocardial infarction within 72h. The PPV and NPV were 100 and 99.7\%, respectively. The sensitivity, 
specificity, PPV and NPV all increased to $100 \%$ when the test was combined with the family physician's clinical decision. They concluded that Troponin T POCT had a very high diagnostic value for the evaluation of patients with non-recent onset chest pain in family practice. ${ }^{18}$

The results of Nilsson were less positive with regards to the sensitivity and PPV of Troponin T POCT. This prospective cohort study investigated the diagnostic value of GP use of Troponin T POCT in 196 patients ( $\geq 35$ years) with chest pain, dyspnoea on exertion, unexplained weakness, and/or fatigue commenced or worsened during the last 7 days. Of all patients, 128 patients were diagnosed by GPs using a Troponin T POCT. Within the intervention group only $3(2.3 \%)$ patients were diagnosed with a myocardial infarction and 4 (3.1\%) with unstable angina. All patients with an unstable angina had a false negative Troponin $T$ POCT, which was also the case in the study by Planer. They calculated a sensitivity of $67 \%$, a specificity of $98 \%$, PPV of $40 \%$, and NPV of $99 \%$ for acute myocardial infarction among patients with chest pain. When adding unstable angina to the outcome group, both the sensitivity and NPV decreased to 29 and $96 \%$, respectively. ${ }^{19}$

Bruins Slot et al. ${ }^{20}$ investigated the diagnostic accuracy of H-FABP POCT in 298 patients - with symptoms less than $24 \mathrm{~h}$ - suspected of acute coronary syndrome in a prospective cohort study in primary care. In this study substantially more patients were diagnosed with an acute coronary syndrome, 66 of $298(22 \%)$ to be exact, of which 14 (21\%) with unstable angina, and 52 (79\%) with myocardial infarction, compared to the study population of Planer and Nilsson. By adding H-FABP POCT to the regular diagnostic model for acute coronary syndrome, the area under the receiver operating curve increased from 0.66 to 0.75 . The sensitivity, specificity, PPV and NPV of H-FABP were 43, 94, 72 and $83 \%$, respectively, when symptoms occurred no longer than 6 h and 39, 94, 65 and $84 \%$, respectively, when symptoms occurred no longer than 24 h. ${ }^{20}$

Burri et al. ${ }^{21}$ investigated the diagnostic accuracy of BNP-guided diagnosis for heart failure in 323 adult patients presenting with new onset or clearly worsening dyspnoea as their primary symptom in an individually randomized controlled trail. Heart failure was diagnosed in 111 (34\%) patients. The BNP 
guided diagnostic strategy compared to standard management increased diagnostic accuracy from 33 to $45 \%$. The area under the receiver operating curve for BNP to identify heart failure was 0.87 . At the optimal cut-off of 153 ng/l, the sensitivity, specificity, PPV and NPV were 72, 93, 88 and 84\%, respectively. ${ }^{21}$

\section{Pulmonary embolism, acute coronary syndromes and heart failure}

In a multicentre cluster-randomized controlled trial, Tomonaga et al. ${ }^{22}$ studied the clinical benefit of a 3-in-1 POCT with Troponin T, BNP and D-dimer, compared to conventional diagnosis in 369 patients with potentially cardiovascular chest pain or symptoms. An acute coronary syndrome was diagnosed in $33(8.9 \%)$ patients, heart failure in $51(13.8 \%)$ patients and a thromboembolic event in 24 (6.5\%) patients. The diagnoses of acute coronary syndromes, heart failure and thromboembolic events were significantly more correct in the POCT group, with $69.8 \%$ correct diagnoses in the POCT group compared to $45.2 \%$ in the standard care group. The sensitivity, specificity, PPV and NPV of Troponin T POCT for acute coronary syndrome were 59, 93, 53 and $95 \%$, respectively. GP use of BNP POCT for heart failure had a sensitivity, specificity, PPV, and NPV of 100, 72, 74 and $100 \%$ respectively and GP use of Ddimer POCT for thromboembolic conditions 93, 78, 36 and 99\%, respectively. ${ }^{22}$

\section{Clinical management}

Hardly any studies evaluated the actual clinical management when using POCT. With regards to treatment, Burri et al. did evaluate the time to appropriate treatment, comparing the intervention group that used a BNP POCT to the control group. GP use of a BNP POCT significantly reduced the time to initiation of appropriate treatment by 12 days. In $66 \%$ of patients appropriate treatment was initiated on the day of initial presentation in the BNP POCT group, compared with $53 \%$ in the control group. 
Only one study evaluated the effect of GP use of a POCT on actual referral rates to secondary care. The Nilsson study had emergency referrals within 30 days of study enrolment as primary outcome. Patients managed by physicians using Troponin T POCT were referred in $25 \%$ of cases compared to $43 \%$ of patients managed by physicians without POCT. However, two patients who were not referred in the Troponin T POCT group were judged as missed cases, with one having an acute myocardial infarction and one unstable angina. Therefore, Nilsson et al concluded that the use of Troponin T POCT in patients with chest pain including those with acute chest pain may reduce emergency referrals, but probably at the cost of an increased risk to miss patients with an acute myocardial infarction or unstable angina. ${ }^{19}$ In all of the other included studies actual referral rates were not determined, although some studies - including those on D-dimer POCT - tried to estimate the number of avoidable referrals to secondary care through scenario analyses.

\section{DISCUSSION}

\section{Summary}

Only few prospective studies evaluating the effect of GP use of POCT on clinical diagnostic accuracy and clinical management in primary care patients with cardiopulmonary symptoms have been performed. All studies were considered at high risk of bias. As such, we currently have insufficient and inconclusive evidence to conclude that GP use of POCT in primary care patients with acute cardiopulmonary symptoms leads to more accurate diagnosis and impacts clinical management. Evidence from a large prospective study on GP use of Ddimer POCT suggests more accurate diagnosis when combining the use of a POCT with a clinical decision rule. As expected, heterogeneity among studies was high and therefore we were unable to perform a meta-analysis. 


\section{Strengths and limitations}

This is the first systematic review on the clinical effectiveness of GP use of POCT in primary care patients with acute cardiopulmonary symptoms. We specifically chose to focus on a broad range of cardiopulmonary symptoms and not one specific condition or biomarker, as typical patients in general practice present with symptoms and not diagnoses. Making an accurate clinical decision within a 10-15 min consultation is part of the complexity of general practice. We therefore chose to perform a broad search to not miss any potential studies. We specifically excluded studies performed in secondary care, including those performed at A\&E departments, to minimize the risk for spectrum bias. Spectrum bias describes the effect a change in patient case mix may have on the performance of a test. ${ }^{23}$

There are several potential limitations of this review. Although we carefully predefined POCT, PICOS criteria and exclusion criteria at the start of the study, some studies were difficult to assess for eligibility because of differences in terminology. Therefore, all records were screened by at least two reviewers and in case of doubt were discussed in a consensus meeting. As all eligible papers of the initial search in four databases were present in PubMed, we decided to only perform the search update in Pubmed.

\section{Comparison with existing literature}

The sensitivity and specificity of GP use of D-dimer POCT as a stand-alone test in a primary care population suspected of pulmonary embolism as shown by Lucassen is comparable to the sensitivity of $82.6 \%$ and specificity of $60.5 \%$ found in a prospective observational study by Runyon et al. ${ }^{24}$ in a low risk emergency department population of 1193 patients evaluated for pulmonary embolism. However, the NPV was somewhat higher in the low risk emergency department population, i.e. 99.4\%. ${ }^{15,24}$ Knudsen et al. ${ }^{25}$ evaluated the accuracy of BNP testing for the diagnosis of heart failure in an unselected group of 155 patients with acute dyspnoea in an emergency department setting and found a 
comparable area under the receiver operating curve for BNP compared to the findings of Burri, ranging between 0.82 and 0.90 depending on age and gender. Two systematic reviews by Bruins Slot et al. concluded that H-FABP POCT at a cut-off value of 6.2 or $7 \mathrm{ng} / \mathrm{ml}$ does not fulfil the requirements for safe and early diagnosis of acute myocardial infarction in a hospital and pre-hospital setting when used as a stand-alone test. ${ }^{26,27}$ This is in line with the conclusion of the primary care study by Bruins Slot et al. ${ }^{20}$ With regards to the clinical value of Troponin POCT in a secondary care population, the literature is inconclusive, which is consistent with the findings of the primary care studies. ${ }^{27}$

\section{Implications for research and practice}

Limited research has been done with regards to cardiopulmonary POCT in primary care clinical practice. Current clinical research mainly evaluates accuracy of POCT and diagnostic yield, when considering the test-treatment pathway. Only a few studies (also) report on clinical management outcomes, e.g. Nilsson evaluated referral rates to secondary care and Burri evaluated timing of treatment. ${ }^{28}$ There are several factors that currently hamper the comparison of outcomes of these studies, including different devices, biomarkers and diseases, study populations and study size, cut-off values and (combinations with) clinical decision rules.

Acute cardiopulmonary conditions can have serious clinical consequences and so excluding serious pathology is one of the key objectives of GPs when managing these patients. Therefore, if GP use of a specific POCT is to be advocated, the NPV of that POCT is of major importance. Some POCT may have a high NPV in a secondary care population, but a lower and insufficient NPV in primary care. For that reason, we should not assume that the outcomes of POCT studies in secondary care are automatically applicable to primary care, as previously discussed in terms of spectrum bias. ${ }^{23}$ Also within primary care, differences in study population could have a major influence on the usefulness of a POCT, as a small difference in test characteristics might render the use of a cardiopulmonary POCT unsafe in certain populations. Therefore, it is very 
important to define, in a clinical decision pathway, for which patients the POCT is tested effective and safely applicable.

One should be careful when determining the NPV for a primary care population wherein the incidence of a certain disease is low, because when the study population is of insufficient size the test characteristics cannot be calculated reliably. Nilsson and Planer did calculate the NPV value even with only very few patients having a myocardial infarction. This may have led to an overestimation of the NPV of a Troponin T POCT for myocardial infarction in their study population. It is also important to notice that all patients with an unstable angina in the studies of Nilsson and Planer had a negative Troponin T POCT. BY definition, the diagnosis of unstable angina is based on unstable cardiac ischemic symptoms without a rise in biomarkers and therefore in essence no biomarkers should be detectable. On the other hand, the incidence of unstable angina is decreasing as patients diagnosed with unstable angina in the past are now being diagnosed with myocardial infarction due to the lower detection thresholds of modern biomarker tests, e.g. high-sensitive Troponin tests. This illustrates the need for modern POCT to gain equal sensitivity to high-sensitive laboratory tests. $^{29}$

The chosen cut-off values have also proven to be important when evaluating POCT. Not all studies use the same cut-off values, which influences test characteristics and study outcomes and it makes comparison among study outcomes difficult. For several biomarkers there is an ongoing debate on the optimal cut-off value. For example, it is suggested that the best NT-proBNP cutoff point to exclude heart failure in an ambulatory population is $280 \mathrm{pg} / \mathrm{ml}$, which showed an area under the ROC curve of 0.94 . This same study compared that cut-off value with recommended diagnostic cut-off values applied to their population, which ranged from $50 \mathrm{pg} / \mathrm{ml}$ in patients younger than 50 years to $400 \mathrm{pg} / \mathrm{ml}$ (NICE guidelines). ${ }^{30,} 31$ The study by Burri only reported the test characteristic when using the optimal cut-off value $(153 \mathrm{pg} / \mathrm{ml})$ for their study population. Not predefining the test threshold, but selecting the optimal cut-off for the study population to optimize test characteristics may lead to an overestimation of test performance, as the test performance of the same POCT 
in another independent sample of patients is likely to be inferior. ${ }^{32} \mathrm{~A}$ similar discussion on the optimal cut-off value can be held for D-dimer POCT in elderly patients, which some believe should be higher than $500 \mathrm{ng} / \mathrm{mL} .{ }^{33}$ The cut-off value for the qualitative D-dimer POCT in the study by Geersing was even lower than $500 \mathrm{ng} / \mathrm{ml}$, to be exact $80 \mathrm{ng} / \mathrm{ml}$. Lower cut-off values for H-FABP and Troponin - when available as POCT - can increase safety by decreasing false negative results. ${ }^{34}$ Differences in cut-off points also play a role in clinical decisions rules, for example the Wells clinical decision rule. Using a Wells cut-off score of $<2$ is safer in the exclusion of pulmonary embolism than a score of $\leq 4$, but at the cost of a lower efficiency and specificity. ${ }^{14}$

Another factor that complicates comparison among studies is that clinical diagnostic accuracy of a POCT is sometimes presented as a stand-alone test and sometimes combined with a clinical decision rule. With regards to the diagnosis of pulmonary embolism a validated and frequently used clinical decision rule in primary care exists, i.e. the Wells rule, which when combined with the D-dimer POCT has a lower failure rate than the D-dimer POCT as a stand-alone test. ${ }^{14,15 \text {, }}$ 35, 36 Such a frequently used and integrated clinical decision rule for the diagnosis of coronary heart disease in primary care does not exist yet. The HEART score for example was developed for patients in an emergency department setting and is not as easily applicable to primary care. ${ }^{37-39}$ The Marburg Heart Score (MHS), however, may be useful in the initial triage of patients suspected of coronary heart disease in general practice. ${ }^{40-42}$ Nonetheless, as of yet this clinical decision rule is not commonly used. If a validated cardiac clinical decision rule like the MHS would be added to a Troponin POCT, this would most likely lead to a more effective and safer exclusion of acute cardiac pathology. More research is necessary to investigate whether the combination of the two leads to a high enough NPV to safely exclude cardiac pathology.

Several factors should be taken into consideration when implementing POCT in practice. ${ }^{43}$ Lack of evidence could lead to limited trust in a POCT, which in turn could lead to referral to secondary care regardless of the test result. If a POCT were to be implemented, physicians should be aware of the risk of non-evidence 
based testing for other conditions, but also within the cardiopulmonary population - i.e. different duration of symptoms than for which the POCT is proven effective. Therefore, it is very important to incorporate a POCT in a tested clinical pathway and to educate GPs on the use of a new POCT. Further research on the effectiveness of using a POCT panel with more than one cardiopulmonary biomarker, may be useful, especially in primary care, where patients sometimes present with vague or a wide range of symptoms. ${ }^{44}$

\section{CONCLUSION}

We conclude that we currently have limited and inconclusive evidence - from prospective and randomized studies with a high risk of bias - that actual GP use of POCT in primary care patients with acute cardiopulmonary symptoms leads to more accurate diagnosis and impacts clinical management. However, some studies show promising results, especially when a POCT is combined with a clinical decision rule, e.g. when GP use of a D-dimer POCT is combined with the Wells clinical decision rule. Further research on the clinical effectiveness of POCT in primary care, preferably in combination with clinical decision rules, is necessary to confirm whether or not POCT could aid GPs in the consultation of patients with acute cardiopulmonary symptoms. 


\section{REFERENCES}

1. Heneghan C, Glasziou P, Thompson M, et al. Diagnostic strategies used in primary care. BMJ. 2009;338:b946.

2. Howick J, Cals JW, Jones C, et al. Current and future use of point-of-care tests in primary care: an international survey in Australia, Belgium, The Netherlands, the UK and the USA. BMJ Open. 2014;4:e005611.

3. Schols AM, van Boekholt TA, Oversier LM, Dinant GJ, Cals JW. General practitioners' experiences with out-of-hours cardiorespiratory consultations: a qualitative study. BMJ Open. 2016;6:e012136.

4. Andreeva $\mathrm{E}$, Melbye $\mathrm{H}$. Usefulness of C-reactive protein testing in acute cough/respiratory tract infection: an open cluster-randomized clinical trial with Creactive protein testing in the intervention group. BMC Fam Pract. 2014;15:80.

5. Laurence $\mathrm{CO}$, Gialamas A, Bubner $\mathrm{T}$, et al. Patient satisfaction with point-of-care testing in general practice. Br J Gen Pract. 2010;60:e98-104.

6. Gialamas A, Yelland LN, Ryan P, et al. Does point-of-care testing lead to the same or better adherence to medication? A randomised controlled trial: the PoCT in General Practice Trial. Med J Aust. 2009;191:487-91.

7. Cals JW, Schot MJ, de Jong SA, Dinant GJ, Hopstaken RM. Point-of-care C-reactive protein testing and antibiotic prescribing for respiratory tract infections: a randomized controlled trial. Ann Fam Med. 2010;8:124-33.

8. Cals JW, Schols AM, van Weert HC, et al. [Point-of-care testing in family practices: present use and need for tests in the future]. Ned Tijdschr Geneeskd. 2014;158:A8210.

9. Engel MF, Paling FP, Hoepelman AI, van der Meer V, Oosterheert JJ. Evaluating the evidence for the implementation of C-reactive protein measurement in adult patients with suspected lower respiratory tract infection in primary care: a systematic review. Fam Pract. 2012;29:383-93.

10. Falk G, Fahey T. C-reactive protein and community-acquired pneumonia in ambulatory care: systematic review of diagnostic accuracy studies. Fam Pract. 2009;26:10-21.

11. Huang $Y$, Chen R, Wu T, Wei X, Guo A. Association between point-of-care CRP testing and antibiotic prescribing in respiratory tract infections: a systematic review and meta-analysis of primary care studies. Br J Gen Pract. 2013;63:e787-94.

12. Higgins JPT, Altman DG, Gøtzsche PC, et al. The Cochrane Collaboration's tool for assessing risk of bias in randomised trials. BMJ. 2011;343.

13. Whiting PF, Rutjes AW, Westwood ME, et al. QUADAS-2: a revised tool for the quality assessment of diagnostic accuracy studies. Ann Intern Med. 2011;155:529-36. 
14. Geersing GJ, Erkens PM, Lucassen WA, et al. Safe exclusion of pulmonary embolism using the Wells rule and qualitative D-dimer testing in primary care: prospective cohort study. BMJ. 2012;345:e6564.

15. Lucassen WA, Erkens PM, Geersing GJ, et al. Qualitative point-of-care D-dimer testing compared with quantitative D-dimer testing in excluding pulmonary embolism in primary care. J Thromb Haemost. 2015;13:1004-9.

16. Erkens PM, Lucassen WA, Geersing GJ, et al. Alternative diagnoses in patients in whom the GP considered the diagnosis of pulmonary embolism. Fam Pract. 2014;31:670-7.

17. Schouten HJ, Geersing GJ, Oudega R, van Delden JJ, Moons KG, Koek HL. Accuracy of the Wells clinical prediction rule for pulmonary embolism in older ambulatory adults. $J$ Am Geriatr Soc. 2014;62:2136-41.

18. Planer D, Leibowitz D, Paltiel O, Boukhobza R, Lotan C, Weiss TA. The diagnostic value of troponin T testing in the community setting. Int J Cardiol. 2006;107:369-75.

19. Nilsson S, Andersson PO, Borgquist L, et al. Point-of-Care Troponin T Testing in the Management of Patients with Chest Pain in the Swedish Primary Care. Int J Family Med. 2013;2013:532093.

20. Bruins Slot $\mathrm{MH}$, Rutten $\mathrm{FH}$, van der Heijden GJ, et al. Diagnostic value of a heart-type fatty acid-binding protein (H-FABP) bedside test in suspected acute coronary syndrome in primary care. Int J Cardiol. 2013;168:1485-9.

21. Burri E, Hochholzer K, Arenja N, et al. B-type natriuretic peptide in the evaluation and management of dyspnoea in primary care. J Intern Med. 2012;272:504-13.

22. Tomonaga Y, Gutzwiller F, Luscher TF, et al. Diagnostic accuracy of point-of-care testing for acute coronary syndromes, heart failure and thromboembolic events in primary care: a cluster-randomised controlled trial. BMC Fam Pract. 2011;12:12.

23. Willis BH. Spectrum bias--why clinicians need to be cautious when applying diagnostic test studies. Fam Pract. 2008;25:390-6.

24. Runyon MS, Beam DM, King MC, Lipford EH, Kline JA. Comparison of the Simplify Ddimer assay performed at the bedside with a laboratory-based quantitative D-dimer assay for the diagnosis of pulmonary embolism in a low prevalence emergency department population. Emerg Med J. 2008;25:70-5.

25. Knudsen CW, Riis JS, Finsen AV, et al. Diagnostic value of a rapid test for B-type natriuretic peptide in patients presenting with acute dyspnoe: effect of age and gender. Eur J Heart Fail. 2004;6:55-62.

26. Bruins Slot MH, Reitsma JB, Rutten FH, Hoes AW, van der Heijden GJ. Heart-type fatty acid-binding protein in the early diagnosis of acute myocardial infarction: a systematic review and meta-analysis. Heart. 2010;96:1957-63. 
27. Bruins Slot MH, van der Heijden GJ, Stelpstra SD, Hoes AW, Rutten FH. Point-of-care tests in suspected acute myocardial infarction: a systematic review. Int J Cardiol. 2013;168:5355-62.

28. Ferrante di Ruffano L, Hyde CJ, McCaffery KJ, Bossuyt PM, Deeks JJ. Assessing the value of diagnostic tests: a framework for designing and evaluating trials. BMJ. 2012;344:e686.

29. Braunwald E, Morrow DA. Unstable angina: is it time for a requiem? Circulation. 2013;127:2452-7.

30. Verdu JM, Comin-Colet J, Domingo M, et al. Rapid point-of-care NT-proBNP optimal cut-off point for heart failure diagnosis in primary care. Rev Esp Cardiol (Engl Ed). 2012;65:613-9.

31. Hildebrandt P, Collinson PO, Doughty RN, et al. Age-dependent values of N-terminal pro-B-type natriuretic peptide are superior to a single cut-point for ruling out suspected systolic dysfunction in primary care. Eur Heart J. 2010;31:1881-9.

32. Leeflang MM, Moons KG, Reitsma JB, Zwinderman AH. Bias in sensitivity and specificity caused by data-driven selection of optimal cutoff values: mechanisms, magnitude, and solutions. Clin Chem. 2008;54:729-37.

33. Righini M, Van Es J, Den Exter PL, et al. Age-adjusted D-dimer cutoff levels to rule out pulmonary embolism: the ADJUST-PE study. JAMA. 2014;311:1117-24.

34. Willemsen RT, van Severen $E$, Vandervoort PM, et al. Heart-type fatty acid binding protein (H-FABP) in patients in an emergency department setting, suspected of acute coronary syndrome: optimal cut-off point, diagnostic value and future opportunities in primary care. Eur J Gen Pract. 2015;21:156-63.

35. Wells PS, Anderson DR, Rodger $M$, et al. Derivation of a simple clinical model to categorize patients probability of pulmonary embolism: increasing the models utility with the SimpliRED D-dimer. Thromb Haemost. 2000;83:416-20.

36. Wells PS, Ginsberg JS, Anderson DR, et al. Use of a clinical model for safe management of patients with suspected pulmonary embolism. Ann Intern Med. 1998;129:997-1005.

37. Backus BE, Six AJ, Kelder JC, et al. A prospective validation of the HEART score for chest pain patients at the emergency department. Int J Cardiol. 2013;168:2153-8.

38. Backus BE, Six AJ, Kelder JC, et al. Chest pain in the emergency room: a multicenter validation of the HEART Score. Crit Pathw Cardiol. 2010;9:164-9.

39. Six $A J$, Cullen $L$, Backus $B E$, et al. The HEART score for the assessment of patients with chest pain in the emergency department: a multinational validation study. Crit Pathw Cardiol. 2013;12:121-6. 
40. Bosner S, Haasenritter J, Becker A, et al. Ruling out coronary artery disease in primary care: development and validation of a simple prediction rule. CMAJ. 2010;182:1295-300.

41. Haasenritter J, Bosner $S$, Vaucher $\mathrm{P}$, et al. Ruling out coronary heart disease in primary care: external validation of a clinical prediction rule. $\mathrm{Br} J$ Gen Pract. 2012;62:e415-21.

42. Haasenritter J, Donner-Banzhoff N, Bosner S. Chest pain for coronary heart disease in general practice: clinical judgement and a clinical decision rule. $\mathrm{Br} J$ Gen Pract. 2015;65:e748-53.

43. Howick J, Bossuyt PM, Cals JWL. Point of care testing in family practice: common myths debunked. Fam Pract. 2017;34:373-5.

44. Harrison A, Amundson S. Evaluation and management of the acutely dyspneic patient: the role of biomarkers. Am J Emerg Med. 2005;23:371-8. 



\title{
Chapter 7
}

GP-use of D-dimer in suspected venous thromboembolism: historical cohort study in one geographical region

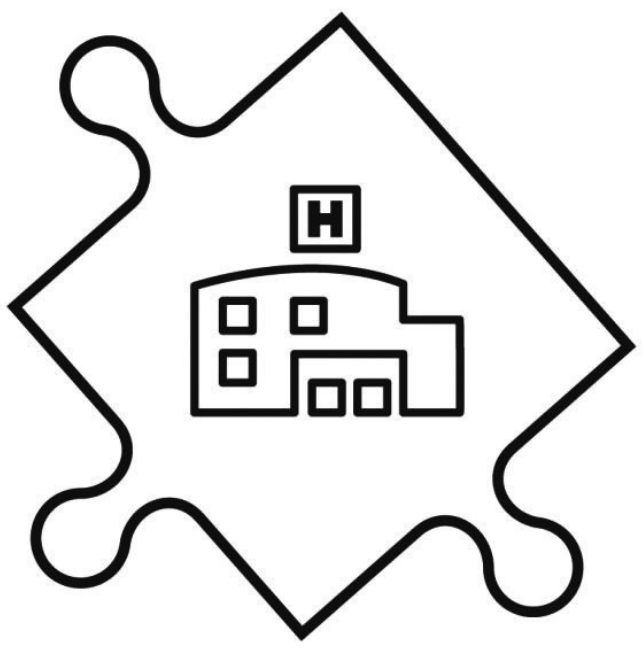

\author{
Angel Schols \\ Eline Meijs \\ Geert-Jan Dinant \\ Jelle Stoffers \\ Mariëlle Krekels \\ Jochen Cals
}




\section{ABSTRACT}

Background Combining a clinical-decision rule and D-dimer test is advocated in diagnosing venous thromboembolic events (VTEs), but D-dimer point-of-care tests (POCTs) are either not or limited available in most countries. Actual use of routine laboratory D-dimer testing by general practitioners (GPs) might provide useful insight for possible future D-dimer POCT implementation.

Aim To investigate how many GP-referred VTEs are diagnosed during one year in one geographical region and to investigate the (urgent) referral pathway of VTE diagnoses, including the role of laboratory D-dimer testing. Additionally, we explored the use of an age-adjusted D-dimer cut-off.

Design and Setting Historical cohort of GP patients of 47 general practices in a region of 161,503 inhabitants.

Method We analysed all patients in whom either the GP determined a D-dimer value or who had a diagnostic work-up for suspected VTE in a nonacademic hospital during 2015.

Results The annual VTE incidence was 0.9 per 1,000 inhabitants. GPs annually ordered 5.1 D-dimer tests per 1,000 inhabitants. Of 470 urgently GP-referred patients, $31.3 \%$ had a VTE. Of those urgently referred based on clinical assessment only (without D-dimer testing), 73.8\% (96/130) had a VTE; based on clinical assessment and laboratory D-dimer testing yielded $15.0 \%(51 / 340)$ VTE. Applying age-adjusted D-dimer cut-offs to all patients aged 50 years or older resulted in a reduction of positive D-dimer results from $97.9 \%$ to $79.4 \%$, without missing any VTE.

Conclusion Although D-dimer testing contributes to the diagnostic work-up of VTE, GPs have a high detection rate for VTE in patients who they urgently refer to secondary care based on clinical assessment only. 


\section{INTRODUCTION}

The annual incidence of venous thromboembolic events (VTEs) -deep vein thrombosis (DVT) and pulmonary embolism (PE)- in high income countries is approximately 70-270 per 100,000 people. ${ }^{1-3}$ It is vital to quickly recognize a VTE and initiate treatment, in order to prevent further morbidity, disability or death. ${ }^{3,} 4$ However, diagnosing VTEs is a challenge in general practice, as symptoms may be nonspecific and the clinical presentation can vary strongly. 5, 6

In the current diagnostic pathways for suspected VTE, it is recommended that general practitioners (GPs) combine clinical decision rules with a D-dimer test in patients with a low clinical pre-test probability for VTE. ${ }^{6-10}$ A low Wells score combined with a D-dimer value below $500 \mu \mathrm{g} / \mathrm{L}$ can safely exclude a VTE. Furthermore, using an age-adjusted D-dimer cut-off in patients $\geq 50$ years seems to be safe. ${ }^{11-18}$ Currently, GPs in the Netherlands have access to D-dimer through routine laboratory tests with results available within a few hours. Using a point-of-care test (POCT) might speed up the diagnosis and inform the decision to refer to secondary care, as the results can immediately support clinical decision-making during the consultation. Many GPs would like to use a Ddimer POCT, although GPs express concerns about the reliability of POCTs in general. ${ }^{5,19}$ Moreover, user-friendliness of existing D-dimer POCTs varies. ${ }^{20}$

The actual use of routine laboratory D-dimer testing by GPs has not been investigated and might provide useful insights in how GPs currently test and refer VTE suspected patients (both low and high risk patients) and may inform possible future D-dimer POCT implementation. The primary aim of this study is to assess how many GP-referred VTEs are diagnosed during one year in one geographical region and to investigate the (urgent) referral pathway of VTE diagnoses, including the role of laboratory D-dimer testing. Moreover, we want to evaluate the possible effect of implementing an age-adjusted D-dimer cut-off. 


\section{METHOD}

\section{Study design and setting}

This is a historical cohort study (2015) in a demarcated geographical area in the Netherlands served by one non-academic hospital and primary care being provided by 47 general practices ( 83 GPs) to 161,503 inhabitants. Patients are primarily referred to this hospital and GPs in this area order laboratory tests via one local diagnostic primary care centre 'MCC Omnes Centre for Diagnostics and Innovation'.

The study protocol was approved by the Medical Ethical Committee of Zuyderland Medical Centre (16-N-145).

\section{Patient selection}

We analysed all patients who were diagnostically worked-up for suspected VTE in hospital or in whom the GP determined a D-dimer value in the year 2015. The cohort was constructed based on data from two sources: the Medical Registration Archives of the hospital and the diagnostic testing database of the local diagnostic centre. From the hospital Medical Registration Archives we selected all patients with a diagnosis-treatment code for DVT and/or PE in the study period. From the diagnostic testing database of the local diagnostic centre we selected all patients of whom the GP requested at least one D-dimer test in the study period. We excluded patients who were registered with a GP working outside the postal code area of the study region or who were not referred by a GP, for example patients who were already admitted to hospital or were translocated from another hospital. Self-referrals and referrals from nursing home physicians were included and analysed as referrals from primary care.

Combining the two data sources resulted in three populations available for analyses: patients urgently referred to hospital, patients non-urgently referred to hospital and patients in whom the GP determined a D-dimer but were not referred to hospital. Urgent referrals were defined as referral within 7 days. All 
referred patients could be divided into patients referred for suspected VTE based on GP clinical assessment only (hence without D-dimer) and patients referred for suspected VTE based on GP clinical assessment and D-dimer testing.

\section{Data extraction and outcomes}

For all urgently referred patients, data was extracted from digital clinical medical records by one researcher (EM) through accessing each patient record and recording data on the final diagnosis, diagnostic work-up, and medical history of patients on a prespecified case record form. In case of doubt, patients were discussed with another researcher (AS). When more than one D-dimer test was performed or more than one diagnosis-treatment code was assigned in referred patients, we evaluated the clinically most relevant event, with the highest suspicion of a PE or DVT. In case a patient had more than one VTE in 2015 this was noted. Diagnoses reported in discharge letters were noted as exactly as possible and subsequently pooled into groups. The number of GP-requested Ddimer tests and $\mathrm{D}$-dimer results in non-referred patients was extracted from the diagnostic testing database of the local diagnostic centre. All data was collected from October till December 2016.

The primary outcomes of this study were the total number of DVTs and PEs per year and diagnostic pathways of patients urgently referred to secondary care for suspected VTE (referred based on clinical assessment only or based on clinical assessment and D-dimer). Therefore, we registered the total number of GPrequested D-dimer tests, the D-dimer values, the time between D-dimer testing and the hospital visit, the final diagnoses after referral, and patient characteristics. For the D-dimer value we used a cut-off of $500 \mu \mathrm{g} / \mathrm{L}$. Additionally, we explored the use of an age-adjusted D-dimer cut-off, defined as age $\times 10$ within patients of $\geq 50$ years. ${ }^{13-16}$ 


\section{Statistical analysis}

Statistical analyses were performed using IBM SPSS Statistics Data Editor Version 23. Analyses consisted primarily of descriptive analyses to describe the study population, patient flow and D-dimer values, using frequencies, averages, medians or percentages. The total population size of 161,503 inhabitants was calculated by adding the number of patients of all included general practices, based on list sizes of practices provided by MCC Omnes. The incidence rate was calculated by dividing the total number of VTEs by the total population size.

\section{RESULTS}

\section{Patient characteristics and VTE incidence}

Figure 7.1 illustrates the patient flow of all included patients. We included 895 primary care patients, of which 148 were diagnosed with a VTE in a total population of 161,503 inhabitants. Three $(2.0 \%)$ patients had more than one VTE during 2015. The annual incidence of GP-referred VTE was 0.9 per 1,000 inhabitants. An average of $5.1 \mathrm{D}$-dimer tests per 1,000 inhabitants were performed by GPs.

\section{Referral pathways}

More than half $(52.5 \%)$ of the included patients were urgently referred to secondary care, 72 patients $(8.0 \%)$ were referred non-urgently and 353 patients (39.4\%) were not referred to secondary care (Figure 7.1). Of all non-urgently referred patients, one self-referred patient was diagnosed with a DVT. About a quarter $(23.8 \%)$ of patients not referred to secondary care had a positive Ddimer, with a median D-dimer value of 648.5 (501-3,386). 


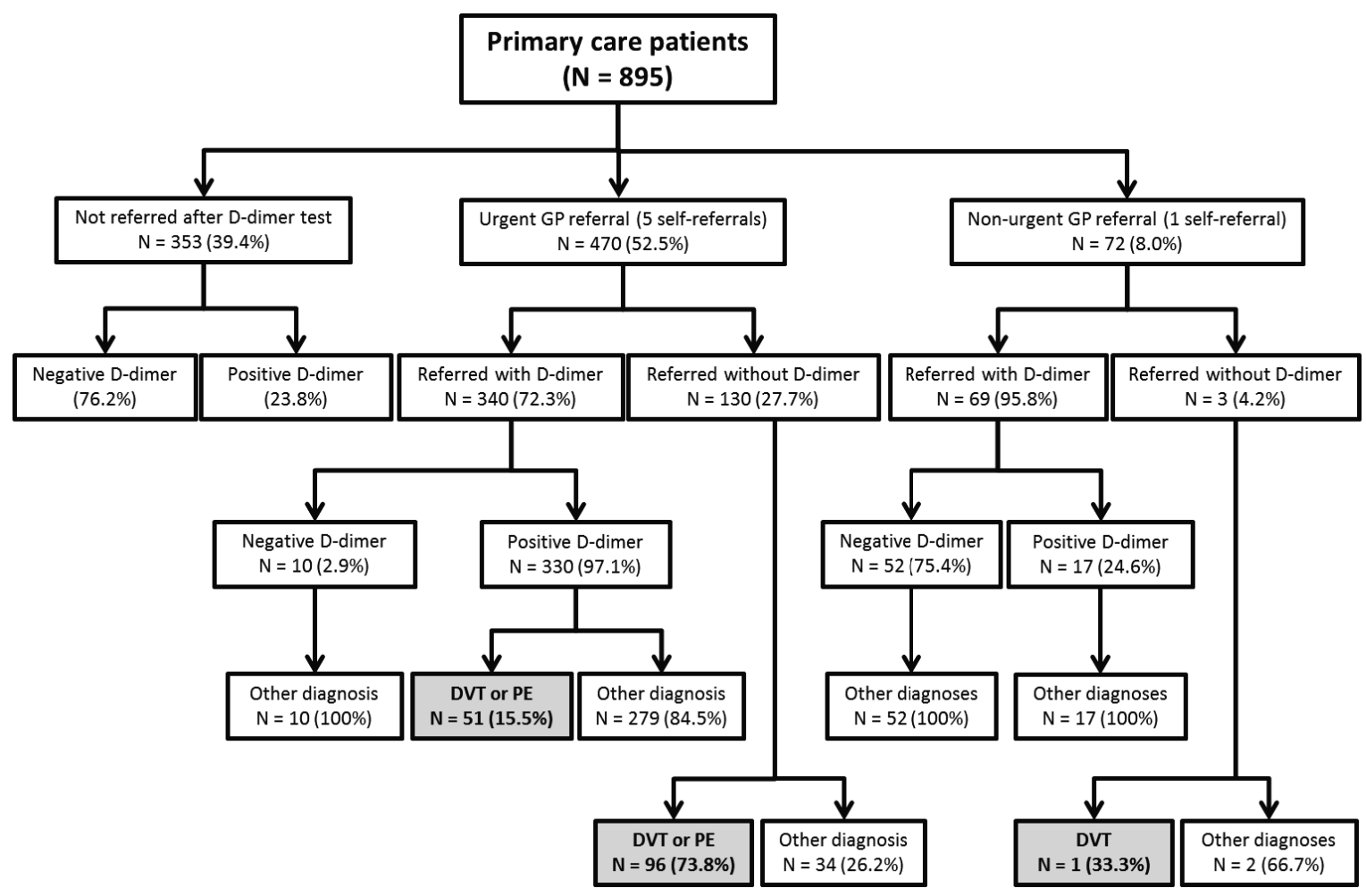

Figure 7.1 Patient flow and GP-use of D-dimer test.

\section{Urgently referred patients}

A total of 470 patients were urgently referred to secondary care for suspected VTE, which is $52.5 \%$ of all patients in this cohort. On average, these patients were 63 years, and $38.9 \%$ were male (Table 7.1 ). 
Table 7.1 Patient characteristics of urgently referred patients $(N=470)$.

\begin{tabular}{ll}
\hline Patient characteristics and D-dimer use & \\
\hline Mean age, years (range) & $63(18-95)$ \\
Gender, male (\%) & $183(38.9)$ \\
Number of GP determined D-dimer tests (\%) & $340(72.3)$ \\
$\quad$ Number of positive D-dimer tests, > $500 \mu \mathrm{g} / \mathrm{( \% )}$ & $330(97.1)$ \\
$\quad$ Median of D-dimer tests, $\mu \mathrm{g} / \mathrm{L}$ (range) & $1041.5(256-22,863)$ \\
\hline Use of medication when referred to hospital & \\
\hline Oral anticoagulation* (\%) & $11(2.3)$ \\
Platelet aggregation inhibitor (\%) & $45(9.6)$ \\
\hline Medical history when referred to hospital & \\
\hline Pregnancy* (\%) & $5(1.1)$ \\
Previous DVT/PE (\%) & $100(21.3)$ \\
Malignancy* (\%) & $36(7.7)$ \\
Diabetes mellitus (\%) & $61(13.0)$ \\
Cardiac disorders* (\%) & $96(20.4)$ \\
Previous CVA/TIA (\%) & $34(7.2)$ \\
Hypertension (\%) & $135(28.7)$ \\
COPD (\%) & $38(8.1)$ \\
Renal insufficiency (\%) & $16(3.4)$
\end{tabular}

$\overline{\mathrm{PE}}=$ pulmonary embolism; DVT = deep vein thrombosis; CVA = cerebrovascular accident; TIA = transient ischaemic attack; COPD = chronic obstructive pulmonary disease.

*Use of anticoagulants consisted of coumarin derivatives, heparins and direct oral anticoagulants; malignancy was defined as active malignancy, malignancy treated within past 6 months or palliation; pregnancy as current pregnancy or postpartum period ( 6 weeks postpartum); cardiac history included any cardiac disorder, e.g. atrial fibrillation, myocardial infarction and bundle branch block.

Urgently referred patients based on clinical assessment and D-dimer

The majority of urgently referred patients $(n=340,72.3 \%)$ were referred based on GP clinical assessment plus a D-dimer test (Table 7.1). Nearly all patients $(94.7 \%)$ were seen within one day after a D-dimer test was requested; average time between D-dimer test and hospital visit was 0.62 days. Of these patients $330(97.1 \%)$ had a positive test $(>500 \mu \mathrm{g} / \mathrm{L})$, with a median D-dimer of 1,072 
$\mu \mathrm{g} / \mathrm{L}(502-22,863)$ (Table 7.2). In 51 of these 340 patients a VTE was diagnosed (15.0\%), of which 19 (37.3\%) patients had a PE, 21 (41.2\%) a DVT and 11 (21.6\%) a PE and DVT. No VTE was found among the 10 patients with a normal D-dimer test.

Table 7.2 GP determined D-dimer values of all urgently referred patients with a positive D-dimer value ( $>500 \mu \mathrm{g} / \mathrm{L})(\mathrm{N}=330)$.*

\begin{tabular}{lc}
\hline Diagnoses & Median D-dimer value (range), $\mathbf{\mu g} / \mathbf{L}$ \\
\hline All urgently referred patients $(\mathrm{N}=330)$ & $1,072(502-22,863)$ \\
Venous thromboembolic event $(\mathrm{n}=51)$ & $3,321(982-21,345)$ \\
Pulmonary embolism $(\mathrm{n}=19)$ & $1,799(1,113-20,492)$ \\
Deep vein thrombosis $(\mathrm{n}=21)$ & $4,449(1,223-16,782)$ \\
Combination of pulmonary embolism and & $5,718(982-21,345)$ \\
deep vein thrombosis $(\mathrm{n}=11)$ & \\
Alternative diagnosis $(\mathrm{n}=279)$ & $928(502-22,863)$ \\
\hline
\end{tabular}

*Of all urgently referred patients $(n=470), 340$ were referred based on GP clinical assessment and D-dimer, and 10 of those were negative $(<500 \mu \mathrm{g} / \mathrm{L})$.

Urgently referred patients based on clinical assessment only

One-hundred-and-thirty (27.7\%) patients were urgently referred to secondary care based on clinical assessment only, hence without a D-dimer test. Of these, $96(73.8 \%)$ were diagnosed with a VTE; $28(29.2 \%)$ patients with a PE, 45 (46.9\%) a DVT and $23(24.0 \%)$ patients had a combined diagnoses of PE and DVT.

VTE and alternative diagnoses in urgently referred patients

Hence in total, of all 470 urgently referred patients (both based on clinical assessment only and clinical assessment plus D-dimer) 147 (31.3\%) were diagnosed with a VTE (Table 7.3). Frequent alternative diagnoses were 
musculoskeletal disorders (14.9\%), respiratory tract infections or other pulmonary disorders $(11.3 \%)$, and oedema and other vascular disorders (10.2\%) (Table 7.3).

Table 7.3 Final diagnoses in patients urgently referred (within 7 days) to secondary care $(\mathrm{N}=470)$, based on hospital medical records.

\begin{tabular}{lc}
\hline Final diagnoses & Number of patients (\%) \\
\hline Venous thromboembolism & $147(31.3)$ \\
$\quad$ Pulmonary embolism & $47(10.0)$ \\
$\quad$ Deep venous thrombosis & $66(14.0)$ \\
$\quad$ Combination pulmonary embolism and deep vein & $34(7.2)$ \\
$\quad$ thrombosis & \\
Musculoskeletal disorders & $70(14.9)$ \\
Respiratory tract infections or other pulmonary & $53(11.3)$ \\
disorders & $12(2.6)$ \\
$\quad$ Pneumonia & \\
Oedema and other vascular disorders* & $48(10.2)$ \\
(skin)Infections of leg & $20(4.3)$ \\
$\quad$ Erysipelas/cellulitis & $18(3.8)$ \\
Thrombophlebitis & $28(6.0)$ \\
Baker's cyst & $20(4.3)$ \\
Cardiac disorders & $10(2.1)$ \\
Other diagnoses & $13(2.8)$ \\
Unclear diagnosis/no diagnosis & $47(10.0)$ \\
More than one differential diagnosis & $14(3.0)$ \\
\hline
\end{tabular}

*Including one mesenteric vein thrombosis

Applying age-adjusted D-dimer cut-off in urgently referred patients

Among urgently referred patients with a D-dimer test, 287 patients were $\geq 50$ years. Using a cut-off of $500 \mu \mathrm{g} / \mathrm{L}, 281$ (97.9\%) patients had a positive D-dimer value. Applying an age-adjusted $\mathrm{D}$-dimer cut-off value to this group would leave $228(79.4 \%)$ patients with a positive D-dimer value; a reduction of $18.5 \%$. No VTE would have been missed. 


\section{DISCUSSION}

\section{Summary}

In this historical cohort study in a well-defined geographical area, we found an annual incidence of 0.9 VTE per 1,000 inhabitants. GPs requested annually 5.1 D-dimer test per 1,000 inhabitants. Of all urgently referred patients to secondary care, $31.3 \%$ was diagnosed with a VTE. Of those urgently referred based on clinical assessment only, $73.8 \%$ had a VTE, while in those referred based on clinical assessment and D-dimer $15.5 \%$ had a VTE. The use of an ageadjusted D-dimer cut-off could have resulted in a reduction of $18.5 \%$ of positive D-dimer tests ( 97.9 to $79.4 \%$ ) in the group of urgently referred patients $\geq 50$ years, without missing any DVT or PE.

\section{Strengths and limitations}

This is the first study that explored the actual use of D-dimer tests in general practice and the diagnostic pathway of DVT and PE in one demarcated geographical region during one year. We not only carefully investigated the patient flow of all GP-referred patients, we also investigated the D-dimer use in all primary care patients in this region.

Unfortunately, we were unable to create a clear overview of the non-referred patients, as we did not have patients permission to access GPs' patient records. We can only speculate as to what reasons GPs had to not refer patients with a positive D-dimer test, for example, GPs may have used age-adjusted D-dimer cut-off values or reconsidered the appropriateness of performing the test in that particular patient, the patient may have refused to go into hospital or was sent to another hospital outside of the study region, or the patient might have died before arrival into hospital. This may have led to a slight underestimation of the number of VTEs in the study population. We tried to reduce this chance by selecting a specific demarcated geographical region where almost all GPs refer their patients to one hospital and where all GPs do all diagnostic tests in one diagnostic centre. We were unable to reliably determine some aspects of the 
consultation and patient history in the medical records, for example, components of the Wells score were missing in discharge letters of many patients and some aspects of the medical history might have been underestimated as these are not always fully reported in the records. Some minor selection bias may have occurred as we only evaluated the most clinically suspected event in each patient.

\section{Comparison with existing literature and recommendation in GP guidelines}

We found an annual incidence of approximately one VTE per 1,000 person-years at risk, which is comparable with incidence rates in other studies. ${ }^{1-3}$ In this study we found that of all urgently referred patients based on clinical assessment only, almost $75 \%$ of patients indeed had a VTE. This suggests that GP's judgment in high risk patients is remarkably good, which supports the current recommendation in the Dutch national guidelines that requesting a $\mathrm{D}$-dimer test in these high risk patients is not advisable and will only delay referral to secondary care. ${ }^{6-10}$ Of those urgently referred after D-dimer testing, $15.5 \%$ of patients was diagnosed with a VTE.

Nonetheless, it is important to note that, although almost $85 \%$ of patients urgently referred to secondary care with a positive D-dimer test did not have a VTE, a significant portion of these patients may still have had another clinically relevant diagnosis for which referral may have been wise or needed. A study by Erkens (2014), found that $28.9 \%$ of patients suspected of a PE but in whom a PE was eventually ruled-out received another clinically relevant diagnoses; a positive Wells rule or a positive D-dimer test were positively associated with a higher probability of another clinically relevant disease. ${ }^{21}$

Applying the age-adjusted D-dimer cut-off to our primary care population again shows that VTE can be safely ruled out with the age-adjusted cut-off value in patients $\geq 50$ years and may reduce the referral rate in patients of 50 years and older by $18.5 \% .^{13-18}$ 


\section{Implications for research and/or practice}

Looking at the patient flow, we can see that the D-dimer test contributes significantly to the diagnostic work-up of VTE, but two-thirds of patients diagnosed with a VTE were found after clinical assessment only. We may speculate, albeit that we did not have access to GP medical records, that these were patients with a high probability of VTE as estimated by the consulting GP and these patients were rightfully directly referred, in line with recommendations in the GP guidelines. Taking into account that a GP will infrequently use a Ddimer test in daily practice and the finding that GPs have a high detection rate for highly suspicious VTE, one might argue that replacing the laboratory D-dimer test by a D-dimer POCT is not directly necessary. Moreover, a D-dimer POCT may be used more often in patients without a clear or evidence based indication, which will most likely - especially in the case of a non-specific test - lead to an increase in referrals to secondary care due to false positive tests. The closer proximity to a D-dimer POCT may also lead to a lower threshold for testing in high probability patients, which is not recommended by guidelines and may lead to a delay in referral. 6-9 This effect of non-evidence based testing (for other indications) has previously been seen with the introduction of the CRP POCT. ${ }^{22-24}$ Excessive test use and a possible increase in referrals in turn may lead to an increased number of patients being anticoagulated inappropriately, due to an increased number of false positive cases with leg ultrasonography and an increased number of overdiagnosis in patients with clinically insignificant subsegmental PEs. ${ }^{25,26}$ Furthermore, the low frequency of test use and potential excessive use of a D-dimer POCT also raises questions with regards to training and cost-effectiveness of such a POCT. However, if a D-dimer POCT were to be implemented, careful monitoring is essential to assess its effect on the diagnostic work-up of patients with suspected VTE and the referral rate to secondary care. 


\section{CONCLUSION}

Although D-dimer testing contributes to the diagnostic work-up of VTE, GPs have a high detection rate for VTE in patients who they urgently refer to secondary care based on clinical assessment only. 


\section{REFERENCES}

1. Raskob GE, Angchaisuksiri P, Blanco AN, et al. Thrombosis: A Major Contributor to Global Disease Burden. Arterioscler Thromb Vasc Biol. 2014;34:2363-71.

2. White RH. The epidemiology of venous thromboembolism. Circulation. 2003;107:148.

3. Cohen AT, Agnelli G, Anderson FA, et al. Venous thromboembolism (VTE) in Europe. The number of VTE events and associated morbidity and mortality. Thromb Haemost. 2007;98:756-64.

4. Smith SB, Geske JB, Maguire JM, Zane NA, Carter RE, Morgenthaler TI. Early anticoagulation is associated with reduced mortality for acute pulmonary embolism. Chest. 2010;137:1382-90.

5. Schols AM, van Boekholt TA, Oversier LM, Dinant GJ, Cals JW. General practitioners' experiences with out-of-hours cardiorespiratory consultations: a qualitative study. BMJ Open. 2016;6:e012136.

6. Konstantinides SV, Torbicki A, Agnelli G, et al. 2014 ESC guidelines on the diagnosis and management of acute pulmonary embolism. Eur Heart J. 2014;35:3033-80.

7. Dupras D, Bluhm J, Felty C, et al. Institute for Clinical Systems Improvement. Venous Thromboembolism Diagnosis and Treatment. [updated 2013 Jan]. Available from: http://bit.ly/VTE0113.

8. Qaseem A, Snow V, Barry P, et al. Current Diagnosis of Venous Thromboembolism in Primary Care: A Clinical Practice Guideline from the American Academy of Family Physicians and the American College of Physicians. Ann Fam Med. 2007;5:57-62.

9. National Institute for Health and Care Excellence (NICE). Diagnosing venous thromboembolism in primary, secondary and tertiary care. [cited 2017 August]. Available from: https://pathways.nice.org.uk/pathways/venous-thromboembolism \#path=view\%3A/pathways/venous-thromboembolism/diagnosing-venousthromboembolism-in-primary-secondary-and-tertiary-care. $x m$ l\&content=view-index.

10. The Dutch College of General Practitioners' working group deep vein thrombosis and pulmonary embolism. [GP guideline Deep vein thrombosis and pulmonary embolism (second partial revision)] Utrecht: Dutch College of General Practitioners. [cited 2018 April 24]. Available from: https://www.nhg.org/standaarden/volledig/nhg-standaarddiepe-veneuze-trombose-en-longembolie.

11. Buller HR, Ten Cate-Hoek AJ, Hoes AW, et al. Safely ruling out deep venous thrombosis in primary care. Ann Intern Med. 2009;150:229-35.

12. Geersing GJ, Erkens PM, Lucassen WA, et al. Safe exclusion of pulmonary embolism using the Wells rule and qualitative $\mathrm{D}$-dimer testing in primary care: prospective cohort study. BMJ. 2012;345:e6564. 
13. Righini M, Van Es J, Den Exter $P L$, et al. Age-adjusted $D$-dimer cutoff levels to rule out pulmonary embolism: the ADJUST-PE study. JAMA. 2014;311:1117-24.

14. Schouten HJ, Geersing GJ, Koek HL, et al. Diagnostic accuracy of conventional or age adjusted D-dimer cut-off values in older patients with suspected venous thromboembolism: systematic review and meta-analysis. BMJ. 2013;346:f2492.

15. Andro M, Righini M, Le Gal G. Adapting the D-dimer cutoff for thrombosis detection in elderly outpatients. Expert Rev Cardiovasc Ther. 2013;11:751-9.

16. Fuchs E, Asakly S, Karban A, Tzoran I. Age-Adjusted Cutoff D-Dimer Level to Rule Out Acute Pulmonary Embolism: A Validation Cohort Study. Am J Med. 2016;129:872-8.

17. Schouten $H J$, Koek $H L$, Oudega $R$, et al. Validation of two age dependent D-dimer cut-off values for exclusion of deep vein thrombosis in suspected elderly patients in primary care: retrospective, cross sectional, diagnostic analysis. BMJ. 2012;344:e2985.

18. Flores J, Garcia de Tena J, Galipienzo J, et al. Clinical usefulness and safety of an age-adjusted $\mathrm{D}$-dimer cutoff levels to exclude pulmonary embolism: a retrospective analysis. Intern Emerg Med. 2016;11:69-75.

19. Howick J, Cals JW, Jones C, et al. Current and future use of point-of-care tests in primary care: an international survey in Australia, Belgium, The Netherlands, the UK and the USA. BMJ Open. 2014;4:e005611.

20. Geersing GJ, Toll DB, Janssen KJ, et al. Diagnostic accuracy and user-friendliness of 5 point-of-care D-dimer tests for the exclusion of deep vein thrombosis. Clin Chem. 2010;56:1758-66.

21. Erkens PM, Lucassen WA, Geersing GJ, et al. Alternative diagnoses in patients in whom the GP considered the diagnosis of pulmonary embolism. Fam Pract. 2014;31:670-7.

22. Minnaard MC, van de Pol AC, Hopstaken RM, et al. C-reactive protein point-of-care testing and associated antibiotic prescribing. Fam Pract. 2016;33:408-13.

23. Cals JW, Chappin FH, Hopstaken RM, et al. C-reactive protein point-of-care testing for lower respiratory tract infections: a qualitative evaluation of experiences by GPs. Fam Pract. 2010;27:212-8.

24. Engstrom S, Molstad S, Lindstrom K, Nilsson G, Borgquist L. Excessive use of rapid tests in respiratory tract infections in Swedish primary health care. Scand J Infect Dis. 2004;36:213-8.

25. Goodacre S, Sampson F, Thomas S, van Beek E, Sutton A. Systematic review and meta-analysis of the diagnostic accuracy of ultrasonography for deep vein thrombosis. BMC Med Imaging. 2005;5:6. 
26. Wiener RS, Schwartz LM, Woloshin S. When a test is too good: how CT pulmonary angiograms find pulmonary emboli that do not need to be found. BMJ. 2013;347:f3368. 



\title{
Chapter 8
}

\section{Point-of-care testing in general practice:} just what the doctor ordered?

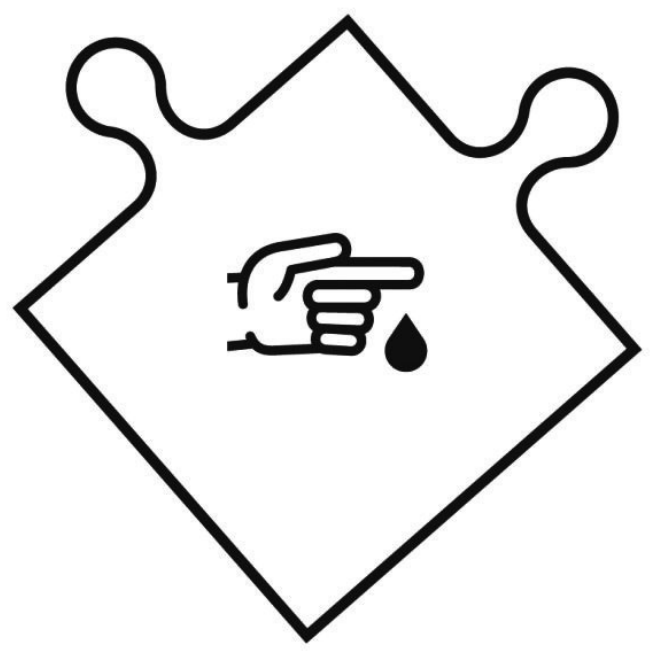

\author{
Angel Schols \\ Geert-Jan Dinant \\ Jochen Cals
}

British Journal of General Practice 2018;68:362-363 

In this time where fast, efficient, and personalised care has become increasingly important, it is not surprising that point-of-care tests (POCTs) are becoming ever more popular. A wide range and growing number of POCTs are now available to GPs. The term POCT is frequently used and many different descriptions of a POCT exist, which sometimes leads to misconceptions and confusion. With a multidisciplinary international panel of POCT experts consisting of family practitioners, laboratory specialists, policymakers, researchers, and manufacturers, we recently performed a modified e-Delphi procedure to reach consensus on a widely supported and recognised international definition of a POCT in family practice: a point-of-care test in family practice is a test to support clinical decision making, which is performed by a qualified member of the practice staff nearby the patient and on any part of the patient's body or its derivatives, during or very close to the time of consultation, to help the patient and physician to decide upon the best-suited approach, and of which the results should be known at the time of the clinical decision making. ${ }^{1}$

\section{GPs' wishes and concerns}

POCTs have many potential benefits, for example, saving patients' and physicians' time, optimising management, reducing referrals to secondary care and healthcare costs, improving patient satisfaction, and better adherence to treatment. An international survey among 2770 GPs in the UK, Australia, Belgium, the Netherlands, and the US has shown that GPs would like to use more laboratory POCTs. They specifically want POCTs to help them diagnose acute conditions, such as infections (C-reactive protein [CRP], chlamydia, gonorrhoea), acute cardiac disease (troponin, B-type natriuretic peptide), pulmonary embolism and deep-vein thrombosis (D-dimer), and some chronic conditions (for example, HbA1c, haemoglobin). ${ }^{2,3}$ However, GPs also expressed reservations towards increasing access to new POCTs. They are concerned about test accuracy, over-reliance on tests, the use of diagnostics without a proper indication, and a lack of skills to safely use and interpret these diagnostics. ${ }^{4,5}$ We believe that these concerns are justified and we will describe why we think that more point of care does not necessarily mean better care. 


\section{POCT evaluation}

Although GPs may wish to use laboratory POCTs for these acute conditions, most of these POCTs are not evaluated sufficiently or are currently unfit for clinical practice. As an example we recently showed that, despite wide clinical interest in POCTs for acute cardiopulmonary conditions, there were only seven prospective studies evaluating relevant patient outcomes for promising laboratory POCTs (troponin, D-dimer, H-FABP, and BNP) in a general practice population, with only very few studies evaluating outcomes beyond clinical performance assessment. ${ }^{6}$

In a previous editorial in the BJGP, Thompson et al rightly pointed out that it is important to structurally evaluate the evidence behind new (point-of-care) diagnostic tests. In doing so it is not only important to evaluate the evidence that a test has been investigated in primary care, but also that the test has been shown to make a difference to patient outcomes, is useful in clinical practice, and is cost-effective. ${ }^{7}$ The Horizon Scan reports are very useful in evaluating new POCTs. These independent reports funded by the National Institute of Health Research (some of which were published by Plüddemann et al in the Clinical Intelligence section of the $B J G P$ ), summarise why the technology is important, provide an overview of the currently available evidence, and assess whether it could be adopted in the NHS, and, if so, what the requirements are for the delivery of the technology into practice.

Recently, the Oxford Diagnostic Evidence Cooperative group systematically analysed all 40 diagnostic Horizon Scan reports on POCTs of recent years. ${ }^{8}$ This systematic review, extracting data from 500 primary studies, showed that only very few POCT evaluations seem to follow the expected evaluation sequence of analytical performance, clinical performance, clinical effectiveness, comparative clinical effectiveness, cost-effectiveness, and broader impact. It strikingly shows that most POCTs undergo clinical performance assessment (71\%), but very few progress to evaluation of their broader impact or cost-effectiveness. Only $18 \%$ of all studies evaluated clinical effectiveness of the POCT and only $18 \%$ of all Horizon Scan reports included evidence for all evaluation components. Notably, the median time to completion of the evaluation cycle from analytical 
performance to broader impact was 9 years, showing that the proper evaluation of rapid tests is anything but rapid. ${ }^{8}$

\section{From analytical accuracy to broader impact}

The only Horizon Scan report that included evidence from analytic accuracy to broader impact and generally followed the expected evaluation sequence was on CRP POCT. ${ }^{8}$ This POCT has been widely introduced in Dutch general practice and more than half of UK GPs would like to use this POCT as well. ${ }^{2}$ CRP appears to check all boxes for successful implementation of a new POCT, as follows:

- there is a medical need for such a test and social awareness (reducing antibiotic prescriptions in the light of antibiotic resistance);

- there is a simple, robust, and reliable CRP POCT available;

- the test is proven effective in reducing the number of antibiotic prescriptions;

- $\quad$ e-learning training modules were developed and made available; and

- $\quad$ the translation was made to clinical practice, where the test was adopted by Dutch GPs.

However, even in the case of the CRP POCT there are some problems after implementation in routine care, such as excessive and non-evidence-based use of the POCT.

Exact figures are lacking, but GPs also use CRP POCT for conditions such as appendicitis and in children, against the advice of current GP guidelines. A Dutch observational study investigating the effects of implementation of the CRP POCT among 40 GPs in nine general practices, in 2012 and 2013, showed that GPs did not use or interpret the POCT according to the guidelines in the majority of patients. ${ }^{9}$ Non-evidence-based POCT use was also observed in Scandinavia, where the POCT was already widely implemented before prospective studies on clinical effectiveness were performed. ${ }^{10}$ 
POCTs are especially vulnerable to excessive and non-evidence-based use, as the proximity and speed of POCTs may prompt physicians to use them. Diagnostic performance of POCTs should be evaluated in a specific primary care population for specific indications. In practice, GPs should then only use these POCTs in the same population and for the same indications for which the POCT is proven effective, because expanding the range of indications can negatively influence the diagnostic performance of a POCT.

\section{Implementation in routine clinical practice}

Even after POCTs have undergone the full evaluation cycle from analytical performance to broader impact, the use of POCTs should be evaluated after implementation in routine clinical practice. Attention should be paid not only to non-evidence-based test use, but also to pre-analytical errors, misinterpretation, and non-adequate documentation of the test results. It is vital that GPs follow the proper training on how and when to accurately use POCTs, how to interpret and chart the results, and how and why quality control is performed. As there are many GPs with busy schedules and limited resources, it may be challenging to train all GPs and practice staff. Online e-learning modules supplemented by short face-to-face user instructions by manufacturers or local laboratories may be a good solution for this problem.

When using POCTs, a quality management system should be implemented, wherein aspects such as the following are addressed:

- $\quad$ responsibility and accountability;

- adequate training and certification, including basic health and safety issues and standard operating procedures; and

- $\quad$ appropriate internal quality control and external quality assurance.

Connectivity between POCT data management software and the electronic patient information system could aid GPs in correct documentation of the test results. ${ }^{11}$ Cooperation with medical laboratories and manufacturers is important 
to support GPs with the correct implementation of POCTs and device maintenance.

\section{CONCLUSION}

Although more POCTs, with potential benefits, are available to GPs nowadays, GPs' concerns about the use of these POCTs are justified. GPs should remain critical about what tests to order, as most POCTs have not been evaluated sufficiently. Only few POCTs have been evaluated with regards to clinical effectiveness or broader impact on patient outcomes, and some POCTs even appear to have been implemented in routine care without completing these essential evaluation stages. Critical appraisal of new POCTs is essential to facilitate implementation. Also, after implementation in routine clinical practice, the use and effect of POCTs should be evaluated and well-considered quality management systems should be implemented. By doing so we can work towards professional POCT use in general practice. Only then we can be sure that more point of care means better care. 


\section{REFERENCES}

1. Schols AMR, Dinant GJ, Hopstaken R, Price CP, Kusters R, Cals JWL. International definition of a point-of-care test in family practice: a modified e-Delphi procedure. Fam Pract. 2018;35:475-408.

2. Howick J, Cals JW, Jones C, et al. Current and future use of point-of-care tests in primary care: an international survey in Australia, Belgium, The Netherlands, the UK and the USA. BMJ Open. 2014;4:e005611.

3. Turner PJ, Van den Bruel A, Jones $\mathrm{CH}$, et al. Point-of-care testing in UK primary care: a survey to establish clinical needs. Fam Pract. 2016;33:388-94.

4. Jones $\mathrm{CH}$, Howick J, Roberts NW, et al. Primary care clinicians' attitudes towards point-of-care blood testing: a systematic review of qualitative studies. BMC Fam Pract. 2013;14:117.

5. Schols AM, van Boekholt TA, Oversier LM, Dinant GJ, Cals JW. General practitioners' experiences with out-of-hours cardiorespiratory consultations: a qualitative study. BMJ Open. 2016;6:e012136.

6. Schols AMR, Stakenborg JPG, Dinant G, Willemsen RTA, Cals JWL. Point-of-care testing in primary care patients with acute cardiopulmonary symptoms: a systematic review. Family Practice. 2018;35:4-12.

7. Thompson M, Pluddemann A, Price CP, Heneghan C. Emerging diagnostic technologies in primary care: what's on the horizon? Br J Gen Pract. 2013;63:177-8.

8. Verbakel JY, Turner PJ, Thompson MJ, et al. Common evidence gaps in point-of-care diagnostic test evaluation: a review of horizon scan reports. BMJ Open. 2017;7:e015760.

9. Minnaard MC, van de Pol AC, Hopstaken RM, et al. C-reactive protein point-of-care testing and associated antibiotic prescribing. Fam Pract. 2016;33:408-13.

10. Andre M, Schwan A, Odenholt I, Swedish Study Group on Antibiotic U. The use of CRP tests in patients with respiratory tract infections in primary care in Sweden can be questioned. Scand J Infect Dis. 2004;36:192-7.

11. Medicines and Healthcare Products Regulatory Agency. Management and use of IVD point of care test devices. December 2013 [cited 2017 May]. Available from: http://www.viapath.co.uk/sites/default/files/upload/POCT/Management\%20and\%20u se\%20of\%20IVD\%20point\%20of\%20care\%20test\%20devices.pdf. 


\section{HUISARTS \\ HVRT WEEK}

\section{Chapter 9}

A clinical decision rule for suspected acute coronary syndrome: nationwide flash mob study in family medicine

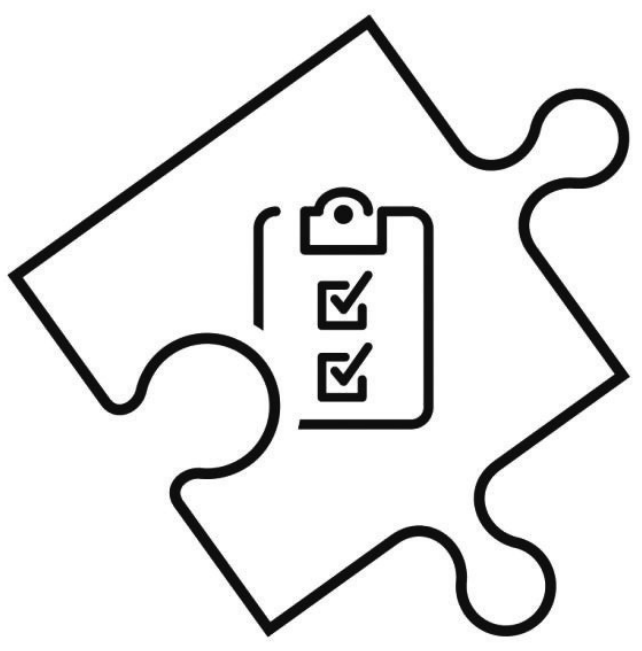

Angel Schols

Robert Willemsen

Tobias Bonten

Martijn Rutten

Patricia Stassen

Bas Kietselaer Geert-Jan Dinant Jochen Cals 


\section{ABSTRACT}

Purpose External validation of the Marburg Heart Score (MHS) or development of an adapted clinical decision rule for family practitioners (FPs) to safely rule out acute coronary syndrome (ACS) in patients referred to secondary care for suspected ACS. Secondary, to evaluate the feasibility of using a flash mob method, an innovative new study design, for large scale research in family medicine.

Methods In this 2-week nationwide prospective observational flash mob study FPs collected data on possible ACS predictors and made an assessment of ACS probability (scale 1-10) in patients referred to secondary care for suspected ACS.

Results FPs registered 258 patients. A final diagnosis was obtained in 243 (94\%) patients, of whom 45 (18.5\%) were diagnosed with ACS. Only gender, gender adjusted age, and ischemic changes on ECG were significantly associated with ACS. The sensitivity of the MHS (cut-off $\leq 2$ ) was $75.0 \%$, specificity $44.0 \%$, positive predictive value $24.3 \%$ and negative predictive value $88.0 \%$. For the FP's assessment (cut-off $\leq 5$ ) these test characteristics were $86.7 \%, 41.4 \%$, $25.2 \%, 93.2 \%$, respectively. When combining a negative result of both MHS and FP's assessment, no ACS would have been missed, while 35 out of 186 (19\%) patients would have been classified as true negative.

Conclusions MHS and FP's clinical assessment individually could not safely rule out ACS in referred patients. The flash mob study design may be considered as a feasible new alternative research method, to investigate relatively simple clinically relevant research questions in family medicine on a large scale in a relatively short timeframe. 


\section{INTRODUCTION}

Chest symptoms can be caused by a life-threatening disorder, such as an acute coronary syndrome (ACS) or self-limiting conditions, such as musculoskeletal and gastro-intestinal conditions, with the latter constituting the majority of cases. $^{1-3}$ The distinction between life-threating and self-limiting conditions is challenging for family practitioners (FPs), due to overlapping signs and symptoms, which are often non-specific, atypical or vague. ${ }^{4-7}$

The Marburg Heart Score (MHS), a clinical decision rule based on five signs and symptoms (Table 9.1), has shown promising results in assisting FPs to identify patients with a low probability of ACS as the underlying cause of chest pain in a primary care population. ${ }^{8-10}$ In contrast to the HEART Score, validated in emergency departments, further diagnostic tests, like an electrocardiogram or cardiac troponin, are not included in MHS. ${ }^{11-13}$ Recently, a large meta-analysis in 3,099 primary care patients with chest pain identified two additional predictors of ACS, that is 'the FPs suspicion of a serious diagnosis' and 'a pain that feels like "pressure"'.14 However, the validity of MHS and these other possible predictors -including the (added) value of the FPs' clinical assessment- to safely rule out ACS in otherwise referred patients is yet unclear. 10,15

Table 9.1 Components of the Marburg Heart Score..$^{8-10}$

\begin{tabular}{ll}
\hline Score component & Assigned points \\
\hline Age/sex (female $\geq 65$ years, male $\geq 55$ years) & 1 \\
Known clinical vascular disease $^{a}$ & 1 \\
Patient assumes cardiac origin of pain $_{\text {Pain worse with exercise }}$ & 1 \\
Pain NOT reproducible by palpation & 1 \\
\hline
\end{tabular}

\footnotetext{
${ }^{a}$ Including coronary heart disease, cerebrovascular disease, or peripheral artery disease.

1 point is assigned to each score variable; 3 different risk categories are derived (low risk $=0-2$ points; intermediate risk $=3$ points; high risk $=4-5$ points).
} 
Assessing the accuracy of clinical decision rules, including FPs' ACS risk estimation, requires large prospective studies in family practice, which are time consuming and costly. Recently, a novel and innovative research method, flash mob research, has been performed in hospital-based studies, allowing the investigation of one simple clinically relevant research question on a large scale in a relatively short timeframe. ${ }^{16,17}$ Flash mob research is based on the concept of flash mobs: 'A large public gathering at which people perform an unusual or seemingly random act and then disperse, typically organized by means of the internet or social media'. ${ }^{18}$ Previous research in hospitals has shown the numerical strength of multiple hospitals and professional and social networks in flash mob research to obtain sufficient data in a short period of time. ${ }^{16,17}$ The geographical widespread organization of family medicine and the relatively low number of relevant patients per FP, is a complicating factor in large scale conventional research that may partially be overcome by this method of data collection. To the best of our knowledge, this flash mob method has never been used in a nationwide study in family medicine.

The primary aim of this prospective study was to externally validate the Marburg Heart Score or to develop an adapted clinical decision rule for FPs to safely rule out ACS in patients referred to secondary care for suspected ACS. Our secondary aim was to evaluate the feasibility of using the flash mob method for large scale, relatively inexpensive and fast research in family medicine.

\section{METHODS}

\section{Study design}

We performed a 2-week nationwide prospective observational flash mob study among FPs. The study was set up by a group of researchers (the steering committee) from several institutions who decided upon the research question and wrote the study protocol, which was approved by the Medical Ethical Committee of Zuyderland Medical Centre (17-N-119) and registered before the start of the study at www.trialregister.nl (NTR6789). 
The flash mob steering committee invited FPs and organizations from their professional and social networks to act as "ambassadors" for the study (Figure 9.1). These ambassadors were asked to actively spread the word and distribute study materials (case report forms and posters) among FPs nationwide. The FP ambassadors consisted of three large groups scattered across the country: 126 specialized FPs who received a special two year training in heart and vascular disease (77) or acute medicine (49, including 31 trainees) and at least one FP per each one of eight vocational training departments of family medicine in the Netherlands. Moreover, there were ten professional organizations supporting this study. All ambassadors as well as the steering committee members used traditional professional networks as well as their social media channels to advertise the study. Furthermore, information about the study was distributed via personal communication, e-mail, social media, scientific journals and our website [www.huisartshartweek.nl]. ${ }^{19,} 20$ Additionally, study materials were sent to the specialized FPs, eight departments of family medicine, over 100 FP out-ofhours services, ambulance services (including emergency control centers) and the case report form was included in a Dutch FP scientific journal distributed to approximately 14,000 professionals.

\section{Setting and participants}

From 20 November until 3 December 2017 -following the Dutch College of General Practitioners Annual Conference were the study was promoted- all FPs in the Netherlands could register patients they referred to secondary care for suspected ACS, using a short one-page case report form, wherein we defined ACS as acute myocardial infarction or unstable angina pectoris. The study was originally planned for one week, which we extended to two weeks to increase the sample size. Patients could be included during practice hours and out-ofhours shifts. The case report form could be filled out either on paper or online (taking $<2$ minutes). We excluded patients who were unable to provide informed consent, were not physically seen by the FP (direct ambulance referral via telephone) or were eventually not referred to hospital. All patients were 
informed about the study by the participating physician and had to provide oral informed consent for the use of their data.

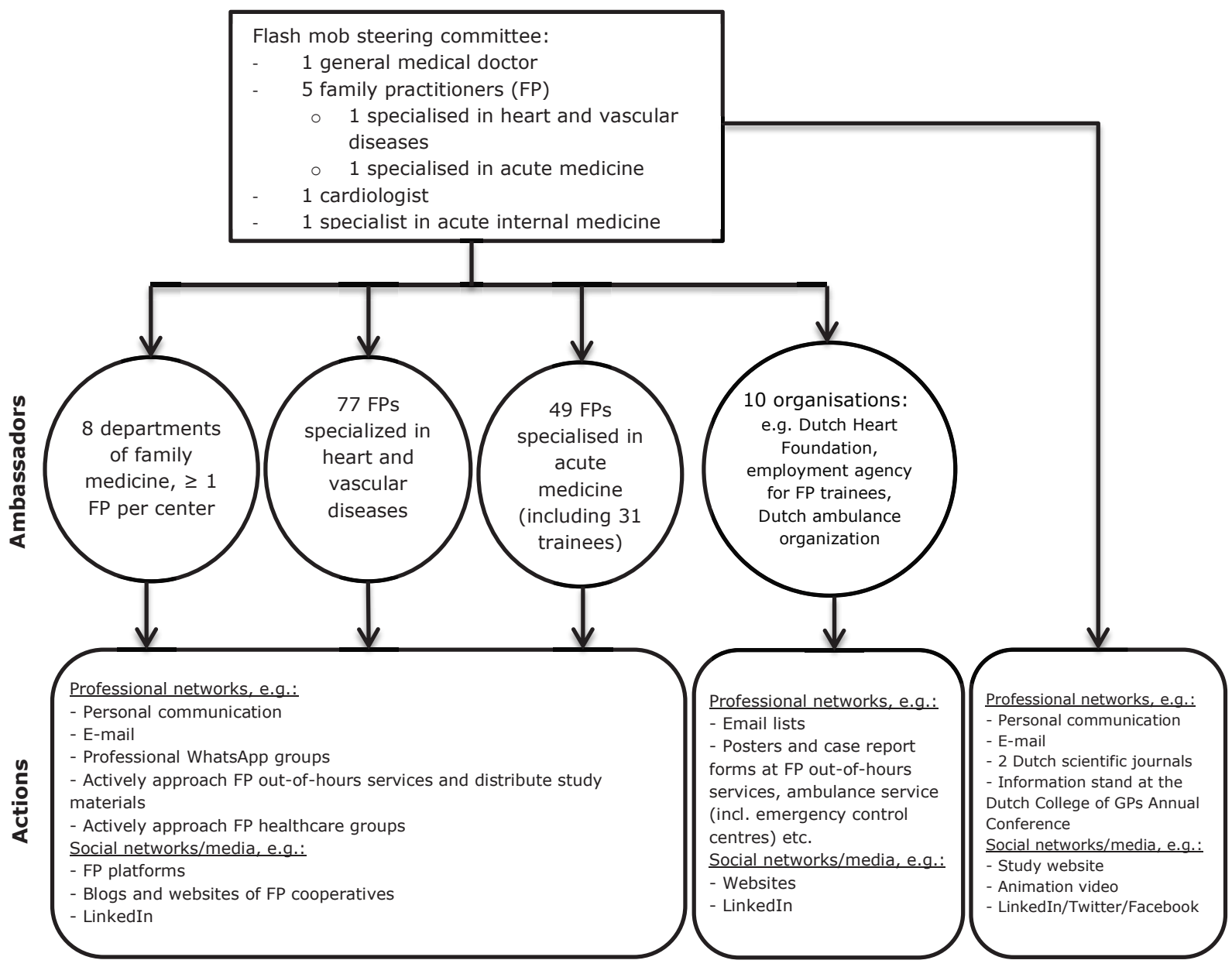

Figure 9.1 Implementation of the flash mob method in current study. 


\section{Case report form}

The case report form consisted of ten consultation items, including MHS items (Table 9.1), the question whether or not the attending FP immediately suspected a serious diagnosis, the pain felt like 'pressure', duration of symptoms, signs of ischemia on ECG if performed, and the attending FP's assessment of ACS probability on a scale of 1-10. Furthermore, we registered the patient's name, gender, date of birth, name of the patient's own FP, whether the attending physician was a FP (if so, years of work experience) or a FP trainee, and the moment the patient was seen (daytime/out-of-hours and date). FPs were not asked to calculate the MHS score.

\section{Reference standard}

The final diagnosis was obtained by contacting all FPs of included patients -via post, followed by at least two telephone reminders and a fax in cases of nonresponse- six weeks or later after the initial consultation. We asked FPs to select the most probable final diagnosis from a short option list -ACS, stable angina, other cardiac diagnosis or non-cardiac diagnosis- and to base their answer on the discharge letter from the cardiologist.

\section{Statistical analysis}

We performed an univariate analysis to detect possible ACS predictors. The odds of having ACS were compared between patients with and without each possible predictor by calculating the odds ratios with $95 \%$ confidence intervals (CI) for each item. Gender adjusted age was defined as age $\geq 65$ years for females and $\geq 55$ for males, as in the original MHS score.

MHS and the FP'S assessment of ACS probability were dichotomized into a positive (high risk) and negative (low risk) result, with a cut-off value of $\leq 2$ for MHS and $\leq 5$ for FP's assessment. For MHS, we performed extra analyses using a cut-off value of $\leq 1$. For each strategy the sensitivity, specificity, positive 
predictive value (PPV) and negative predictive value (NPV) were calculated with corresponding $95 \%$ CIs, according to the efficient-score method (corrected for continuity). ${ }^{21,22}$

The diagnostic ability of MHS and the FP's assessment to discriminate between patients with and without ACS was assessed by plotting the sensitivity against the 1-specificity in a receiver operating characteristic (ROC) curve for both strategies and by calculating the area under the curve (AUC).

We performed sensitivity analyses for cases with missing MHS items, and imputated a 0 -score for missing MHS items in patients with chest pain, assuming these missing items would have led to a negative score on that specific item. Statistical analyses were performed using IBM SPSS Statistic Data Editor Version 23 and the following website: http://vassarstats.net/clin1.html.

\section{RESULTS}

\section{Patients registered via flash mob}

FPs (including FP trainees) registered 258 patients $-113(43.8 \%)$ online and 145 (56.2\%) on paper- deriving from all provinces in the Netherlands. Of these, 203 (78.7\%) were included by a FP (median work experience 8.0 years (IQR 3.0$18.3)$ ) and $55(21.3 \%)$ by a FP trainee. One-hundred-and-eighty-two $(70.5 \%)$ patients were registered during office hours. Figure 9.2 shows patient inclusion and follow-up. A final diagnosis was obtained in 243 out of 258 patients $(94.2 \%)$. MHS scores could be determined in 186 patients. 


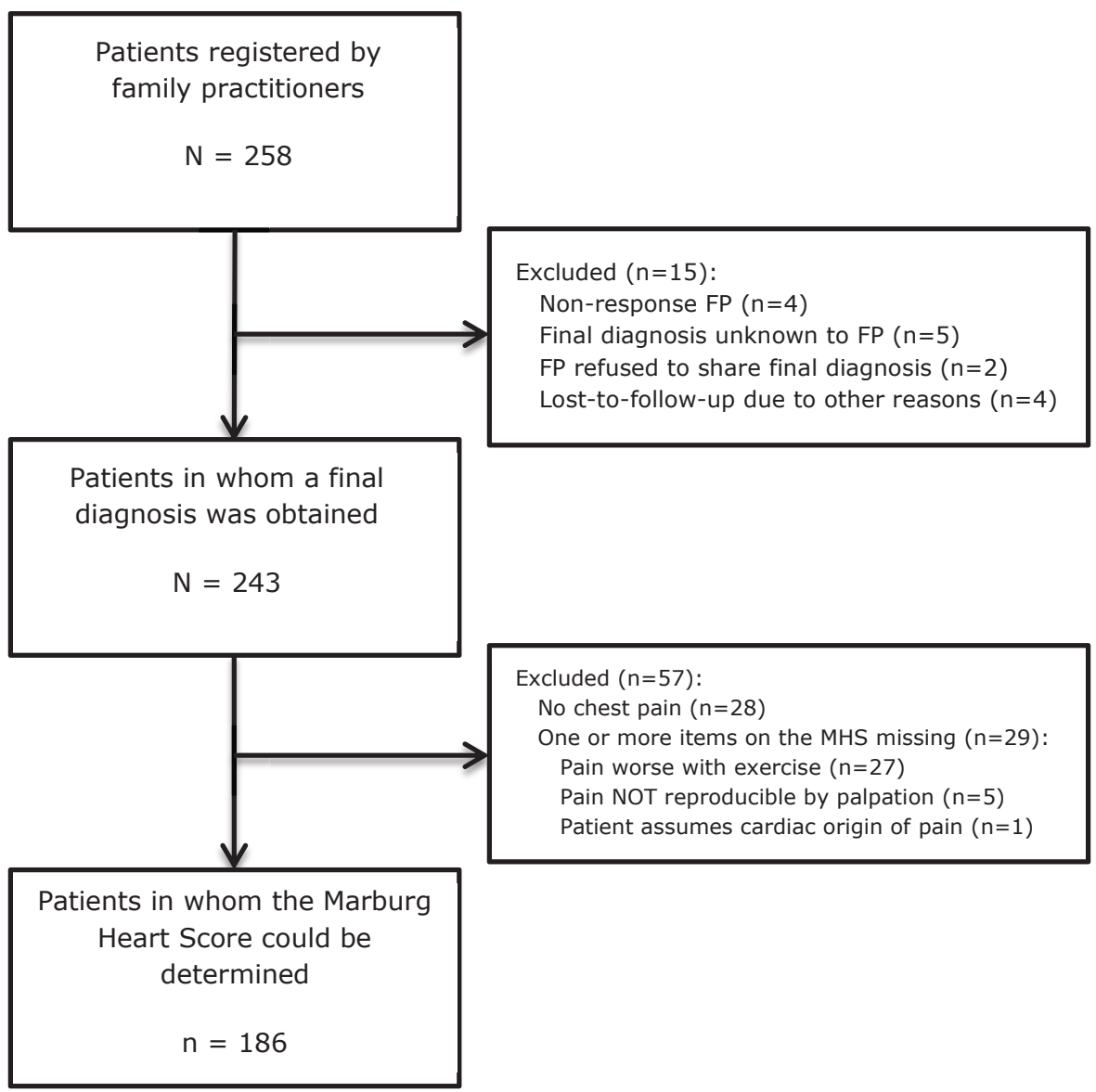

Figure 9.2 Patient inclusion and follow-up.

Final diagnosis and univariate analyses of possible ACS predictors $(n=243)$

Of the 243 patients with a final diagnosis, 45 (18.5\%) patients were diagnosed with ACS, of whom $34(77.3 \%)$ had a myocardial infarction, $10(22.7 \%)$ unstable angina, and in one patient ACS was confirmed but not further specified. Stable angina was diagnosed in $11(4.5 \%)$ patients, another cardiac diagnosis in $40(16.5 \%)$ patients, and a non-cardiac diagnosis in $153(63.0 \%)$ patients. Table 9.2 shows the patients characteristics and investigated predictors. 
Only three possible predictors - gender, gender adjusted age, and ischemic changes on ECG - were significantly associated with ACS in the univariate analysis (Table 9.2). The possible predictors 'FP immediately suspected a serious condition' and 'pain feels like pressure' showed no significant association with ACS.

\section{FP's assessment of ACS probability $(n=243)$}

According to FP's assessment, 88 out of 243 (36.2\%) patients were at low risk of ACS $(\leq 5)$ and $155(63.8 \%)$ at high risk $(>5)$. Table $9.3 \mathrm{c}$ shows the test characteristics of the FP's assessment. Six (2.5\%) patients would have been falsely classified as not having an ACS when using the FP's assessment with a cut-off of $>5$. The AUC for the FP's assessment was 0.72 (95\%CI 0.63-0.81).

\section{Marburg Heart Score $(n=186)$}

Of all 186 patients for whom MHS could be calculated, 75 (40.3\%) patients were at low risk of ACS (MHS 0-2) and 111 (59.7\%) at intermediate-high risk (MHS 3-5). The ACS incidence in the MHS-group was 19.4\%. Table 9.3 shows the test characteristics of MHS using a cut-off value of $\leq 2$ (Table 9.3a) and $\leq 1$ (Table 9.3b). Nine (4.8\%) patients would have been falsely classified as not having an ACS when using MHS with a cut-off of $\leq 2$. When using MHS with a cut-off value of $\leq 1,2(1.1 \%)$ patients would have been missed and 24 (12.9\%) patients would have been classified as true negative. The AUC for MHS was 0.64 (95\%CI $0.54-0.74)$ and $0.71(95 \% \mathrm{CI} 0.61-0.80)$ for $\mathrm{FP}^{\prime} \mathrm{s}$ assessment in the group wherein the MHS could be determined (Figure 9.3). 


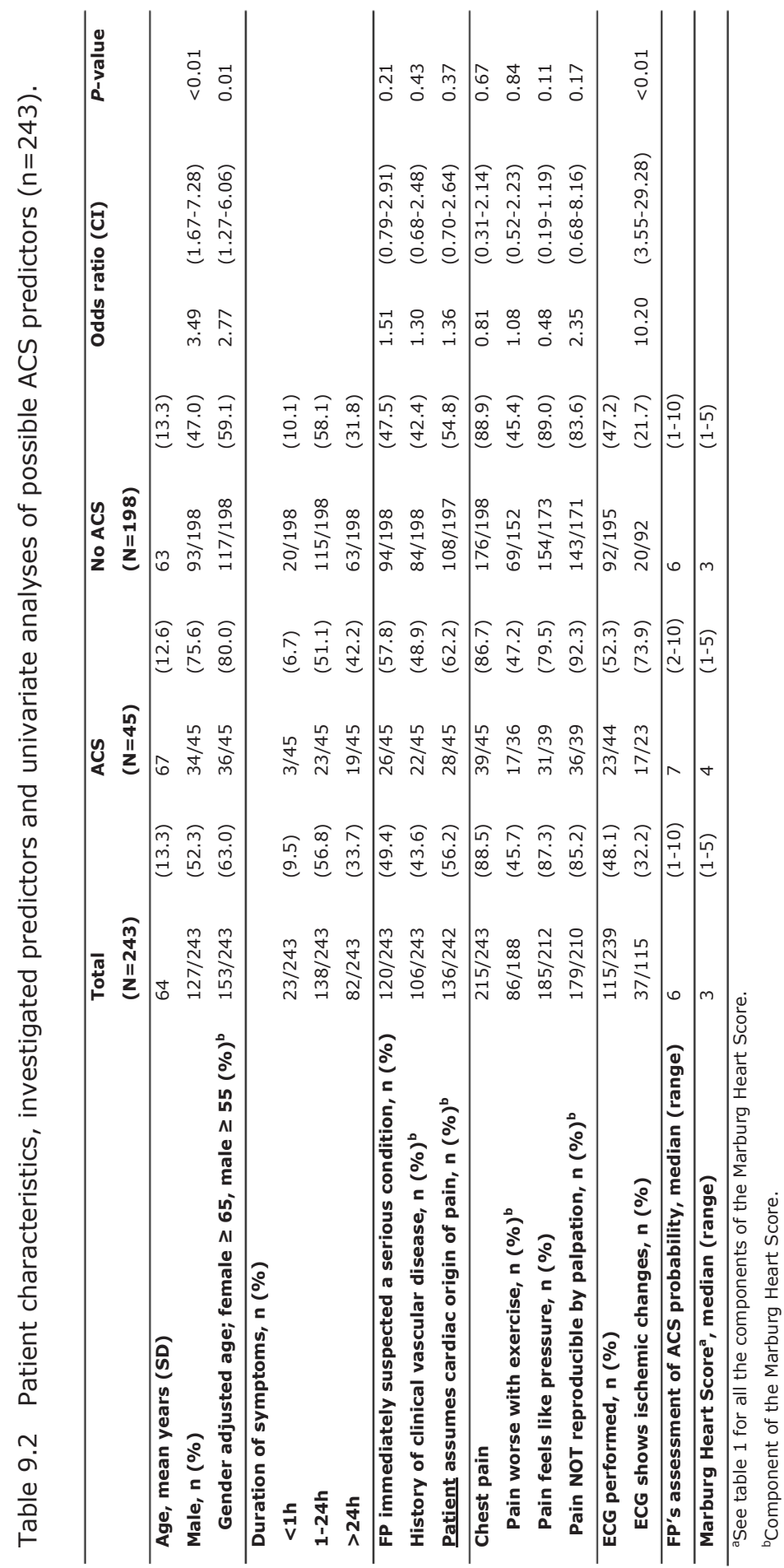


Table 9.3 Test characteristics of the Marburg Heart Score (MHS) and the FP'S assessment.

a) MHS, using a cut-off value of $\leq 2$.

\begin{tabular}{llll}
\hline & ACS & No ACS & Total \\
\hline MHS >2 & 27 & 84 & 111 \\
MHS $\leq \mathbf{2}$ & 9 & 66 & 75 \\
\hline Total & 36 & 150 & 186 \\
\hline Sensitivity: $75.0 \%(95 \%$ CI 57.5-87.3) & Incidence ACS: $19.4 \%(95 \%$ CI 14.1-25.9) \\
Specificity: $44.0 \%(95 \%$ CI 36.0-52.3) & Incidence no ACS: 80.6\% (95\% CI 74.1-85.9) \\
Positive predictive value: $24.3 \%(95 \%$ CI $16.9-33.6)$ & Odds Ratio: 2.36 (95\% CI 1.04-5.35) \\
Negative predictive value: $88.0 \%(95 \%$ CI 78.0-94.0) & Chi-square: 0.04 & \\
\hline
\end{tabular}

b) MHS, using a cut-off value of $\leq 1$.

\begin{tabular}{llll}
\hline & ACS & No ACS & Total \\
\hline MHS $>\mathbf{1}$ & 34 & 126 & 160 \\
MHS $\leq \mathbf{1}$ & 2 & 24 & 26 \\
\hline Total & 36 & 150 & 186 \\
\hline Sensitivity: $94.4 \%(95 \%$ CI $80.0-99.0)$ & Incidence ACS: $19.4 \%(95 \%$ CI 14.1-25.9) \\
Specificity: $16.0 \%(95 \%$ CI 10.7-23.1) & Incidence no ACS: $80.6 \%(95 \%$ CI 74.1-85.9) \\
Positive predictive value: $21.3 \%(95 \%$ CI 15.4-28.6) & Odds Ratio: 3.24 (95\% CI 0.73-14.39) \\
Negative predictive value: $92.3 \%(95 \%$ CI 73.4-98.7) & Chi-square: 0.11 & \\
\hline
\end{tabular}

c) FP's probability assessment, using a cut-off value of $\leq 5$.

\begin{tabular}{llll}
\hline & ACS & No ACS & Total \\
\hline FP's probability assessment high (>5) & 39 & 116 & 155 \\
FP's probability assessment low $(\mathbf{5})$ & 6 & 82 & 88 \\
\hline Total & 45 & 198 & 243 \\
\hline Sensitivity: $86.7 \%(95 \%$ CI 72.5-94.5) & Incidence ACS: $18.5 \%(95 \%$ CI 14.0-24.1) \\
Specificity: 41.4\% (95\% CI 34.5-48.6) & Incidence no ACS: 81.5\% (95\% CI 75.9-86.0) \\
Positive predictive value: $25.2 \%(95 \%$ CI 18.7-32.9) & Odds Ratio: 4.60 (95\% CI 1.86-11.36) \\
Negative predictive value: $93.2 \%(95 \%$ CI 85.2-97.2) & Chi-square: $<0.01$ & \\
\hline
\end{tabular}


d) Combined approach using the MHS and the FP's assessment of probability.

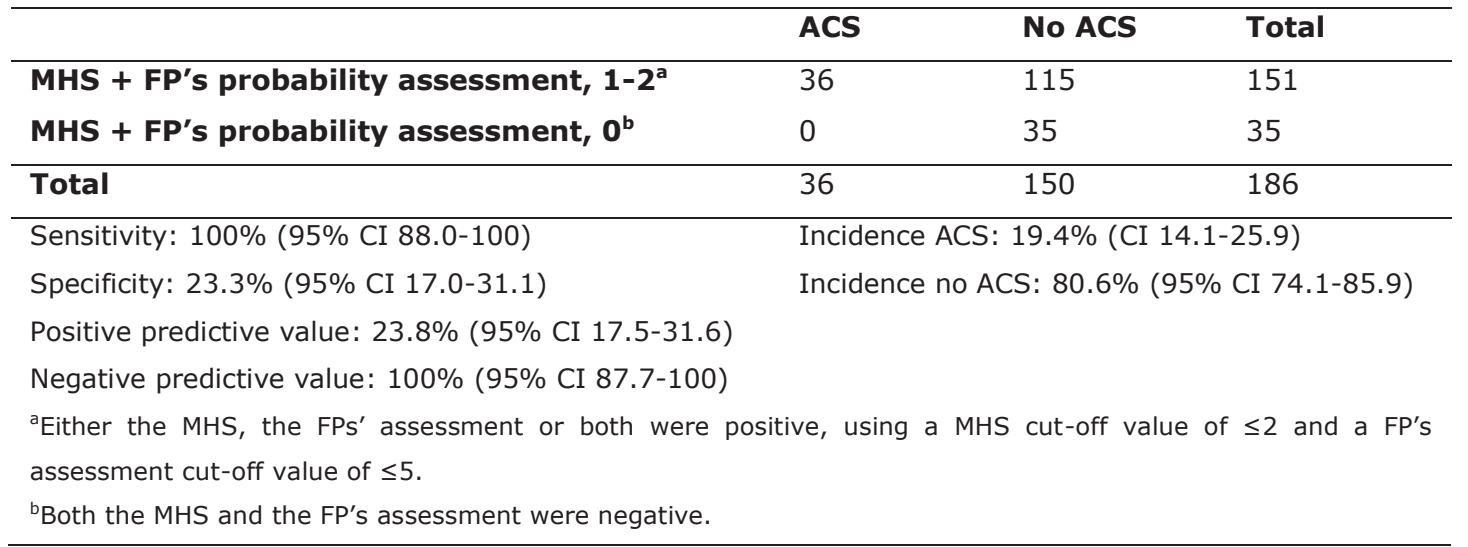

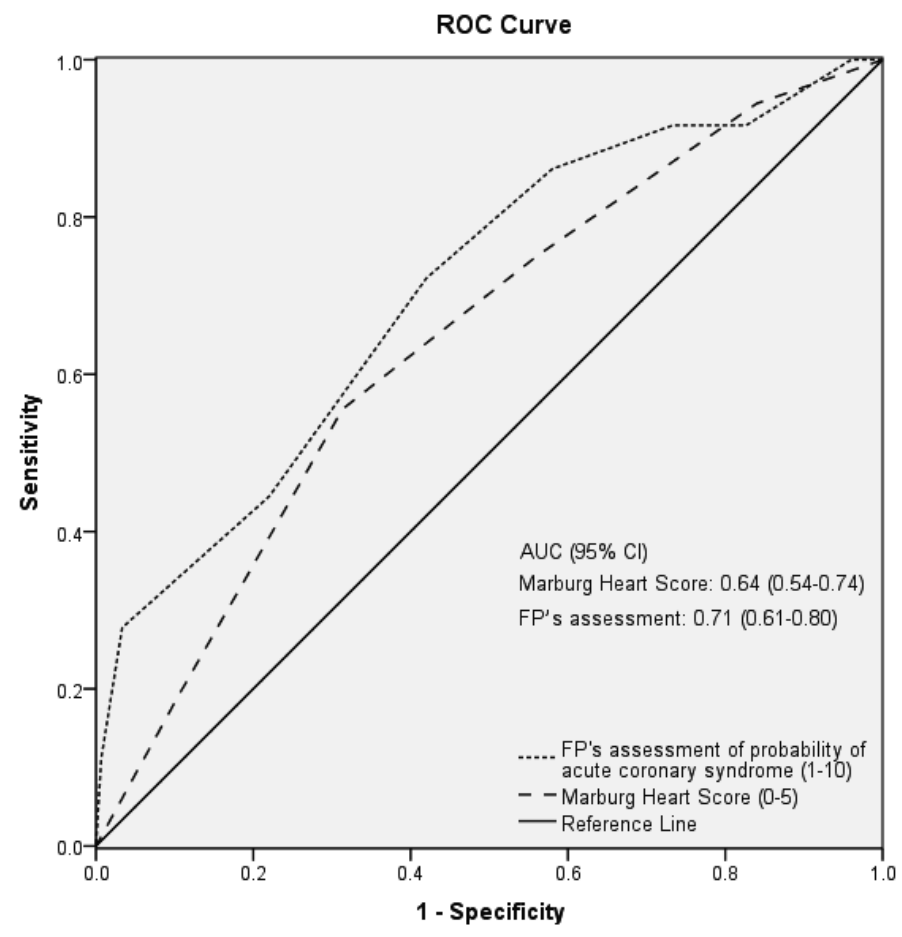

Figure 9.3 ROC curves for the FP's assessment of ACS probability and the Marburg Heart Score in patients referred for suspected acute coronary syndrome $(n=186)$. 


\section{Sensitivity analyses MHS ( $\mathbf{n = 2 1 5 )}$}

The sensitivity analysis showed a slightly higher sensitivity (76.9\%), specificity (44.9\%) and NPV (89.8\%) of MHS for ACS using a cut-off $\leq 2$. The PPV was $23.6 \%$. The sensitivity analysis of the MHS using a cut-off $\leq 1$ showed a sensitivity of $94.9 \%$, specificity of $17.0 \%$, PPV of $20.2 \%$ and NPV of $93.8 \%$ for ACS.

\section{Ancillary scenario analysis}

In a strategy wherein both MHS and FP's assessment were negative, no patient would have been missed, while 35 out of 186 (19\%) patients would have been classified as true negative (Table 9.3d).

\section{DISCUSSION}

\section{Summary}

In this prospective 2-week $24 / 7$ flash mob study, FPs in the Netherlands registered 258 patients. The incidence of ACS, in the 243 (94\%) patients with a known final diagnosis, was $18.5 \%$. MHS (cut-off $\leq 2$ ) and FP's assessment of ACS probability individually showed an insufficient diagnostic accuracy to safely rule out ACS in patients referred to secondary care for suspected ACS. We were unable to construct a more accurate adapted clinical decision rule from the available possible predictors of ACS.

\section{Strengths and limitations}

This is, to the best of our knowledge, the first nationwide flash mob study in family medicine, which made it possible to collect data on 258 patients in only two weeks. Included patients were registered by many different FPs who did not receive additional instructions or training, thus resembling daily practice. All 
patients were immediately referred to and assessed in secondary care, after receiving standard diagnostic work-up according to current clinical practice. Although MHS scores could only be determined in 186 patients due to missing items, sensitivity analyses showed only minor differences in test characteristics after imputating a 0-score for missing MHS items.

For diagnostic research though, 258 patients is still a limited number, which has led to relatively wide confidence intervals. As in many ACS studies, some selection bias may have occurred, since it is possible that very ill patients may not have been included in the study. However, in these severe cases the use of a clinical decision rule would not be advised. FP's assessment of ACS probability was registered at the end of the case report form and may therefore have been slightly biased by the preceding items. Although ischemic changes on ECG were significantly associated with ACS, we should note this result was influenced by incorporation bias, because ECG abnormalities are part of establishing an ACS diagnosis in secondary care (reference standard).

\section{Comparison with existing literature}

In contrast to previous studies on MHS, we found an insufficient diagnostic accuracy of MHS to safely rule out ACS at a cut-off value of $\leq 2$ (NPV of $88.0 \%$ compared to $97.7-98.1 \%$ in previous studies). ${ }^{8-10}$ This difference may be explained by spectrum bias, because the current study was performed in a referred population with a higher incidence of ACS (19.4\%) compared to previous MHS studies (3.7\% and 2.5\%). ${ }^{8-10,} 23$ Moreover, in these previous studies a lower risk population was represented, since patients with stable coronary artery disease were mixed with patients with unstable presentations of chest pain. The influence of selecting only referred patients and referral patterns on test characteristics is well described in the literature, also in patients with chest pain. ${ }^{24,25}$ This explanation is in line with our finding that MHS could accurately rule out ACS in the subgroup that was estimated at low risk according to the FP and is comparable with the finding of a previous study in a primary care population with a comparable ACS incidence of $22 \%$. This study also found 
that a clinical decision rule could be used to safely rule out ACS in patients considered to be at low risk according to the FP's assessment. ${ }^{15}$ The overall AUC we found for the FP's assessment was also in line with this study, that showed an AUC for the FP's risk estimation of 0.75 (95\%CI $0.68-0.82$ ) compared to 0.72 (95\%CI $0.63-0.81$ ) in our study. ${ }^{15}$

\section{Implications for research and clinical practice}

First, this study served as a proof-of-concept for large scale clinical diagnostic research among FPs within a short time frame, the flash mob method. With this study we showed that flash mob research in family medicine is feasible. We were able to involve and motivate many organizations and FPs, and to collect data on 258 patients in only two weeks, by mobilizing FPs throughout the country via ambassadors (FPs and organizations) who used their professional networks and social media strategies. However, the number of included patients was lower than we expected at the start of the study, as in those two weeks an estimated 2,700 patients would have had an acute myocardial infarction, based on national figures [https://www.nivel.nl/nl/NZR/incidenties-en-prevalenties]. Nonetheless, considering that many patients with chest symptoms are directly referred via ambulance or 911 calls, hence without consulting a FP, many of these patients would not have been eligible for inclusion. Moreover, previous studies on signs and symptoms and clinical decision rules in similar populations (including nonreferred patients, so allowing a larger group eligible for recruitment) showed inclusion rates of less than 30 to 40 patients per week. ${ }^{8-10,26-28}$

Although we consider flash mob research in family medicine feasible, it should be noted that the flash mob method is not suitable for all diagnostic research in family medicine. It should only be used if: (a) the research question can be answered with a small dataset per patient, (b) the research question is relatively simple and considered to be relevant and urgent by FPs, (c) the patient selection and data collection are sufficiently robust and self-explanatory, so that hardly any instructions are necessary, (d) the flash mob study can be performed in a large region to include patients among a large number of FPs. 
Second, this study shows that MHS and FP's assessment individually have an insufficient diagnostic accuracy to safely rule out ACS in referred patients, as the goal is to not miss any patients with ACS, while still reducing the number of referrals. However, this study also shows that when combining the results of MHS and FP's assessment, the number of referrals may safely be reduced by $19 \%$, when applying MHS only in referred patients who are considered to be at low risk of having an ACS by the FP's assessment. Yet, such a strategy meets practical limitations. FPs would have to apply this strategy after they made the decision to refer, which means that FPs should incidentally correct their decision to refer. Preferably, we would like to apply a clinical decision rule in all primary care patients suspected of ACS, even in low risk patients. Therefore, the suggested strategy should be validated in a sufficiently large cohort including both referred and non-referred patients suspected of ACS. An important question in such future studies would be the false positivity rate of the strategy, as applying this strategy also to initially non-referred patients, may lead to more referrals to secondary care again, due to false positives among initially nonreferred patients.

\section{CONCLUSION}

MHS and FP's clinical assessment individually showed an insufficient diagnostic accuracy to safely rule out ACS in referred patients and we were unable to construct a more accurate clinical decision rule from the available possible predictors of ACS.

In this study we showed that flash mob research is feasible in family medicine. Therefore, the flash mob study design may be considered as a new alternative research method, for specific studies, to investigate relatively simple clinically relevant research questions in family medicine on a large scale in a relatively short timeframe. 


\section{REFERENCES}

1. Bosner S, Becker A, Haasenritter J, et al. Chest pain in primary care: epidemiology and pre-work-up probabilities. Eur J Gen Pract. 2009;15:141-6.

2. Verdon $F$, Herzig $L$, Burnand $B$, et al. Chest pain in daily practice: occurrence, causes and management. Swiss Med Wkly. 2008;138:340-7.

3. Hoorweg BBN, Willemsen RT, Cleef LE, et al. Frequency of chest pain in primary care, diagnostic tests performed and final diagnoses. Heart. 2017;103:1727-32.

4. Bruyninckx R, Aertgeerts B, Bruyninckx P, Buntinx F. Signs and symptoms in diagnosing acute myocardial infarction and acute coronary syndrome: a diagnostic meta-analysis. Br J Gen Pract. 2008;58:105-11.

5. Body R, Carley S, Wibberley C, McDowell G, Ferguson J, Mackway-Jones K. The value of symptoms and signs in the emergent diagnosis of acute coronary syndromes. Resuscitation. 2010;81:281-6.

6. Schols AM, van Boekholt TA, Oversier LM, Dinant GJ, Cals JW. General practitioners' experiences with out-of-hours cardiorespiratory consultations: a qualitative study. BMJ Open. 2016;6:e012136.

7. Swap CJ, Nagurney JT. Value and limitations of chest pain history in the evaluation of patients with suspected acute coronary syndromes. JAMA. 2005;294:2623-9.

8. Bosner S, Haasenritter J, Becker A, et al. Ruling out coronary artery disease in primary care: development and validation of a simple prediction rule. CMAJ. 2010;182:1295-300.

9. Haasenritter J, Bosner S, Vaucher $\mathrm{P}$, et al. Ruling out coronary heart disease in primary care: external validation of a clinical prediction rule. $\mathrm{Br} J$ Gen Pract. 2012;62:e415-21.

10. Haasenritter J, Donner-Banzhoff N, Bosner S. Chest pain for coronary heart disease in general practice: clinical judgement and a clinical decision rule. $\mathrm{Br} J$ Gen Pract. 2015;65:e748-53.

11. Backus BE, Six AJ, Kelder JC, et al. Chest pain in the emergency room: a multicenter validation of the HEART Score. Crit Pathw Cardiol. 2010;9:164-9.

12. Backus BE, Six AJ, Kelder JC, et al. A prospective validation of the HEART score for chest pain patients at the emergency department. Int J Cardiol. 2013;168:2153-8.

13. Six $A J$, Cullen $L$, Backus BE, et al. The HEART score for the assessment of patients with chest pain in the emergency department: a multinational validation study. Crit Pathw Cardiol. 2013;12:121-6.

14. Aerts $M$, Minalu G, Bosner $S$, et al. Pooled individual patient data from five countries were used to derive a clinical prediction rule for coronary artery disease in primary care. J Clin Epidemiol. 2017;81:120-8. 
15. Bruins Slot MH, Rutten FH, van der Heijden GJ, Geersing GJ, Glatz JF, Hoes AW. Diagnosing acute coronary syndrome in primary care: comparison of the physicians' risk estimation and a clinical decision rule. Fam Pract. 2011;28:323-8.

16. Semler MW, Stover DG, Copland AP, et al. Flash mob research: a single-day, multicenter, resident-directed study of respiratory rate. Chest. 2013;143:1740-4.

17. Alsma J, van Saase J, Nanayakkara PWB, et al. The Power of Flash Mob Research: Conducting a Nationwide Observational Clinical Study on Capillary Refill Time in a Single Day. Chest. 2017;151:1106-13.

18. Oxford Dictionaries [Internet]. Flash mob. [cited 2018 May 3]. Available from: https://en.oxforddictionaries.com/definition/flash_mob.

19. Schols AMR, Cals JWL. [Flash mob research on decision rule for acute coronary syndrome]. Ned Tijdschr Geneeskd. 2017;161:D2280.

20. Schols A, Cals ]. [New: flash mob research Family Practitioner Heart Week]. Huisarts en wetenschap. 2017;60:603.

21. Newcombe RG. Two-sided confidence intervals for the single proportion: comparison of seven methods. Stat Med. 1998;17:857-72.

22. Wilson EB. Probable Inference, the Law of Succession, and Statistical Inference. Journal of the American Statistical Association. 1927;22:209-12.

23. Willis $\mathrm{BH}$. Spectrum bias--why clinicians need to be cautious when applying diagnostic test studies. Fam Pract. 2008;25:390-6.

24. Knottnerus $J A$, Leffers $P$. The influence of referral patterns on the characteristics of diagnostic tests. J Clin Epidemiol. 1992;45:1143-54.

25. Knottnerus JA. The effects of disease verification and referral on the relationship between symptoms and diseases. Med Decis Making. 1987;7:139-48.

26. Buntinx F, Truyen J, Embrechts P, Moreel G, Peeters R. Evaluating patients with chest pain using classification and regression trees. Fam Pract. 1992;9:149-53.

27. Nilsson $S$, Scheike M, Engblom $D$, et al. Chest pain and ischaemic heart disease in primary care. Br J Gen Pract. 2003;53:378-82.

28. Bosner S, Becker A, Abu Hani M, et al. Accuracy of symptoms and signs for coronary heart disease assessed in primary care. Br J Gen Pract. 2010;60:e246-57. 



\section{Chapter 10}

General Discussion

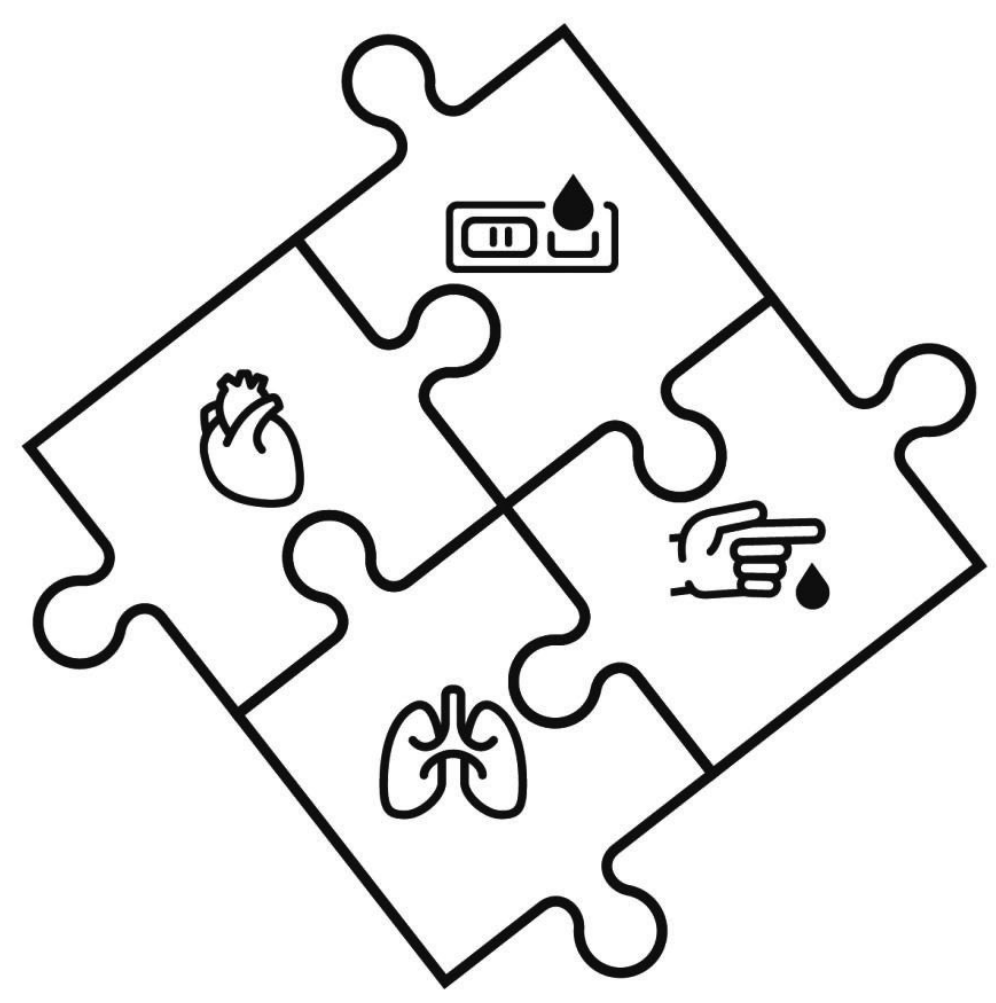





\section{GENERAL DISCUSSION}

The general aim of this thesis is to assess the current state of point-of-care tests (POCTs) in general practice. After evaluating the current use, wishes of and attitudes towards POCTs, we increasingly shifted the focus to diagnostics at the point-of-care in patients presenting with acute cardiopulmonary symptoms.

In this chapter we first discuss the main findings and their implications. We evaluate diagnostics at the point-of-care in general and more specifically in patients with acute cardiopulmonary symptoms, within existing clinical pathways. Hereafter, we discuss recruitment challenges in primary care research, wherein we focus on a novel and innovative study design (flash mob research).

\section{Point-of-care tests and diagnostics at the point-of-care}

We should first define what a POCT in general practice is. Chapter 4 summarizes the results of an international Delphi study we performed among expert panel members from various professional backgrounds, to develop an internationally and multidisciplinary supported definition. This led to the following definition:

'a POCT in family practice is a test to support clinical decision making, which is performed by a qualified member of the practice staff nearby the patient and on any part of the patient's body or its derivatives, during or very close to the time of consultation, to help the patient and physician to decide upon the best suited approach, and of which the results should be known at the time of the clinical decision making.'

Although this definition is clear as to which tests should be considered a POCT, it is important to note that the process of point-of-care testing entails a broader multidisciplinary concept, in which all elements of the chain - including indication, execution, interpretation, documentation and follow-up - need to be taken into account. ${ }^{1,2}$ 
While analysing this multidisciplinary definition of a POCT, it becomes clear that many tests performed in general practice can be considered a POCT, as long as the test is performed at the office and on the patient's body or its specimens. Examples of frequently performed POCTs in general practice include: temperature and blood pressure measurement, oxygen saturation measurement, urine dipstick and electrocardiography (ECG). With these ancillary diagnostic tests, the results are known at the time of making a clinical decision and results can therefore support the general practitioner (GP) during consultations. These elements are considered crucial by the international panel developing the definition.

As this multidisciplinary definition of a POCT encompasses so many tests, it is relevant to clearly define if only a specific subset of POCTs are discussed or investigated. In the chapters specifically adressing POCTs, we focussed on laboratory POCTs. In the other chapters we also focus on other diagnostics at the point-of-care, including ECG, ultrasonography (Chapter 2) and a clinical decision rule (Chapter 9). We chose to use the phrase 'diagnostics at the pointof-care' to also include clinical decision rules. These rules often only consist of items from the medical history or physical examination and therefore cannot be considered a POCT, but still assist clinical decision-making at the point-of-care. Therefore, in this thesis, including its title, we sometimes refer to diagnostics at the point-of-care instead of POCTs.

\section{Diagnostics at the point-of-care: access, wishes and attitudes}

During office hours, GPs in the Netherlands typically have access to most medical imaging, laboratory tests and a variety of POCTs without referral to secondary care, often with an option to receive test results within a few hours. ${ }^{3}$ It is advised by their profession that GPs have sufficient access to diagnostic facilities, not only during office hours, but also during out-of-hours care. ${ }^{4}$ However, in chapter 2 we show that GPs have limited and varying access to diagnostics during GP out-of-hours shifts, e.g. in 2014 ECG was only available in $26 \%$ of all services, regular laboratory blood tests in $37 \%$ and a D-dimer POCT 
in $21 \%$ of all services. GPs express a desire for more access to POCTs during GP out-of-hours care, with a precentage as high as $92 \%$ wanting access to a Ddimer POCT (Chapter 3). Currently, not all GPs are able to adhere to all Dutch GP guidelines during out-of-hours care, because of a lack of availability of diagnostics. For example, D-dimer testing is incorporated in the diagnostic algorithm for deep vein thrombosis and ECG in the algorithm for atrial fibrillation. ${ }^{5-7}$

In chapter 3, we show that Dutch GPs use a limited number of POCTs during office hours, but wish to have more POCTs available for acute thromboembolic diseases (D-dimer) and heart conditions (troponin, B-type natriuretic peptide). Given that GPs consider cardiopulmonary consultations as challenging and relate them with diagnostic uncertainty leading to defensive behaviour, including a lower threshold for performing diagnostics (Chapter 5), this desire seems logical. ${ }^{8-10}$ The desire for these specific POCTs, is fairly comparable to other countries, such as Belgium, the UK, USA, Australia and Ireland. Although some variations across these countries exist, POCTs for D-dimer, troponin and Chlamydia are highly desired in all countries (ranging from 41 to $85 \%$ of GPS wanting to use a POCT). Overall, the UK and USA report the highest actual and desired use for POCTs. ${ }^{11,12}$ In the UK, POCTs for acute thromboembolic diseases and acute cardiac diseases are considered most helpful in reducing the number of referrals. ${ }^{13}$

Although additional diagnostics may assist GPs in these consultations, increased availability of diagnostics is also a cause for concern. ${ }^{14-17}$ Dutch GPs consider the proven effect of a POCT on the immediate decision-making in general practice and the reliability of the POCT as the two most important aspects of POCTS (Chapter 3). Therefore, it is crucial to first perform a thorough evaluation of these desired POCTs before considering implementation in daily practice. 


\section{DIAGNOSTICS AT THE POINT-OF-CARE WITHIN EXISTING CLINICAL PATHWAYS}

\section{Research on new POCTs}

In chapter 8 , we discuss the results of a recent systematic review, wherein all 40 diagnostic Horizon Scan reports on POCTs of recent years have been analysed. The review shows that most POCTs are investigated for clinical performance (71\%), while only $18 \%$ of all studies evaluated clinical effectiveness of a POCT. ${ }^{18}$ Given the fast growing number of POCTs, there is a need for more research on POCT use. Yet, in the few cases wherein a Horizon Scan report did include evidence of all evaluation components, the median time to completion of the evaluation cycle was nine years. ${ }^{18}$

\section{Research on GP use of POCTs in acute cardiopulmonary symptoms}

With regard to POCTs in primary care patients with acute cardiopulmonary symptoms, the systematic review in this thesis (chapter 6) shows that there is limited and inconclusive evidence that GP use of POCTs in these patients leads to more accurate diagnoses and affects clinical management. By 2016, only seven prospective studies evaluated the effect of GP use of a POCT - D-dimer, troponin, heart-type fatty acid-binding protein (H-FABP) and B-type natriuretic peptide (BNP) - on clinical diagnostic accuracy. Only two of these also evaluated outcomes with regard to clinical management. One study concluded that a troponin POCT may reduce emergency referrals, but probably at the expense of missed cases. ${ }^{19}$ The other study showed that the use of a BNP POCT may significantly reduce the time to initiation of appropriate treatment. ${ }^{20}$ Both studies reported additional outcomes that went beyond the scope of the review. The former study concluded that a troponin POCT may be cost saving, but again noted that this was at the expense of missed cases. ${ }^{21}$ The latter study showed no difference in the number of hospitalizations, functional status and total 
medical costs at three months between the groups with or without the use of a BNP POCT. ${ }^{20}$

The clinical performance of POCTs in primary care patients with acute cardiopulmonary symptoms is yet unclear. However, several studies show promising results, especially when a POCT is combined with a clinical decision rule, e.g. when GP use of a D-dimer POCT is combined with the Wells clinical decision rule. ${ }^{22,23}$ However, a frequently used D-dimer POCT was recently taken off the market, due to doubts about its reliability. Around 2017, a new general practice study, the EVA study, was started in collaboration with laboratories to investigate the safety and analytical and clinical performance of available Ddimer POCTs for general practice. ${ }^{24}$ Next to the H-FABP study included in the review, recently another, as of yet unpublished primary care study by our department, showed an insufficient diagnostic accuracy to safely rule out acute coronary syndrome (ACS), using a lower cut-off value than the previous study (4 ng/ml compared to $7 \mathrm{ng} / \mathrm{ml}$ ). ${ }^{25,} 26$ Therefore, we may state that the H-FABP POCT has an insufficient clinical performance to safely rule out ACS as a standalone test in general practice.

Research with regard to the cost-effectiveness of laboratory POCTs in primary care patients with acute cardiopulmonary symptoms is also limited. Next to the previously discussed two studies reporting cost outcomes, ${ }^{20,} 21$ recently, two early health technology assessments calculated the possible cost effects of either a future clinical decision rule incorporating a cardiac POCT or a clinical algorithm integrating a troponin POCT in low risk patients with at least $4 \mathrm{~h}$ symptoms. ${ }^{27,28}$ The former study estimated a necessary reduction of at least $29 \%$ in false positives for the addition of a POCT as part of a clinical decision rule to become cost-saving. ${ }^{27}$ The latter study concluded that the troponin POCT strategy is likely cost-saving, due to a reduction of referral rates in non-ACS patients from $38.5 \%$ to $31.9 \%$. This strategy leads to a small increase in nonreferrals among ACS patients from $0.22 \%$ to $0.27 \%$, but the overall health effects were estimated to be negligible. ${ }^{28}$ With regard to replacement of the laboratory D-dimer test by a D-dimer POCT, two studies have estimated that this strategy will be cost-effective in patients suspected of deep vein 
thrombosis. 29,30 However, theoretical models cannot calculate in all factors influencing cost-effectiveness, such as behavioural factors. ${ }^{31}$ Therefore, if in the future a troponin POCT was to become available with a sufficiently high diagnostic accuracy to safely rule out ACS in general practice patients or the Ddimer POCT was to be widely implemented in practice, prospective studies are still needed to confirm the cost-effectiveness of these POCTs.

\section{Potential purpose of cardiopulmonary diagnostics at the point-of-care}

As discussed in the general introduction (chapter 1), it is important to start the test evaluation process with defining the test's potential purpose and role. ${ }^{32,33}$ At the level of the test, a diagnostic test or strategy in patients with acute cardiopulmonary symptoms may have three evident potential purposes, that is (i) to reduce missed cases of potentially life-threatening illnesses such as ACS or pulmonary embolism (PE), (ii) to safely rule out potentially life-threatening illnesses (so ruling out without missing extra cases), (iii) to confirm a diagnosis. However, these purposes do not go beyond the clinical performance of a test. From the perspective of the test within the clinical pathway, sometimes also referred to as the test-treatment pathway, the ultimate purpose of a test is to have an influence on health related outcomes or an even broader impact. ${ }^{32,} 34$ In the case of patients with acute cardiopulmonary symptoms, these potential purposes of a test or strategy should therefore be redefined into: (i) reduce heart or lung damage or reduce morbidity and mortality, (ii) reduce referrals to secondary care without missing serious conditions, reduce strain on secondary care resources, avoid negative emotional (anxiety) or physical effects (unwished negative effects of unnecessary diagnostics), reduce health care costs, (iii) reduce the patient's and GP's anxiety and uncertainty with regard to missing a potentially life-threatening condition (reassurance).

Nonetheless, there are many factors that may influence the effect of a test on the ultimately desired health related outcome or broader impact, e.g. the physician's and patient's trust in a result, as this will determine whether a physician will act according to the diagnostic test results. ${ }^{34,} 35$ So, after carefully 
defining the tests ultimate purposes and outcomes, it is important to analyse all aspects within the complete clinical pathway that may influence the final clinical management and treatment outcome. ${ }^{32}$ Research should first focus on possible bottlenecks within the pathway. In the case of acute cardiopulmonary symptoms, two important bottlenecks may be: the lack of evidence that (i) the use of a POCT will have an effect on clinical management and (ii) the POCT is reliable - it can determine whether ASC or PE is present (Chapter 3).

\section{Safely reducing referrals}

At the moment, GPs have a low threshold for referring patients suspected of ACS or PE to secondary care. This seems to be an effective strategy for GPs to avoid missed cases. The downside of this approach is that a significant number of patients are referred to secondary care, which leads to e.g. strain on resources in secondary care, anxiety in patients and high health care costs. ${ }^{36-41}$ In order to reduce referrals, it is crucial to first develop a test strategy that can safely rule out a serious cardiopulmonary condition.

Although previous studies showed promising results with the Marburg Heart Score (MHS) and some other potential predictors of $\mathrm{ACS}^{42-45}$ we could not externally validate MHS (cut-off value $\leq 2$ ) in a referred primary care population, nor did we find any other more accurate clinical decision rule. However, a scenario analysis showed that applying MHS only in patients considered being at low risk of ACS according to the GP's clinical assessment, safely ruled out ACS in $19 \%$ of patients referred for suspected ACS (chapter 9). It is questionable, though, whether GPs will apply the suggested strategy only in initially referred patients and trust the result of a clinical decision rule to change the decision to refer. Applying this strategy in all low risk primary care patients, may lead to more false positives among initially non-referred patients, in turn leading to more referrals again. Further research is needed to validate the suggested strategy - using MHS only in low risk patients - in a sufficiently large cohort including both referred and non-referred patients suspected of ACS. 
It will be challenging to develop a robust strategy to reduce the number of referrals whilst not increasing the number of missed cases, especially since most clinical decision rules and potential cardiopulmonary laboratory POCTs are nonspecific or have an insufficient sensitivity. A possible future POCT or clinical decision rule, should have a higher specificity and at least equivalent sensitivity compared to current clinical practice.

\section{Reassurance of GPs and patients}

Reassurance of GPs and patients, that no serious condition is being missed, may be one of the key reasons why GPs desire more diagnostics at the point-of-care. Previous research has shown that GPs see laboratory testing as a tool to manage uncertainty. ${ }^{46,47}$ The need for reassurance may partially be fed by the context of increased litigation, risk aversion and reduced continuity of care. ${ }^{46,48 \text {, }}$ 49 However, it is questionable whether this should be the most important purpose of a test, as tolerating uncertainty comes along with rapid decisions in general practice. ${ }^{50-52}$ Moreover, studies have shown that GPs consider laboratory testing as an easy, cost- and time-effective strategy to reassure patients and deal with perceived pressure from patients. ${ }^{46,48,53}$ It is arguable whether or not this purpose is justifiable, as several studies have shown no significant contribution of diagnostic tests at the level of the patient's reassurance and have little effect on the patient's anxiety. ${ }^{54,55}$ Though, they might lead to a slight reduction in the number or future consultations in primary care. ${ }^{55}$

\section{Potential role of cardiopulmonary diagnostics at the point-of-care}

In chapter 7, we summarize the current role of the laboratory D-dimer test in the current clinical pathway of suspected venous thromboembolism (VTE) in Dutch general practice. We hypothesise whether it may be wise to replace the laboratory D-dimer test by a POCT and discuss why implementation of a D-dimer POCT in general practice needs careful consideration. GPs currently have a high detection rate for VTE in patients who they urgently refer based on clinical 
assessment only. The closer proximity to a D-dimer POCT may lead to testing without explicitly using the D-dimer test in combination with a clinical decision rule, possibly leading to an increased use of the test, resulting in an increase in referrals. Moreover, given the present low frequency of D-dimer use ( $\leq$ once a month) by GPS, GPs would only infrequently use a D-dimer POCT in daily practice, which raises questions with regard to training and costs. Arguably, as the D-dimer does contribute to the diagnostic work-up of VTE, this reasoning may differ among countries with GPs working in remote rural areas, such as in Ireland and Scandinavia, where routine laboratory D-dimer testing may take days and replacement of the laboratory D-dimer may be the only suitable option for adequate access to $D$-dimer testing. ${ }^{12}$

Taking the diagnostic pathway of suspected PE as an example for the diagnostic pathway of suspected ACS, two kinds of add-on diagnostics at the point-of-care could be interesting to investigate to improve the clinical pathway in patients suspected of an ACS, that is a cardiac POCT and a clinical decision rule. As the H-FABP POCT has shown an insufficient diagnostic accuracy to detect ACS and no other potential cardiac POCT robust and reliable enough for use in general practice exists yet, we decided to investigate a potentially promising clinical decision rule (MHS) (chapter 9). ${ }^{25,26,42-44}$ Unfortunately, MHS only showed to be sufficiently accurate to rule out ACS in referred patients considered to be at low risk of ACS.

In reality, it will be a challenge to reach the ultimate purposes of a test or diagnostic strategy, by adding just one test to the current clinical pathway. At the moment, no such POCTs or clinical decision rules have proven to be clinically effective in patients with acute cardiopulmonary conditions. In the future a combination of a clinical decision rule with a cardiac POCT, or a combination of POCTs in addition to the clinical assessment, is a diagnostic approach worthwhile investigating. In any case, the use of a POCT as a stand-alone test is not advisable, it should always function as an additional test within the current clinical pathway. ${ }^{23,56}$ 


\section{Relevant patient population}

Finally, when evaluating diagnostic tests, the relevant patient population for a specific test or strategy should be carefully defined, so that spectrum bias can be prevented. ${ }^{32}$ Spectrum bias describes the changes in test performance that reflect actual differences in disease severity or the a priori chance of having a disease. In other words, it describes the effect a change in case mix may have on the performance of a test. ${ }^{57,58}$ So, although some of the POCTs discussed in this thesis were investigated more extensively in secondary care, these results should not automatically be generalized to general practice. The incidence of serious and life-threatening conditions is lower in primary care compared to secondary care and patients are often seen in an early stage of disease. ${ }^{17,59}$ This reasoning should also be applied to the study we performed in chapter 9, wherein we investigated the clinical decision rule in a referred primary care population. As discussed earlier, we expect test characteristics to change, after we apply MHS to all low risk primary care patients suspected of ACS.

\section{After POCT implementation}

Even after a POCT or diagnostic strategy has undergone the full evaluation cycle successfully, the use of such tests and strategies should be evaluated in routine clinical practice (Chapter 8 ). Due to their close proximity and speed, POCTs are especially vulnerable to excessive and non-evidence based use. Expanding the range of indications can negatively influence the diagnostic performance of a POCT. ${ }^{17}$ Non-evidence based test use and expanding the range of indications was previously seen with the implementation of the C-Reactive Protein (CRP) POCT.60-62 Moreover, attention should be payed to pre-analytical errors, misinterpretation, and non-adequate documentation of the test results. A quality management system should be implemented alongside the implementation of a POCT. ${ }^{63}$ Cooperation with medical laboratories and manufacturers is vital to support GPs in the process of point-of-care testing. ${ }^{64}$ 


\section{RECRUITMENT CHALLENGES IN PRIMARY CARE RESEARCH}

Diagnostic research in primary care has proven to be challenging, since it requires large scale prospective studies, making these studies time consuming and costly. Researchers often experience difficulties to include a sufficient number of patients to meet the targeted sample size, leading to extension of the study period, need to include more practices, or studies being terminated early while remaining underpowered. ${ }^{65-67}$ Specifically, the latter is a waste of research resources and should be prevented at all times.

Barriers that hinder patient recruitment may be (i) a lack of time to participate, (ii) the possible influence the participation in research may have on the doctorpatient relationship, (iii) the burden of participation for the patient or GP, (iv) the GP considers the topic insufficiently important or interesting, ( $v$ ) the relatively low number of relevant patients per GP, especially in less common and incident cases. ${ }^{65,68-71}$ Although literature on recruitment problems in prospective studies exists, nearly all papers focus on secondary care or other non-general practice settings. ${ }^{68,72}$ Information on barriers, facilitators and recommendations for successful recruitment are often non-applicable to the primary care setting. In general practice for example, the geographically widespread location of practices throughout large regions is one of the complicating organizational factors that hinder recruitment.

\section{Flash mob research}

Chapter 9 shows the use of a novel and innovative study design, the flash mob method. The secondary aim of this study was to evaluate the feasibility of using the flash mob method for large scale, relatively inexpensive and fast research in general practice. Using this method may partially overcome some of the barriers of patient recruitment discussed above. To the best of our knowledge, this flash mob method has never been used in a nationwide general practice study before. Therefore, our study served as a proof-of-concept of using the flash mob method in general practice. 
Flash mob research is based on the concept of flash mobs: 'A large public gathering at which people perform an unusual or seemingly random act and then disperse, typically organized by means of the internet or social media'. ${ }^{73}$ Originally, flash mobs were designed for entertainment and artistic expression, but on June 5th 2012 a flash mob was first used for medical research. In this single-day, multi-institution, prospective observational study, the recorded versus direct observed vital signs in non-ventilated patients in six large tertiarycare centres across the United States were compared. ${ }^{74}$ As far as we know, since then, two also hospital-based flash mob studies were performed in the Netherlands; one sleep study (INSOMNIA study) and one on the capillary refill time (FAMOUS study). ${ }^{75-77}$ These hospital-based studies have shown the numerical strength of multiple hospitals and professional and social networks participating in flash mob research to obtain sufficient data in a short period of time.

Flash mob research allows the investigation of one simple clinically relevant research question on a large scale in a relatively short timeframe. Like in traditional flash mobs, flash mob research uses mostly modern ways of communication, such as the internet, and the exact number of participant is unknown at the start of the study. This method deviates from most traditional diagnostic research in several relevant ways, (i) the study period is short, (ii) a minimal amount of data is collected per patient, with a minimal time effort for the participating clinician, (iii) the number of participants is not set at the beginning of the study, (iv) recruitment is facilitated by ambassadors and through professional and social networks.

Compared to previous hospital-based flash mob studies, the general practice flash mob study we performed, was slightly more challenging. Direct communication among GPs is often difficult as they are widely spread over a large region and suspected ACS is an incident case. ${ }^{65}$ Therefore, it was difficult to estimate an expected number of inclusions. Eventually, we were able to collect data on 258 patients in only two weeks. This inclusion rate is 3 to 4 times higher than previous studies on signs and symptoms and clinical decision rules in similar populations (also including non-referred patients, allowing a larger 
group eligible for recruitment), as these studies on average showed inclusion rates of less than 30 to 40 patients per week. ${ }^{42-44,78-80}$ With our study, we showed that flash mob research is feasible in general practice and that this design may be considered as a new research method, to investigate relatively simple clinically relevant research questions in general practice on a large scale in a relatively short timeframe.

\section{Considerations when performing a flash mob study}

Although we consider flash mob research in general practice feasible, it should be noted that this method is not suitable for all research in general practice. The flash mob method should not be seen as an easy fix for recruitment problems or as fast and labour-poor research. The opposite is true. One should first carefully consider a list of conditions before deciding whether or not to use this research method. This method should only be used if: (i) the research question can be answered with a small dataset per patient, (ii) the research question is relatively simple and considered to be relevant and urgent by GPs, (iii) the patient selection and data collection are sufficiently robust and self-explanatory, so that hardly any instructions are necessary, (iv) the study can be performed in a large region to include patients among a large number of GPs (chapter 9). Moreover, from our experiences with the flash mob study, it is advisable to have a large steering committee spread throughout the entire study area, so that all regions are covered by one member of the steering committee. Furthermore, anonymous data collection will stimulate participation as no informed consent procedure is necessary.

Although this method may seem suitable for research with POCTs, as the need for more research is high, we consider this method not suitable for 'invasive' laboratory POCTs, were it not only for the need to obtain written consent of all included patients, but also the necessity for instructions for correct use and interpretation of the test. However, this does not imply that we cannot learn from differences between flash mob research and traditional research and apply several aspects of flash mob research in more traditional research. For example, 
in traditional research, often a large amount of data is collected per patient. Reducing the latter, reduces the burden of participation, in turn leading to a lower threshold for GPs and patients to participate.

\section{GENERAL CONCLUSION}

The results of this thesis show that GPs wish to use more POCTs, specifically to assist them in the decision-making process in patients with acute cardiopulmonary symptoms, as they consider these consultations challenging. However, currently there is limited and inconclusive evidence that GP use of POCTs in primary care patients with acute cardiopulmonary symptoms leads to more accurate diagnoses and affects clinical management. The Marburg Heart Score, a clinical decision rule, could not be validated in a referred population suspected of ACS, nor were we able to construct a more accurate clinical decision rule. Future research should focus on either a strategy combining a clinical decision rule and a POCT or a clinical decision rule incorporating a POCT. 


\section{REFERENCES}

1. Hopstaken RM, Kleinveld HA, Balen van JAM, et al. [Guideline Point of care testing (POCT) in general practice]. 2015. [cited 2017 May]. Available from: https://www.nhg.org/sites/default/files/content/nhg_org/uploads/final_richtlijnpoct_ 2015Imlres.pdf.

2. Hopstaken RM, van Balen JA, Kusters R. [Point-of-care-testing in general practice]. Ned Tijdschr Geneeskd. 2015;159:A9475.

3. Giesen P, Huibers L, Padros Goossens M, Willekens M. [Between dream and achievement. GPs' future vision of their position in acute care]. Medisch Contact. 2007;62:653-5.

4. Dutch College of General Practitioners. [Dutch College of General Practitioners' position on GPs and acute care] Utrecht; 2013 [cited 2016 March 14]. Available from: https://www.nhg.org/themas/publicaties/nhg-standpunt-huisarts-en-spoedzorg-juni2013.

5. Dutch College of General Practitioners guidelines [Internet]. Utrecht: Dutch College of General Practitioners. [cited 2016 March 14]. Available from: https://www.nhg.org/ nhg-standaarden.

6. The Dutch College of General Practitioners' working group deep vein thrombosis and pulmonary embolism. [GP guideline Deep vein thrombosis and pulmonary embolism (second partial revision)] Utrecht: Dutch College of General Practitioners. [cited 2018 April 24]. Available from: https://www.nhg.org/standaarden/volledig/nhg-standaarddiepe-veneuze-trombose-en-longembolie.

7. Dutch College of General Practitioners' working group Atrial fibrillation. [GP guideline Atrial fibrillation (thrid partial revision)]. Huisarts en wetenschap. 2017;60:460.

8. McConaghy JR, Oza RS. Outpatient diagnosis of acute chest pain in adults. Am Fam Physician. 2013;87:177-82.

9. Willemsen RT, Kietselaer BL, Kusters R, Buntinx F, Dinant G]. [Diagnostic tools for acute coronary syndrome (ACS): a challenge for general practitioners and cardiologists]. Ned Tijdschr Geneeskd. 2014;158:A8078.

10. Body R, Carley S, Wibberley C, McDowell G, Ferguson J, Mackway-Jones K. The value of symptoms and signs in the emergent diagnosis of acute coronary syndromes. Resuscitation. 2010;81:281-6.

11. Howick J, Cals JW, Jones C, et al. Current and future use of point-of-care tests in primary care: an international survey in Australia, Belgium, The Netherlands, the UK and the USA. BMJ Open. 2014;4:e005611.

12. Varzgaliene L, Heerey $A, \operatorname{Cox} C$, et al. Point-of-care testing in primary care: needs and attitudes of Irish GPs. BJGP Open. 2018;1:bjgpopen17X101229. 
13. Turner PJ, Van den Bruel A, Jones $\mathrm{CH}$, et al. Point-of-care testing in UK primary care: a survey to establish clinical needs. Fam Pract. 2016;33:388-94.

14. Jones $\mathrm{CH}$, Howick J, Roberts NW, et al. Primary care clinicians' attitudes towards point-of-care blood testing: a systematic review of qualitative studies. BMC Fam Pract. 2013;14:117.

15. Hardy V, Thompson M, Alto W, et al. Exploring the barriers and facilitators to use of point of care tests in family medicine clinics in the United States. BMC Fam Pract. 2016;17:149.

16. Butler CC, Simpson S, Wood F. General practitioners' perceptions of introducing nearpatient testing for common infections into routine primary care: a qualitative study. Scand J Prim Health Care. 2008;26:17-21.

17. Cals J, van Weert H. Point-of-care tests in general practice: hope or hype? Eur J Gen Pract. 2013;19:251-6.

18. Verbakel JY, Turner PJ, Thompson MJ, et al. Common evidence gaps in point-of-care diagnostic test evaluation: a review of horizon scan reports. BMJ Open. 2017; 7:e015760.

19. Nilsson S, Andersson PO, Borgquist L, et al. Point-of-Care Troponin T Testing in the Management of Patients with Chest Pain in the Swedish Primary Care. Int J Family Med. 2013;2013:532093.

20. Burri E, Hochholzer K, Arenja N, et al. B-type natriuretic peptide in the evaluation and management of dyspnoea in primary care. J Intern Med. 2012;272:504-13.

21. Nilsson S, Andersson A, Janzon M, Karlsson JE, Levin LA. Cost consequences of pointof-care troponin $\mathrm{T}$ testing in a Swedish primary health care setting. Scand J Prim Health Care. 2014;32:241-7.

22. Geersing GJ, Erkens PM, Lucassen WA, et al. Safe exclusion of pulmonary embolism using the Wells rule and qualitative $\mathrm{D}$-dimer testing in primary care: prospective cohort study. BMJ. 2012;345:e6564.

23. Lucassen WA, Erkens PM, Geersing GJ, et al. Qualitative point-of-care D-dimer testing compared with quantitative D-dimer testing in excluding pulmonary embolism in primary care. J Thromb Haemost. 2015;13:1004-9.

24. Nederlands Trial Register [Internet]. Amsterdam: Academic Medical Center (The Netherlands). 2004 Oct 26 - . Identifier NTR6348, Evaluation of biomarkers in VTE study; the EVA study; 2016 Nov 20 [cited 2018 June 27]; [1 page]. Available from: http://www.trialregister.nl/trialreg/admin/rctview.asp?TC=6348.

25. Bruins Slot $M H$, Rutten $F H$, van der Heijden GJ, et al. Diagnostic value of a heart-type fatty acid-binding protein (H-FABP) bedside test in suspected acute coronary syndrome in primary care. Int J Cardiol. 2013;168:1485-9. 
26. Willemsen RT. Assessing chest pain in primary care. [dissertation]. Maastricht: Maastricht University; 2018.

27. Willemsen RTA, Kip MMA, Koffijberg $H$, et al. Early health technology assessment of future clinical decision rule aided triage of patients presenting with acute chest pain in primary care. Prim Health Care Res Dev. 2018;19:176-88.

28. Kip MMA, Koffijberg H, Moesker MJ, MJ IJ, Kusters R. The cost-utility of point-of-care troponin testing to diagnose acute coronary syndrome in primary care. BMC Cardiovasc Disord. 2017;17:213.

29. Hendriksen JM, Geersing GJ, van Voorthuizen SC, et al. The cost-effectiveness of point-of-care D-dimer tests compared with a laboratory test to rule out deep venous thrombosis in primary care. Expert Rev Mol Diagn. 2015;15:125-36.

30. Ten Cate-Hoek AJ, Toll DB, Buller HR, et al. Cost-effectiveness of ruling out deep venous thrombosis in primary care versus care as usual. J Thromb Haemost. $2009 ; 7: 2042-9$.

31. Howick J, Bossuyt PM, Cals JWL. Point of care testing in family practice: common myths debunked. Fam Pract. 2017;34:373-5.

32. Horvath AR, Lord SJ, StJohn A, et al. From biomarkers to medical tests: The changing landscape of test evaluation. Clinica Chimica Acta. 2014;427:49-57.

33. Bossuyt PM, Irwig L, Craig J, Glasziou P. Comparative accuracy: assessing new tests against existing diagnostic pathways. BMJ. 2006;332:1089-92.

34. Ferrante di Ruffano L, Hyde CJ, McCaffery KJ, Bossuyt PM, Deeks JJ. Assessing the value of diagnostic tests: a framework for designing and evaluating trials. BMJ. 2012;344:e686.

35. Bossuyt PM, McCaffery K. Additional patient outcomes and pathways in evaluations of testing. Med Decis Making. 2009;29:E30-8.

36. Goodacre S, Cross E, Arnold J, Angelini K, Capewell S, Nicholl J. The health care burden of acute chest pain. Heart. 2005;91:229-30.

37. Biesemans $L$, Cleef LE, Willemsen RTA, et al. Managing chest pain patients in general practice: an interview-based study. BMC Fam Pract. 2018;19:80.

38. Hoorweg BBN, Willemsen RT, Cleef LE, et al. Frequency of chest pain in primary care, diagnostic tests performed and final diagnoses. Heart. 2017;103:1727-32.

39. Groarke J, O'Brien J, Go G, Susanto M, Owens P, Maree AO. Cost burden of nonspecific chest pain admissions. Ir J Med Sci. 2013;182:57-61.

40. Mourad G, Alwin J, Stromberg A, Jaarsma T. Societal costs of non-cardiac chest pain compared with ischemic heart disease--a longitudinal study. BMC Health Serv Res. 2013;13:403. 
41. Kohn MA, Kwan E, Gupta M, Tabas JA. Prevalence of acute myocardial infarction and other serious diagnoses in patients presenting to an urban emergency department with chest pain. J Emerg Med. 2005;29:383-90.

42. Bosner S, Haasenritter J, Becker A, et al. Ruling out coronary artery disease in primary care: development and validation of a simple prediction rule. CMAJ. 2010;182:1295-300.

43. Haasenritter J, Bosner S, Vaucher $\mathrm{P}$, et al. Ruling out coronary heart disease in primary care: external validation of a clinical prediction rule. $\mathrm{Br} J$ Gen Pract. 2012;62:e415-21.

44. Haasenritter J, Donner-Banzhoff N, Bosner S. Chest pain for coronary heart disease in general practice: clinical judgement and a clinical decision rule. $\mathrm{Br} J$ Gen Pract. 2015;65:e748-53.

45. Aerts M, Minalu G, Bosner S, et al. Pooled individual patient data from five countries were used to derive a clinical prediction rule for coronary artery disease in primary care. J Clin Epidemiol. 2017;81:120-8.

46. van der Weijden $T$, van Bokhoven MA, Dinant GJ, van Hasselt CM, Grol RP. Understanding laboratory testing in diagnostic uncertainty: a qualitative study in general practice. Br J Gen Pract. 2002; 52:974-80.

47. Guthrie B. Why do general practitioners take blood? A cross-sectional study of use of blood tests in UK general practice. Eur J Gen Pract. 2001;7:138-60.

48. Watson J, de Salis I, Banks J, Salisbury C. What do tests do for doctors? A qualitative study of blood testing in UK primary care. Fam Pract. 2017;34:735-9.

49. Winkens R, Dinant GJ. Evidence base of clinical diagnosis: Rational, cost effective use of investigations in clinical practice. BMJ. 2002;324:783.

50. Green C, Holden J. Diagnostic uncertainty in general practice. A unique opportunity for research? Eur J Gen Pract. 2003;9:13-5.

51. Dixon AS. 'There's a lot of it about': clinical strategies in family practice. $J R$ Coll Gen Pract. 1986;36:468-71.

52. Rosser WW. Approach to diagnosis by primary care clinicians and specialists: is there a difference? J Fam Pract. 1996;42:139-44.

53. Van Boven K, Dijksterhuis $\mathrm{P}$, Lamberts $\mathrm{H}$. Defensive testing in Dutch family practice. Is the grass greener on the other side of the ocean? J Fam Pract. 1997;44:468-72.

54. van Ravesteijn $H$, van Dijk $I$, Darmon $D$, et al. The reassuring value of diagnostic tests: a systematic review. Patient Educ Couns. 2012;86:3-8.

55. Rolfe $A$, Burton $C$. Reassurance after diagnostic testing with a low pretest probability of serious disease: systematic review and meta-analysis. JAMA Intern Med. 2013;173:407-16. 
56. Kelder JC, Cowie MR, McDonagh TA, et al. Quantifying the added value of BNP in suspected heart failure in general practice: an individual patient data meta-analysis. Heart. 2011;97:959-63.

57. Schmidt RL, Factor RE. Understanding sources of bias in diagnostic accuracy studies. Arch Pathol Lab Med. 2013;137:558-65.

58. Willis BH. Spectrum bias--why clinicians need to be cautious when applying diagnostic test studies. Fam Pract. 2008;25:390-6.

59. Summerton N. Diagnosis and general practice. Br J Gen Pract. 2000;50:995-1000.

60. Minnaard MC, van de Pol AC, Hopstaken RM, et al. C-reactive protein point-of-care testing and associated antibiotic prescribing. Fam Pract. 2016;33:408-13.

61. Andre M, Schwan A, Odenholt I, Swedish Study Group on Antibiotic U. The use of CRP tests in patients with respiratory tract infections in primary care in Sweden can be questioned. Scand J Infect Dis. 2004;36:192-7.

62. Engstrom S, Molstad S, Lindstrom K, Nilsson G, Borgquist L. Excessive use of rapid tests in respiratory tract infections in Swedish primary health care. Scand J Infect Dis. 2004;36:213-8.

63. Medicines and Healthcare Products Regulatory Agency. Management and use of IVD point of care test devices. December 2013 [cited 2017 May]. Available from: http://www.viapath.co.uk/sites/default/files/upload/POCT/Management\%20and\%20u se\%20of\%20IVD\%20point\%20of\%20care\%20test\%20devices.pdf

64. Kleinveld HA, Raijmakers MT, Vermeer HJ, Oosterhuis WP. [Vision document NVKC Point-of-care tests in primary care]. Utrecht: NVKC; 2012. [cited 2018 Jun 28]. Available from: https://www.nvkc.nl/sites/default/files/visiedocument_POCT_def\% 286\%29.pdf.

65. van der Wouden JC, Blankenstein AH, Huibers MJ, van der Windt DA, Stalman WA, Verhagen AP. Survey among 78 studies showed that Lasagna's law holds in Dutch primary care research. J Clin Epidemiol. 2007;60:819-24.

66. Knottnerus JA, Tugwell P. Prevention of premature trial discontinuation: how to counter Lasagna's law. J Clin Epidemiol. 2016;80:1-2.

67. Bower $\mathrm{P}$, Wallace $\mathrm{P}$, Ward $\mathrm{E}$, et al. Improving recruitment to health research in primary care. Fam Pract. 2009;26:391-7.

68. Ross S, Grant A, Counsell C, Gillespie W, Russell I, Prescott R. Barriers to participation in randomised controlled trials: a systematic review. J Clin Epidemiol. 1999;52:1143-56.

69. Kocken RJ, Knottnerus JA, Smeets PE. GPs as participants in scientific research. $\mathrm{Br}$ J Gen Pract. 1993;43:305-6.

70. Tognoni G, Alli C, Avanzini F, et al. Randomised clinical trials in general practice: lessons from a failure. BMJ. 1991;303:969-71. 
71. Ngune I, Jiwa M, Dadich A, Lotriet J, Sriram D. Effective recruitment strategies in primary care research: a systematic review. Qual Prim Care. 2012;20:115-23.

72. Treweek S, Lockhart $P$, Pitkethly $M$, et al. Methods to improve recruitment to randomised controlled trials: Cochrane systematic review and meta-analysis. BMJ Open. 2013;3:e002360.

73. Oxford Dictionaries [Internet]. Flash mob. [cited 2018 May 3]. Available from: https://en.oxforddictionaries.com/definition/flash_mob.

74. Semler MW, Stover DG, Copland AP, et al. Flash mob research: a single-day, multicenter, resident-directed study of respiratory rate. Chest. 2013;143:1740-4.

75. Alsma J, Schuit S. ['Capillary refill' time measurement in flash mob research: The FAMOUS-TRIAL]. Ned Tijdschr Geneeskd. 2014;158:A8218.

76. Alsma J, van Saase J, Nanayakkara PWB, et al. The Power of Flash Mob Research: Conducting a Nationwide Observational Clinical Study on Capillary Refill Time in a Single Day. Chest. 2017;151:1106-13.

77. Flashmob Research Nederland [Internet]. [cited 2017 Jun 31]. Available from: http://www.flashmobresearch.nl/.

78. Buntinx F, Truyen J, Embrechts P, Moreel G, Peeters R. Evaluating patients with chest pain using classification and regression trees. Fam Pract. 1992;9:149-53.

79. Nilsson S, Scheike M, Engblom D, et al. Chest pain and ischaemic heart disease in primary care. Br J Gen Pract. 2003;53:378-82.

80. Bosner S, Becker A, Abu Hani M, et al. Accuracy of symptoms and signs for coronary heart disease assessed in primary care. Br J Gen Pract. 2010;60:e246-57. 
Summary 



\section{SUMMARY}

In chapter 1, the general introduction of this thesis, we discuss that diagnostic tests can assist general practitioners (GPs) in the clinical decision-making process. Point-of-care tests (POCTs), in particular, may be useful in patients presenting with acute symptoms in general practice, because the results may affect the decision-making at the time of the consultation. The number of available POCTs has increased exponentially in the past few decades and POCTs are increasingly wanted and used by GPs. Although POCTs have a number of potential benefits, GPs also have expressed concerns with regard to such tests. Therefore, it is important that these tests are thoroughly evaluated before implementation in clinical practice.

Acute cardiopulmonary symptoms are fairly common in general practice and can be caused by serious or minor conditions, with the latter constituting the majority of cases. Accurately diagnosing patients with these symptoms is often considered challenging and GPs have expressed a desire to use POCTs in these patients specifically.

The general aim of this thesis is to assess the current state of point-of-care tests in general practice in general and in acute cardiopulmonary symptoms specifically.

In the Netherlands, during office hours, GPs typically have access to most medical imaging, laboratory tests and a variety of POCTs without referral to secondary care, but knowledge on GPs' access to diagnostic tests during out-ofhours care was lacking. Chapter 2 provides an overview of current GP access to diagnostic tests - imaging, function tests, laboratory tests and POCTs - during GP out-of-hours care in the Netherlands and chapter 3 describes the current GP use, future needs and GPs' attitudes toward POCTs in the Netherlands.

In 2014, GPs in the Netherlands had limited and varying access to diagnostics during GP out-of-hours care. Electrocardiography was only available in $26 \%$ of all services and regular laboratory blood tests in 37\% of out-of-hours services. All services had a glucose POCT and a urine dipstick test available while merely 
$21 \%$ utilized a D-dimer POCT and none a troponin POCT. In the same year, a limited number of POCTs - glucose (96\%), urine nitrite and leucocytes (96\%), pregnancy (94\%), haemoglobin (58\%) and C-Reactive Protein (CRP) (48\%) were used by GPs during office hours. GPs stated a desire for POCTs to be available for acute thromboembolic diseases (D-dimer), heart conditions (troponin, BNP) and infections (CRP, chlamydia), with POCTs for cardiopulmonary diseases at the top of the list. They considered a proven effect on the immediate decision-making in general practice (46\%) and reliability of the POCT (35\%) key aspects of a POCT.

Chapter 4 describes the results of a modified international e-Delphi procedure of four rounds among expert panel members from different professional backgrounds, aiming to reach consensus on an internationally and multidisciplinary supported definition of a POCT in general practice. This led to the following definition: 'A POCT in family practice is a test to support clinical decision making, which is performed by a qualified member of the practice staff nearby the patient and on any part of the patient's body or its derivatives, during or very close to the time of consultation, to help the patient and physician to decide upon the best suited approach, and of which the results should be known at the time of the clinical decision making.'

As POCTs for cardiopulmonary diseases were desired most, we decided to investigate GPs' experiences with cardiopulmonary consultations at GP out-ofhours services. Chapter 5 discusses the results of a qualitative study, consisting of 15 face-to-face semi-structured interviews with Dutch GPs, on their experiences with out-of-hours cardiopulmonary consultations. And indeed, GPS considered cardiopulmonary consultations at GP out-of-hours services as challenging and difficult, which is comparable to results from other studies. They related these consultations with tension and uncertainty leading to defensive behaviour, including a lower threshold for performing diagnostics and referrals to secondary care. Views with regard to additional diagnostic tests, as a partial solution for the percieved problem, differed among GPs, with some GPS advocating more access to diagnostics, while others primarily expressed concerns with regard to new diagnostics. 
To evaluate the possible role of POCTs in patients with acute cardiopulmonary symptoms, we systematically reviewed the literature to assess whether using POCTs in primary care patients with these symptoms leads to more accurate diagnosis and impacts clinical management, as these aspects were considered as most important by GPs. Chapter 6 shows that only seven prospective studies evaluated the effect of GP use of a POCT - four different biomarkers, that is Ddimer, troponin, heart-type fatty acid-binding protein (H-FABP) and B-type natriuretic peptide (BNP) - on clinical diagnostic accuracy and only two of these also evaluated outcomes with regard to clinical management. One study investigated the effect of a troponin POCT on actual referral rates to secondary care and the other study reported the effect of a BNP POCT on time to appropriate treatment. The results of this review show that there is limited and inconclusive evidence that actual GP use of POCTs in primary care patients with acute cardiopulmonary symptoms leads to more accurate diagnoses and affects clinical management. However, one large prospective study on GP use of a Ddimer POCT included in the review showed promosing results, especially when the POCT was combined with a clinical decision rule.

Before considering wide implementation of a D-dimer POCT, it is useful to investigate the current (urgent) referral pathways of venous thromboembolism (VTE) and to analyse the current role of laboratory D-dimer testing in those referred with suspected VTE. This might provide useful insights on how GPS currently test and refer VTE suspected patients and may inform possible widespread D-dimer POCT implementation. Chapter 7 discusses the results of a retrospective analyses of patients in whom the GP determined a D-dimer value or had a diagnostic work-up for suspected VTE in a non-academic hospital in 2015. We found that of those patients urgently referred, approximately one third was diagnosed with VTE. Urgent referrals based on clinical assessment only (without D-dimer testing) led to a VTE diagnosis in $74 \%$ of patients, while in those referred based on clinical assessment and a D-dimer test this was $15 \%$. GPs annually requested approximately five D-dimer tests per 1000 patients. This means that in the Netherlands, a GP will infrequently ( $\leq$ once a month) use a D-dimer test in daily practice. We conclude that although D-dimer testing contributes to the diagnostic work-up of VTE, GPs have a high detection rate for 
VTE in patients who they urgently refer to secondary care based on clinical assessment only.

Chapter 8 is an editorial wherein we argue that more point-of-care does not necessarily mean better care; we address several concerns with regard to the evaluation and implementation of POCTs. In this chapter we discuss a recent systematic review that analysed all 40 diagnostic Horizon Scan reports on POCTs of recent years. The review shows that most POCTs were investigated for clinical performance ( $71 \%)$, but only $18 \%$ of all studies evaluated the clinical effectiveness of a POCT. Moreover, the mean time to completion of a full evaluation cycle was 9 years. Furthermore, we address some issues with regard to implementation of POCTs, paying special attention to aspects such as excessive and non-evidence based test use and quality management.

Taking the diagnostic pathway of suspected pulmonary embolism as an example for the diagnostic pathway in patients with suspected acute coronary syndrome (ACS), two kinds of add-on diagnostics at the point-of-care could be interesting to investigate, that is a cardiac POCT and a clinical decision rule. As the H-FABP POCT has shown an insufficient diagnostic accuracy to detect ACS and no other potential cardiac POCT robust and reliable enough for use in general practice exists yet, we decided to investigate a potentially promising clinical decision rule, the Marburg Heart Score (MHS), and a few other potential predictors of ACS. In chapter 9, we present the results of a novel and innovative nationwide 2-week 24/7 flash mob study. The primary aim of this prospective flash mob study was to externally validate MHS or to develop an adapted clinical decision rule for GPs to safely rule out ACS in patients referred to secondary care for suspected ACS. Moreover, we evaluated the feasibility of using this new flash mob method for large scale, relatively inexpensive and fast research in general practice.

The results of this study show that MHS, using a cut-off value of $\leq 2$, and the GP's clinical assessment of ACS individually have an insufficient diagnostic accuracy to safely rule out ACS in patients referred to secondary care for suspected ACS. We were unable to construct a more accurate clinical decision rule from the investigated possible predictors of ACS. Moreover, with this study 
we illustrate that flash mob research in family medicine is feasible and may be considered as a new research method, to investigate relatively simple clinically relevant research questions in general practice on a large scale in a relatively short timeframe.

In chapter 10, the general discussion, we discuss the main findings of this thesis and their implications. We evaluate diagnostics at the point-of-care specifically in patients with acute cardiopulmonary symptoms, within the existing clinical pathways. The purpose and role of cardiopulmonary diagnostics at the point-of-care and other considerations, such as the patient population and POCT implementation, are discussed. Moreover, we elaborate on recruitment challenges in general practice research and a novel research design (flash mob research).

The results of this thesis show that GPs wish to use more POCTs, specifically to assist them in the decision-making process in patients with acute cardiopulmonary symptoms. Yet, there is limited and inconclusive evidence that GP use of POCTs in primary care patients with acute cardiopulmonary symptoms leads to more accurate diagnoses and affects clinical management. Moreover, MHS could not be validated in a referred population suspected of ACS. We argue that future research on diagnosing patients with acute cardiopulmonary symptoms should focus on either a strategy combining a clinical decision rule and a POCT or a clinical decision rule incorporating a POCT. 

Samenvatting 



\section{SAMENVATTING}

In hoofdstuk 1, de algemene introductie van dit proefschrift, bespreken we hoe diagnostische testen huisartsen kunnen ondersteunen bij de medische besluitvorming. Vooral sneltesten kunnen waardevol zijn in de huisartsenpraktijk bij patiënten die zich presenteren met acute klachten, omdat de resultaten van deze testen nog tijdens het consult van invloed kunnen zijn op de besluitvorming. Het aantal beschikbare sneltesten is exponentieel gestegen gedurende de laatste decennia. Huisartsen hebben toenemend behoefte aan sneltesten en het gebruik hiervan neem toe. Ondanks de mogelijke voordelen van sneltesten, hebben huisartsen ook een aantal bedenkingen met betrekking tot dit soort testen. Daarom is het van belang (snel)testen zorgvuldig te evalueren voorafgaand aan eventuele implementatie in de praktijk.

Acute cardiopulmonale klachten komen vaak voor in de huisartspraktijk en kunnen worden veroorzaakt door een ernstige onderliggende aandoening of een onschuldige aandoening, waarbij laatstgenoemde het vaakst voorkomt. Het correct diagnosticeren van patiënten met dergelijke symptomen wordt vaak gezien als uitdagend en huisartsen hebben juist bij deze patiënten behoefte aan sneltesten.

Het primaire doel van dit promotieonderzoek is om de huidige stand van zaken van sneltesten in de huisartspraktijk - in het algemeen en meer specifiek bij acute cardiopulmonale klachten - te bepalen.

Tijdens reguliere praktijkuren hebben huisartsen in Nederland over het algemeen direct toegang tot beeldvormend onderzoek, laboratoriumbepalingen en verschillende sneltesten zonder dat een verwijzing naar de tweede lijn nodig is. Hoofdstuk 2 geeft een overzicht van de beschikbaarheid en toegang van huisartsen tot diagnostische testen - beeldvorming, functietesten, laboratoriumtesten en sneltesten - tijdens avond-, nacht- en weekenddiensten (ANW-diensten) in Nederland. Hoofdstuk 3 beschrijft het huidige gebruik van, de behoefte aan en de houding ten aanzien van sneltesten onder Nederlandse huisartsen. 
In 2014 hadden huisartsen in Nederland beperkte en per huisartsenpost sterk wisselende toegang tot diagnostiek tijdens ANW-diensten. Electrocardiografie was slechts beschikbaar op $26 \%$ van de huisartsenposten en standaard laboratorium bloedtesten op $37 \%$ van de posten. Op alle posten waren glucosesneltesten en urine-dipsticktesten beschikbaar, terwijl op slechts $21 \%$ van de posten een D-dimeersneltest en op geen van de posten een troponinesneltest beschikbaar was. In datzelfde jaar werden door huisartsen een beperkt aantal sneltesten - glucose (96\%), nitriet en leukocyten in de urine (96\%), zwangerschap (94\%), hemoglobine (58\%) en C-Reactief Proteïne (CRP) $(48 \%)$ - gebruikt tijdens reguliere praktijkuren. Huisartsen hebben vooral behoefte aan sneltesten voor acute trombo-embolische aandoeningen (Ddimeren), hartklachten (troponine, BNP) en infecties (CRP, chlamydia), waarbij sneltesten voor cardiopulmonale aandoeningen het meest worden gewenst. Volgens huisartsen zijn de betrouwbaarheid (35\%) en een bewezen effect op het directe handelen in de huisartspraktijk (46\%) de belangrijkste aspecten van een sneltest.

In hoofdstuk 4 beschrijven we de resultaten van een internationale, e-Delphi studie van vier rondes onder expert panelleden met verschillende professionele achtergronden. Het doel van deze procedure was het bereiken van consensus over een internationale en multidisciplinair gesteunde definitie van sneltesten ('point-of-care' testen) in de huisartsgeneeskunde. Dit leidde tot de volgende definitie: 'Een sneltest ('point-of-care' test) in de huisartsgeneeskunde is een test ter ondersteuning van de medische besluitvorming, welke wordt uitgevoerd door een gekwalificeerd medewerker van de huisartspraktijk, nabij de patient en op ieder lichaamsdeel van de patient of derivaten daarvan, gedurende of rondom het consult, waarvan de resultaten bekend dienen te zijn ten tijde van de medische besluitvorming om de patiënt en arts te ondersteunen bij de beslissing voor het meest gepaste beleid.'

Aangezien huisartsen aangaven het meest behoefte te hebben aan sneltesten voor cardiopulmonale aandoeningen, besloten we om de ervaringen van huisartsen met cardiopulmonale consulten op de huisartsenpost te onderzoeken. Hoofdstuk 5 toont de resultaten van een kwalitatieve studie, bestaande uit 15 
semigestructureerde interviews met huisartsen in Nederland over hun ervaringen met cardiopulmonale consulten op de huisartsenpost. Zoals verwacht, beschouwden huisartsen cardiopulmonale consulten op de huisartsenpost als uitdagend en moeilijk, hetgeen overeenkomt met de resultaten uit eerdere studies. Ze associeerden deze consulten met gevoelens van spanning en onzekerheid. Dit leidt tot defensief gedrag dat zich uit in een lagere drempel voor het verrichten van diagnostiek en het verwijzen van patiënten naar de tweede lijn. Opvattingen met betrekking tot het gebruik van aanvullende diagnostische testen, als een gedeeltelijke oplossing voor het ervaren probleem, verschilden tussen huisartsen. Sommige huisartsen pleitten voor meer toegang tot diagnostiek, terwijl anderen vooral zorgen uitten met betrekking tot nieuwe diagnostische middelen.

Om de rol van sneltesten bij patiënten met acute cardiopulmonale symptomen te evalueren, hebben we een systematisch literatuuronderzoek verricht (hoofdstuk 6). We onderzochten hierbij of het gebruik van sneltesten bij eerstelijns patiënten met deze symptomen leidt tot meer correcte diagnoses en invloed heeft op het medisch beleid, aangezien huisartsen deze aspecten in ons eerder onderzoek als het meest relevant beschouwden. We vonden slechts zeven prospectieve studies die het effect op de diagnostische waarde van het gebruik van sneltesten - vier verschillende biomarkers, namelijk D-dimeer, troponine, heart-type fatty acid-binding proteïne (H-FABP) en B-type natriuretisch peptide (BNP) - door huisartsen in de dagelijkse praktijk evalueerden. Slechts twee van deze studies evalueerden ook uitkomsten met betrekking tot het medisch beleid. Eén studie onderzocht het effect van een troponinesneltest op het daadwerkelijke aantal verwijzingen naar de tweede lijn en de andere studie raporteerde over het effect van een BNP sneltest op de tijdsduur tot aan een adequate behandeling. De resultaten van dit literatuuronderzoek laten zien dat er beperkt en geen overtuigend bewijs is dat het daadwerkelijk gebruik van sneltesten door huisartsen bij eerstelijns patiënten met acute cardiopulmonale klachten leidt tot meer correcte diagnoses en van invloed is op het medisch beleid. Echter, één grote - in het literatuuronderzoek geïncludeerde - prospectieve studie over het gebruik van een D-dimeer sneltest bij de verdenking op een longembolie toonde 
veelbelovende resultaten, vooral wanneer de sneltest werd gecombineerd met een beslisregel.

Voordat wordt overwogen om een D-dimeer sneltest op grote schaal te implementeren, is het zinvol om de huidige (spoed)verwijspaden bij een verdenking op veneuze tromboembolieën (VTE) te onderzoeken en om de huidige rol van de laboratorium D-dimeer test bij patiënten die worden verwezen met de verdenking VTE te analyseren. Dit kan mogelijk tot zinvolle inzichten leiden over hoe huisartsen op dit moment patiënten met verdenking VTE diagnosticeren en verwijzen en zou ons kunnen informeren over mogelijk wijdverspreide D-dimeer sneltest implementatie. Hoofdstuk $\mathbf{7}$ bespreekt de resultaten van een restrospectieve analyse van patiënten waarbij de huisarts een D-dimeer heeft bepaald dan wel patiënten waarbij diagnostiek is verricht voor de verdenking VTE in een niet-academisch ziekenhuis in 2015. Van alle met spoed verwezen patiënten werd ongeveer een derde gediagnostiseerd met VTE. Spoedverwijzingen gebaseerd op enkel de klinische beoordeling van de huisarts (zonder D-dimeer test) leidde in 74\% van de gevallen tot een VTE diagnose. Bij spoedverwijzing gebaseerd op de klinische beoordeling plus D-dimeer test door de huisarts gold dat in $15 \%$ van de gevallen. Jaarlijks vroegen huisartsen ongeveer vijf D-dimeer testen per 1000 patiënten aan. Een huisarts gebruikt de D-dimeer test dus slechts incidenteel (minder dan één keer per maand) in de dagelijkse praktijk. We concluderen dat, hoewel de D-dimeer test bijdraagt aan het diagnostisch onderzoek bij VTE, huisartsen patiënten goed kunnen inschatten die zij rechtstreeks met spoed verwijzen naar de tweedelijn voor de verdenking op VTE op basis van enkel de klinische beoordeling.

Hoofdstuk 8 is een redactioneel artikel waarin we beargumenteren warom meer sneltesten niet per definitie leiden tot betere zorg; we beschrijven verschillende bedenkingen ten aanzien van de evaluatie en implementatie van sneltesten. In dit hoofdstuk bespreken we een recent systematisch literatuuronderzoek waarin alle 40 diagnostische 'Horizon Scan' rapporten van recent ontwikkelde sneltesten zijn geanalyseerd. Het literatuuronderzoek laat zien dat de meeste sneltesten op hun testkarakteristieken en onderscheidend vermogen om een aandoening aan te tonen of uit te sluiten werden onderzocht 
(71\%). Daarentegen evalueerden slechts $18 \%$ van alle studies de klinische effectiviteit van een sneltest, dat wil zeggen of het gebruik van de test patiënt gerelateerde uitkomsten verbetert. Bovendien bedraagt de gemiddelde tijd van aanvang tot afronden van een volledige evaluatiecyclus 9 jaar. Verder bespreken we een aantal aandachtspunten met betrekking tot de implementatie van sneltesten, zoals buitensporig en niet evidence-based testgebruik en kwaliteitsmanagement.

Als we het diagnostisch zorgpad van patiënten met de verdenking op een longembolie als voorbeeld nemen voor het diagnostisch zorgpad van patiënten verdacht voor een acuut coronair syndroom (ACS), dan zijn twee vormen van aanvullende sneltestdiagnostiek interessant om te onderzoeken, namelijk een cardiale sneltest en een beslisregel. Een bestaande H-FABP sneltest heeft recentelijk een onvoldoende diagnostische waarde getoond in de dagelijkse huisartspraktijk om ACS te detecteren en vooralsnog is er geen alternatieve cardiale sneltest, robuust en betrouwbaar genoeg voor gebruik in de huisartspraktijk, voorhanden. We besloten daarom om een potentiele veelbelovende klinische beslisregel, de Marburg Heart Score (MHS), en enkele andere veelbelovende voorspellers voor ACS te evalueren. In hoofdstuk 9 presenteren we de resultaten van een innovatieve, landelijke twee weken durende 24/7 flashmob studie. Met deze prospectieve flashmob studie beoogden we de MHS extern te valideren of een aangepaste beslisregel te ontwikkelen voor het veilig uitsluiten van ACS bij verwezen patiënten verdacht voor ACS. Daarnaast wilden we de haalbaarheid evalueren van het gebruik van deze nieuwe flashmob methode voor relatief goedkoop en snel onderzoek op grote schaal binnen de huisartspraktijk.

De resultaten van deze studie laten zien dat de MHS, met een afkapwaarde van $\leq 2$, en het klinisch oordeel van de huisarts onafhankelijk van elkaar een onvoldoende onderscheidend vermogen hebben om ACS in de huisartspraktijk veilig uit te sluiten bij verwezen patiënten verdacht voor ACS. We konden geen nauwkeurigere beslisregel ontwikkelen uit de onderzochte mogelijke predictoren van ACS. We laten met deze studie zien dat flashmob onderzoek in de huisartsgeneeskunde haalbaar is en beschouwd mag worden als een nieuwe 
onderzoeksmethode om relatief eenvoudige medisch relevante onderzoeksvragen in de huisartspraktijk op grote schaal en in een relatief kort tijdsbestek te onderzoeken.

In hoofdstuk 10, de algemene discussie, bespreken we de belangrijkste bevindingen en hun implicaties. We evalueren sneltestdiagnostiek in het bijzonder bij patiënten met acute cardiopulmonale klachten binnen de bestaande medische zorgpaden. Het doel en de rol van cardiopulmonale sneltestdiagnostiek en andere overwegingen, zoals de patiëntpopulatie en sneltest implementatie, worden besproken. Bovendien weiden we uit over wervingsuitdagingen in huisartsgeneeskundig onderzoek en een nieuw onderzoeksdesign (flashmob onderzoek).

De resultaten in dit proefschrift laten zien dat huisartsen graag meer sneltesten zouden willen gebruiken, met name om hen te ondersteunen bij de besluitvorming bij patiënten met acute cardiopulmonale klachten. Echter, op dit moment is er beperkt en geen overtuigend bewijs dat het gebruik van sneltesten door huisartsen bij patiënten met acute cardiopulmonale klachten leidt tot meer correcte diagnoses en het beleid beïnvloedt. Bovendien kon de MHS niet worden gevalideerd in een voor ACS verdachte verwezen populatie. Wij stellen dat toekomstig onderzoek naar het diagnosticeren van patiënten met acute cardiopulmonale klachten zich zou moeten richten op een strategie waarbij ofwel een klinische beslisregel wordt gecombineerd met een sneltest dan wel een sneltest is geïntegreerd in een beslisregel. 


\section{Valorisation}





\section{VALORISATION}

Valorisation is the process of creating value out of knowledge. In the General Discussion we paid attention to various possible societal and economic implications of the research we performed. For specific implications of the different studies in this thesis we refer to the individual chapters. In this chapter we will shortly summarize the implications of the main findings.

\section{Relevance, target groups and implementation}

In the past few decades, more point-of-care tests (POCTs) have become available that might aid physicians in clinical decision-making. We assessed the access of GPs to diagnostics at GP out-of-hours services. It is advised by the profession that GPs should have sufficient access to diagnostics not only during routine day care, but also during out-of-hours care. ${ }^{1}$ In chapter 2 we showed that, in 2014, GPs in the Netherlands had limited and varying access to diagnostics during GP out-of-hours care. Therefore, GPs were unable to adhere to all Dutch GP guidelines during out-of-hours care. These findings may guide changes in policy-making with regard to the availability of diagnostics at GP outof-hours services.

In chapter 3 we illustrate that GPs currently use a limited number of POCTs, but wish to have more POCTs available for acute cardiopulmonary conditions. This is understandable as patients with these symptoms are fairly common in general practice, nonetheless accurately diagnosing these patients is often considered challenging (chapter 5). ${ }^{2-4}$ Chest pain alone accounts for about $0.7 \%$ to $2.7 \%$ of all general practice consultations, with annually over one million doctor-patient contacts in primary care in the Netherlands. ${ }^{5-9}$ Acute cardiopulmonary symptoms can be caused by either serious or minor conditions, with the latter constituting the majority of patients. ${ }^{5,7,8}$ However, missing a possibly life-treatening condition, such as a pulmonary embolism (PE) or acute coronary syndrome (ACS), could have serious consequences. Distinguishing the potentially serious and life-threating causes from minor conditions is a challenge, due to 
overlapping signs and symptoms and often non-specific, atypical or even vague symptoms. ${ }^{4,10,11}$

In chapter 5 we explored GPs' experiences with and views on the diagnosis and management of patients with acute cardiopulmonary symptoms at GP out-ofhours services. The results of this study provide insights into the cardiopulmonary decision-making process, which may aid the development of strategies to reduce the number of referrals and could aid in improving mutual understanding between primary and secondary care physicians. Besides the value of these results to guide policy-making and maintaining professional relations, these acquired insights may refine GP vocational training, as these results may be used to illustrate the experiences of experienced GPs.

Currently, GPs have a low threshold for referring patients suspected of ACS or PE to secondary care, which seems to be an effective strategy for GPs to avoid missed cases. However, the downside of this approach is that a significant number of patients are referred to secondary care, which leads to e.g. strain on resources in secondary care, anxiety in patients and high health care costs. ${ }^{5,12-}$ 16 The annual societal cost of non-cardiac chest pain patients is about $€ 10000$ and the cost of the index admission to the hospital is estimated around $€ 2000 .{ }^{15}$ Thus, reducing the number of referrals is of interest to the patient, health care providers, society and economy.

In order to safely reduce referrals, we focussed on test strategies to safely rule out a serious cardiopulmonary condition, such as the use of POCTs and a clinical decision rule in the decision-making process. However, in chapter 6, we show that there currently is limited and inconclusive evidence that GPs' use of POCTs in primary care patients with acute cardiopulmonary symptoms leads to more accurate diagnoses and affects clinical management. In chapter 9 we also investigated a potentially promising clinical decision rule, the Marburg Heart Score (MHS), and a few other potential predictors of ACS. Nevertheless, we could not validate the MHS in a referred primary care population, nor were we able to construct a more accurate clinical decision rule from the investigated possible predictors of ACS. 
In the systematic review of chapter 6, one large prospective study on GPs' use of a D-dimer POCT included in the review showed promising results, especially when the POCT was combined with a clinical decision rule. However, before considering wide scale implementation of a D-dimer POCT, it is useful to investigate the current (urgent) referral pathways of venous thromboembolism (VTE) and analyse the role of laboratory D-dimer testing in patients referred with suspected VTE. We showed that GPs currently have a high detection rate for VTE in patients who they urgently refer based on clinical assessment only. We argue that a closer proximity to a D-dimer POCT may lead to testing without explicitly using the D-dimer test in combination with a clinical decision rule, possibly leading to an increased use of the test, resulting in an increase in referrals. Moreover, GPs would only infrequently use a D-dimer POCT in daily practice, which raises questions with regard to training and costs.

In summary, the results of this thesis show that we currently cannot advise a specific adapted strategy in primary care patients with acute cardiopulmonary symptoms that would safely reduce the number of referrals to secondary care. We advise future research to focus on a strategy combining a clinical decision rule and a POCT or a clinical decision rule incorporating a POCT in diagnosing patients with acute cardiopulmonary symptoms. Nevertheless, the use of POCTs in patients with these symptoms may reassure patients and physicians (see General Discussion).

\section{Products and innovativeness}

Although this thesis did not lead to any physical products, we did produce an intellectual product. Close collaboration with secondary care providers, medical laboratories and diagnostic test manufacturers is necessary for professional POCT use. As differences in the definition of a POCT in general practice may lead to misconceptions and confusion, we decided to perform a modified e-Delphi procedure among expert panel members from different professional backgrounds. The aim was to reach consensus on an internationally and multidisciplinary supported definition of a POCT in general practice. The results 
of this study are shown in chapter 4 . The described definition of a POCT can inform GPs, laboratory specialists, policymakers, researchers and manufactures on the most widely supported international definition. It could act as a clear starting point for the organisation and execution of professional point-of-care testing worldwide.

Finally, diagnostic research in primary care has proven to be challenging, since it requires large scale prospective studies, which makes this kind of research time consuming and costly. Researchers often experience difficulties to include a sufficient number of patients, leading to extension of the study period, need to include more practices, or studies being terminated early while remaining underpowered. ${ }^{17-19}$ Specifically the latter is a waste of research resources. Chapter 9 illustrates the use of a novel and innovative study design, the flash mob method, a method we used trying to overcome some of the barriers of patient recruitment. To the best of our knowledge, we performed the first nationwide flash mob study in general practice and we showed that this method is feasible in general practice. This design may be considered as a new research method, to investigate relatively simple clinically relevant research questions in general practice on a large scale in a relatively short time frame. Ideas about a yearly flash mob study in the week following the Dutch College of General Practitioners Annual Conference are already being discussed. 


\section{REFERENCES}

1. Dutch College of General Practitioners. [Dutch College of General Practitioners' position on GPs and acute care] Utrecht; 2013 [cited 2016 March 14]. Available from: https://www.nhg.org/themas/publicaties/nhg-standpunt-huisarts-en-spoedzorg-juni2013.

2. McConaghy JR, Oza RS. Outpatient diagnosis of acute chest pain in adults. Am Fam Physician. 2013;87:177-82.

3. Willemsen RT, Kietselaer BL, Kusters R, Buntinx F, Dinant G]. [Diagnostic tools for acute coronary syndrome (ACS): a challenge for general practitioners and cardiologists]. Ned Tijdschr Geneeskd. 2014;158:A8078.

4. Body R, Carley S, Wibberley C, McDowell G, Ferguson J, Mackway-Jones K. The value of symptoms and signs in the emergent diagnosis of acute coronary syndromes. Resuscitation. 2010;81:281-6.

5. Hoorweg BBN, Willemsen RT, Cleef LE, et al. Frequency of chest pain in primary care, diagnostic tests performed and final diagnoses. Heart. 2017;103:1727-32.

6. Nilsson $S$, Scheike M, Engblom $D$, et al. Chest pain and ischaemic heart disease in primary care. Br J Gen Pract. 2003;53:378-82.

7. Bosner S, Becker A, Haasenritter J, et al. Chest pain in primary care: epidemiology and pre-work-up probabilities. Eur J Gen Pract. 2009;15:141-6.

8. Verdon $F$, Herzig $L$, Burnand $B$, et al. Chest pain in daily practice: occurrence, causes and management. Swiss Med Wkly. 2008;138:340-7.

9. Willemsen RTA, Kip MMA, Koffijberg $H$, et al. Early health technology assessment of future clinical decision rule aided triage of patients presenting with acute chest pain in primary care. Prim Health Care Res Dev. 2018;19:176-88.

10. Bruyninckx R, Aertgeerts B, Bruyninckx P, Buntinx F. Signs and symptoms in diagnosing acute myocardial infarction and acute coronary syndrome: a diagnostic meta-analysis. Br J Gen Pract. 2008;58:105-11.

11. Swap CJ, Nagurney JT. Value and limitations of chest pain history in the evaluation of patients with suspected acute coronary syndromes. JAMA. 2005;294:2623-9.

12. Goodacre S, Cross E, Arnold J, Angelini K, Capewell S, Nicholl J. The health care burden of acute chest pain. Heart. 2005;91:229-30.

13. Biesemans $L$, Cleef LE, Willemsen RTA, et al. Managing chest pain patients in general practice: an interview-based study. BMC Fam Pract. 2018;19:80.

14. Groarke J, O'Brien J, Go G, Susanto M, Owens P, Maree AO. Cost burden of nonspecific chest pain admissions. Ir J Med Sci. 2013;182:57-61. 
15. Mourad G, Alwin J, Stromberg A, Jaarsma T. Societal costs of non-cardiac chest pain compared with ischemic heart disease--a longitudinal study. BMC Health Serv Res. 2013;13:403.

16. Kohn MA, Kwan E, Gupta M, Tabas JA. Prevalence of acute myocardial infarction and other serious diagnoses in patients presenting to an urban emergency department with chest pain. J Emerg Med. 2005;29:383-90.

17. van der Wouden JC, Blankenstein AH, Huibers MJ, van der Windt DA, Stalman WA, Verhagen AP. Survey among 78 studies showed that Lasagna's law holds in Dutch primary care research. J Clin Epidemiol. 2007;60:819-24.

18. Knottnerus JA, Tugwell P. Prevention of premature trial discontinuation: how to counter Lasagna's law. J Clin Epidemiol. 2016;80:1-2.

19. Bower $P$, Wallace $P$, Ward $E$, et al. Improving recruitment to health research in primary care. Fam Pract. 2009;26:391-7. 
Dankwoord 



\section{DANKWOORD}

Een proefschrift schrijf je nooit alleen. Daarom wil ik graag gebruik maken van deze gelegenheid om een aantal mensen te bedanken. Uiteraard zijn er naast onderstaande personen nog veel meer mensen, teveel om op te noemen, die op de één of andere manier hebben bijgedragen aan dit eindresultaat: bedankt allemaal voor jullie steun, wijze lessen, interesse of gewoon gezelligheid.

Allereerst wil ik beginnen met mijn promotieteam, Jochen en Geert-Jan. Zonder jullie had dit proefschrift niet bestaan. Vier jaar geleden hebben jullie mij de kans gegeven om aan dit promotietraject te beginnen. Jochen en Geert-Jan, veel dank voor jullie goede begeleiding de afgelopen jaren en de ruimte die jullie mij hebben gegeven om mijzelf ook op andere vlakken verder te ontwikkelen. Ook hebben jullie je uiterste best gedaan om met mij dit proefschrift in een kortdurende verlenging in hoog tempo af te ronden. Veel dank voor de snelle commentaren en suggesties. Het was een plezier om met jullie samen te werken. Jochen, jij werd aan het einde van mijn traject benoemd tot professor. Ik ben er trost op dat ik jouw eerste promovendus ben die jij als eerste promotor naar de eindstreep hebt geholpen.

Zo klein als mijn promotieteam, bestaande uit slechts 2 professoren, zo groot was het aantal coauteurs met wie ik samen heb mogen werken. Bijna geen één project bestond uit hetzelfde team. Steeds opnieuw werd er nagedacht over wie een goede aanvulling zou zijn voor het projectteam en steeds kwamen daar mooie nieuwe samenwerkingsverbanden uit. Femke, Camiel, Christel, Henk, Gea, Wim, Marjolein, Rogier, Christopher, Ron, Tessa, Lex, Jacqueline, Robert, Eline, Jelle, Mariëlle, Tobias, Martijn, Patricia en Bas bedankt voor de samenwerking. Robert, naast jouw bijdrage als coauteur, ook veel dank voor je taalkundige suggesties bij de Nederlandse samenvatting van dit proefschrift en je zinvolle literaire suggesties.

Tessa, Lex en Eline, leuk dat jullie je wetenschapsstage in het kader van jullie opleiding tot arts bij Jochen en mij hebben gedaan. Het was voor mij leuk en leerzaam om met jullie als student-onderzoekers samen te mogen werken. En met succes. Tessa en Lex, jullie artikel is inmiddels gepubliceerd. Eline, ik heb 
er alle vertrouwen in dat dit ook gaat lukken met jouw artikel. Veel dank voor jullie inzet en veel succes met jullie verdere carrière.

Paddy en Mascha, we hebben vakantieavonturen, theateravonturen en de nodige ditjes en datjes gedeeld. Vaak leidde het ene onderwerp vanzelfsprekend tot het volgende onderwerp. Dit waren altijd gezellige intermezzo's. Dank daarvoor. Maar er werd ook hard gewerkt, zoals aan het D-dimeerproject en de Huisarts HART Week. Paddy, jouw ondersteuning was onmisbaar tijdens de Huisarts HART Week. In korte tijd moest er in het laatste jaar van mijn promotietraject nog veel werk worden verzet om dit project van de grond te krijgen en de data snel te verwerken. Zonder jouw hulp was het niet gelukt om de Huisarts HART Week in zo een korte tijd op touw te zetten. Mascha, ook jou wil ik graag bedanken voor je hulp bij onder andere de begeleiding van één van de WESPen.

Ook wil ik alle directe en indirecte collega's bedanken die hebben bijgedragen aan de Huisarts HART Week, waarbij ik met name alle ambassadeur (kader)huisartsen en huisartsen in opleiding, collega's van de huisartsenpost, de ambulancedienst en de cardiologie wil bedanken. Ook wil ik alle organisaties bedanken die de Huisarts HART Week hebben gesteund: HartVaatHAG, SpoedHAG, Ambulancezorg Nederland, InEen, $\mathrm{SBOH}$, Nederlandse Vereniging voor Cardiologie (NVvC), de Hartstichting, LOVAH, Harteraad, alle 8 vakgroepen huisartsgeneeskunde en ZonMW.

Collega's bij MMC Omnes veel dank voor de samenwerking in het D-dimeer project.

Collega's bij het MEMIC, Jacqueline en Remy, veel dank voor jullie ondersteuning bij de ontwikkeling en uitvoering van de digitale vragenlijst voor de Huisarts HART Week.

Niet te vergeten alle deelnemers aan de vele onderzoeken. Zonder jullie deelname was dit onderzoek niet mogelijk geweest. Veel dank voor jullie tijd en inzet. 
Ook dank aan de leescommissie, bestaande uit Otto Bekers, André Knottnerus, Arnoud van 't Hof, Patrick Bossuyt en Ann van den Bruel, voor het zorgvuldig lezen van mijn proefschrift en de begeleidende commentaren. Dank voor jullie interesse en snelle beoordeling en dat zelfs in de vakantieperiode.

Armand en Jan, van Bonné+Jan, veel dank voor jullie ondersteuning bij de vormgeving van de Huisarts HART Week en dit proefschrift. Voor alle lastminute aanpassingen en spoedopdrachten van de Huisarts HART Week. Ik ben jullie ook zeer dankbaar voor alle extra tijd die jullie in de kaft van het proefschrift hebben gestoken om er een mooie 3D afbeelding van te maken en mijn technisch wat complexe idee tot uitvoering te brengen.

Rogier Gorissen, dank voor je ondersteuning bij de Huisarts HART Week website.

Bjorn Winkens, dank dat ik altijd even mocht binnenlopen als ik een vraag had, waarop jij dan altijd wel een antwoord had.

Alle mensen die mij voorafgaand aan dit promotietraject al de eerste kneepjes van het onderzoek doen hebben bijgeleerd, Pieter Kubben, Daniëlle Verstegen, Jeroen Donkers, Karen Könings, Floris Schreuder, Julie Staals, Robert van Oostenbrugge, en alle coauteurs. Dank dat jullie mij deze kansen hebben gegeven en voor de lessen die ik hieruit geleerd heb. Ingrid van der Heijden, dank voor je persoonlijke begeleiding tijdens mijn coschap huisartsgeneeskunde.

Babette, bij jou kon ik altijd binnen lopen voor hulp en advies over de zoektocht naar deelnemende huisartsen en om over de toekomst en mogelijkheid van de huisartsenopleiding te spreken. Dank daarvoor.

AIOTHO's, Eefje, Nicole, Eva, Krista en Ruud dank voor jullie hulp bij de Delphi en Huisarts HART Week. Door jullie commentaren hebben we ons onderzoek kunnen verfijnen.

Bezorgde Ine en toegankelijke Ellen, jullie hielden altijd in de gaten of het nog wel goed met me ging. Als er iets was, zelfs met onbenullige vragen over bijvoorbeeld formeel papierwerk, kon ik altijd bij jullie aankloppen. Bedankt. 
Karin, Susanne, Hilde, Silvia, Marion, Judith, Frits, Karin, Anneke, Hanny, Sandrien, dank dat ik altijd terecht bij jullie kon met vragen en voor de gezellige gesprekken.

Bo en Esther, dank voor de leuke gesprekken. Esther, ik zag dat je inmiddels ook met je eigen promotietraject bent begonnen, gefeliciteerd!

Mede-promovendi en postdocs Annerika, Anneke, Esther, Floor, Anouk, Marjolein, Maartje, Karin, Eefje, Eva, Nicole, Krista, Ruud, Jolijn, Lennart, Ies, Luc, Jerôme, Jeanny, Ramon, Robert, Janine, Wilma, Hélène, Donna, jullie hebben de afgelopen 4 jaren bij de huisartsgeneeskunde een stuk gezelliger gemaakt met de lunchwandelingen en het gezellige geklets, maar soms ook serieuze gesprekken bij het koffieapparaat, op de gang of in één van onze kamers. Annerika, dank voor al je adviezen en collega's voor het altijd welkom zijn als ik vragen had. Ik wens jullie veel succes met jullie toekomstige carrières.

En naast alle junioren, ook de senioren, bedankt voor de interessante en gezellige gesprekken en jullie interesse voor mij.

Ramon, Eefje, Jochen, Roy Beekman en Nens van Alfen, naast mijn promotie heb ik tot mijn plezier ook met jullie mogen samenwerken aan twee publicaties. Ik wilde graag wat meer met de neurologie doen naast mijn promotietraject en jullie hebben dit mogelijk gemaakt. Veel dank voor de prettige samenwerking.

Ruud, ongeacht hoe ons projectje ook afloopt, het was leuk om samen met een andere promovendus een project te bedenken en te starten. Een speciale samenwerking van een combinatie van twee onderwerpen van twee verschillende promotietrajecten.

Kirsten en Login (Lujain), mijn lieve kamergenootjes. Kirsten, wij zijn gelijk gestart en vrijwel gelijk geëindigd met onze promotie. Ik heb je leren kennen als een rustig en sportief persoon. Fietsen is voor jou meer dan een hobby. Ik heb bewondering voor hoe jij topsport en een promotietraject combineert. Je bent inmiddels gestart met een nieuwe baan als postdoc bij een andere vakgroep. Een perfecte overgang tussen je promotietraject en het vervolg, gefeliciteerd, daar mag je trots op zijn. Lujain, you joined our room about 1,5 years ago 
During that time you got pregnant and we got to see Zuhair be born. You still have some time to go and you are getting new roommates. I wish you very nice roommates and lots of success with the rest of your PhD trajectory.

Lieve vriendinnen, Claudia, Renske en Michelle, we hebben elkaar leren kennen tijdens de musicalcursus. We konden uren kletsen en nog steeds. Hoewel het contact niet meer zo intensief is als een paar jaar geleden, omdat we allemaal onze eigen weg zijn gegaan, waardeer ik het des temeer als we bij elkaar op de koffie gaan of samen naar een voorstelling gaan.

Mam, bedankt voor het altijd erin geloven dat ik arts kon worden daar waar er op het voorgezet onderwijs nogal eens aan mijn capaciteiten werd getwijfeld. $\mathrm{Na}$ vele jaren alleen, heeft u nu een nieuwe partner, Albert, ik wens jullie nog vele mooie jaren samen.

Ron, mijn peetoom en neef. Mijn hele leven sta je al klaar voor mij als peetoom. Zelfs nu ik al een stuk ouder ben, wordt mijn verjaardag nooit vergeten. Veel dank dat je me als paranimf bij wilt bijstaan tijdens de verdediging.

And last maar zeker not least Manuela, mijn lieve grote zus en vriendin, ik waardeer enorm dat je er altijd voor me bent. Niet alleen als paranimf heb je bijgedragen aan mijn promotie en sta je me bij tijdens de verdediging, maar je hebt ook de nodige teksten voor mij overgelezen. Heel veel dank daarvoor. Ook naast werk doen we veel dingen samen, zoals onze vakanties, waar ik met volle teugen van geniet. Ik had mij geen andere zus gewenst. 

Curriculum vitae 



\section{CURRICULUM VITAE}

Angel (Maria Ronnie) Schols was born in Maastricht on February 8, 1986. She completed secondary school at Sint Maartens College in Maastricht. In 2005 she started studying General Health Sciences at Maastricht University, with a major in Movement Sciences. In 2008 she obtained her bachelor's degree. In the meanwhile, in 2007, she also started to study Medicine at Maastricht University, and she obtained her master's degree in 2013. During these years she was a student-assistant in several

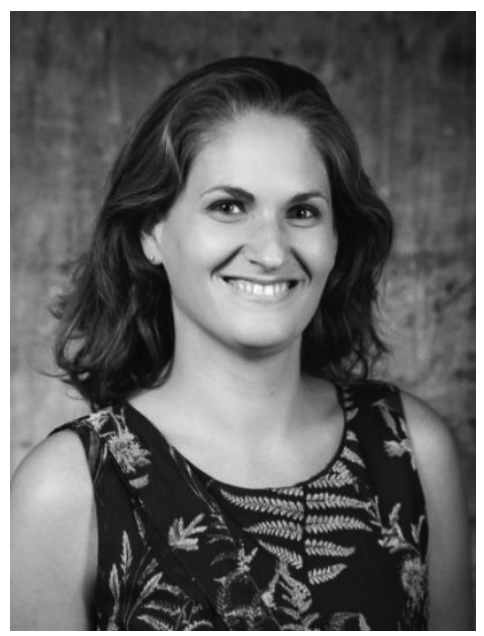
research projects at Maastricht University. In 2014 she started her PhD trajectory at the department of Family Medicine at Maastricht University. 


\section{PUBLICATION LIST AND PRESENTATIONS}

\section{PhD publications in international journals}

Angel M.R. Schols, Geert-Jan Dinant, Jochen W.L. Cals. Point-of-care testing in general practice: just what the doctor ordered? Br J Gen Pract 2018;68:362363.

Angel M.R. Schols, Geert-Jan Dinant, Rogier Hopstaken, et al. International definition of a point-of-care test in family practice: a modified e-Delphi procedure. Fam Pract 2018;35:475-480.

Angel M.R. Schols, Jacqueline P.G. Stakenborg, Geert-Jan Dinant, et al. Pointof-care testing in primary care patients with acute cardiopulmonary symptoms: a systematic review. Fam Pract 2018;35:4-12.

Angel M.R. Schols, Tessa A. van Boekholt, Lex M.R. Oversier, et al. General practitioners' experiences with out-of-hours cardiorespiratory consultations; a qualitative study. BMJ Open 2016;6:e012136.

Angel M.R. Schols, Femke Stevens, Camiel G. I. P. Zeijen, et al. Access to diagnostic tests during GP out-of-hours care: A cross-sectional study of all GP out-of-hours services in the Netherlands. Eur J Gen Pract 2016;22:176-181. 


\section{PhD publications in national journals}

Angel Schols en Jochen Cals. Nieuw: flashmobonderzoek Huisarts HART Week. Huisarts \& Wetenschap 2017;11:593.

Angel M.R. Schols en Jochen W.L. Cals. Flashmob-onderzoek naar beslisregel voor acuut coronair syndroom: Huisarts HART Week. Ned Tijdschr Geneeskd. 2017;161:D2280.

Angel M.R. Schols, Femke Stevens, Camiel G.I.P. Zeijen, et al. Aanvullende diagnostiek op Nederlandse huisartsenpost. Ned Tijdschr Geneeskd. 2015;159: A9022.

Jochen W.L. Cals, Angel M.R. Schols, Henk C.P.M. van Weert, et al. Sneltesten in de huisartspraktijk: huidig gebruik en behoefte aan testen in de toekomst. Ned Tijdschr Geneeskd. 2014;158:A8210.

\section{Other publications}

Angel Schols, Roy Beekman, Nens van Alfen, Jochen Cals, Ramon Ottenheijm. Carpaletunnelsyndroom: een klinische (syndroom)diagnose. Geaccepteerd door het Nederlands Tijdschrift voor Geneeskunde.

Angel Schols en Eefje de Bont. Geen preventieve medicatie bij koortsconvulsies. Huisarts \& Wetenschap 2017;11:608.

A.M.R. Schols, F.H.B.M. Schreuder, E.P. van Raak, et al. Incidence of Oral Anticoagulant-Associated Intracerebral Hemorrhage in South-Limburg, the Netherlands. Stroke. 2014; 45: 268-270.

A.M.R. Schols, H.H.L.M. Donkers, M. Voorend, et al. The use of smartphones and Mobile Clinical Decision Support Systems in clinical clerkships: a pilot study. iJIM 2013: 7(2); 80-84. 


\section{PhD presentations}

Angel Schols, Robert Willemsen, Tobias Bonten, Martijn Rutten, Bas Kietselaer, Patricia Stassen, Geert-Jan Dinant, Jochen Cals. Huisarts HART Week: flashmobonderzoek naar een beslisregel voor acuut coronair syndroom. Oral presentation at the NHG-Wetenschapsdag 2018 on June 8 at VUmc Amsterdam.

Angel Schols, Geert-Jan Dinant, Rogier Hopstaken, Christopher Price, Ron Kusters, Jochen Cals. International definition of a point-of-care test in family practice: a modified e-Delphi procedure. Poster presentation at the DEGAMKongress 2017 on September 22 in Düsseldorf.

Angel Schols, Eline Meijs, Geert-Jan Dinant, Marielle Krekels, Jochen Cals. General practitioners' use of D-dimer in venous thrombo-embolic events: cohort study in one geographical region in The Netherlands. Oral presentation at the DEGAM-Kongress 2017 on September 22 in Düsseldorf.

Angel Schols, Jacqueline Stakenborg, Geert-Jan Dinant, Robert Willemsen, Jochen Cals. Point-of-care testing in eerstelijns patiënten met acute cardiopulmonale klachten: een systematische literatuurstudie. Oral presentation at NHG-Wetenschapsdag 2017 on June 2 at the UMC Utrecht, Julius Centrum.

Angel Schols, Geert-Jan Dinant, Rogier Hopstaken, Christopher Price, Ron Kusters, Jochen Cals. Internationale definitie van een point-of-care test in de huisartsenpraktijk: Delphi studie. Oral presentation at the NHG-Wetenschapsdag 2017 on June 2 at the UMC Utrecht, Julius Centrum.

Angel Schols, Tessa van Boekholt, Lex Oversier, Geert-Jan Dinant, Jochen Cals. Ervaringen van huisartsen met cardiopulmonale consulten op de huisartsenpost; een kwalitatieve studie. Oral presentations at the NHGWetenschapsdag 2016 on May 27 at the AMC Amsterdam and at a refresher course for cardiologists and general practitioners on June 16, 2016. 


\section{Other presentations}

A.M.R. Schols, F.H.B.M. Schreuder, A.H.C.M.L. Schreuder, F.A. Rooyer, R.J. van Oostenbrugge, J. Staals. The Incidence of Oral Anticoagulation-Associated Intracerebral Haemorrhage in South-Limburg, the Netherlands. Poster presentation on the second science day MUMC+ on March 6, 2013.

F.H.B.M. Schreuder, A.M.R. Schols, E.P. van Raak, A.H.C.M.L. Schreuder, F.A. Rooyer, R.J. van Oostenbrugge, J.E.A. Staals. De incidentie van orale anticoagulantia-gerelateerde intracerebrale bloedingen in Nederland. Oral presentation at the science meeting of the NVN on November 8, 2013.

Jeroen Donkers, Pieter Kubben, Angel Schols, et al. Gebruik van Smartphones tijdens de Co-schappen. Onderwijs Research Dagen 2011, 8-10 juni, Maastricht. 
